\title{
S-Ribosylhomocysteine analogues with the carbon-5 and sulfur atoms replaced by a vinyl or (fluoro)vinyl unit
}

\author{
Stanislaw F. Wnuk ${ }^{a},{ }^{*}$, Jennifer Lalamaa ${ }^{a} \dagger$, Craig A. Garmendia ${ }^{a}$, Jenay Robert ${ }^{a}$, Jinge \\ Zhub, and Dehua Pei ${ }^{b}$ \\ aDepartment of Chemistry \& Biochemistry, Florida International University, Miami, FL 33199, USA \\ bDepartment of Chemistry and Ohio State Biochemistry program, The Ohio State University, Columbus, Ohio \\ 43210, USA
}

\begin{abstract}
Treatment of the protected ribose or xylose 5-aldehyde with sulfonyl-stabilized fluorophosphonate gave (fluoro)vinyl sulfones. Stannyldesulfonylation followed by iododestannylation afforded 5,6dideoxy-6-fluoro-6-iodo-o-ribo or xylo-hex-5-enofuranoses. Coupling of the hexenofuranoses with alkylzinc bromides gave ten-carbon ribosyl- and xylosylhomocysteine analogues incorporating a fluoroalkene. The fluoroalkenyl and alkenyl analogues were evaluated for inhibition of Bacillus subtilis $S$-ribosylhomocysteinase (LuxS). One of the compounds, 3,5,6-trideoxy-6-fluoro-d-erythrohex-5-enofuranose, acted as a competitive inhibitor of moderate potency $\left(K_{\mathrm{I}}=96 \mu \mathrm{M}\right)$.
\end{abstract}

\section{Keywords}

LuxS enzyme; Negishi coupling; $S$-ribosylhomocysteine; vinyl fluorides; vinyl stannanes

\section{Introduction}

$S$-Adenosyl-L-homocysteine (SAH) is a byproduct of many methyltransferase reactions and a potent inhibitor of the methyltransferases. In eukaryotes and some bacteria, detoxification of SAH is mediated by SAH hydrolase (EC 3.3.1.1), which effects hydrolytic cleavage of SAH to L-homocysteine (Hcy) and adenosine (Figure 1). ${ }^{1} \mathrm{Hcy}$ appears to be a risk factor for coronary artery diseases. ${ }^{2}$ Alternatively, most bacteria utilize enzyme 5 '-methylthioadenosine (MTA)/SAH nucleosidase (EC 3.2.2.9) to irreversibly cleave SAH yielding adenine and $S$ ribosyl-L-homocysteine (SRH). ${ }^{3}$ The SRH is then converted to Hcy and 2,4-dihydroxy-2,3pentadione (DPD) by a metalloenzyme $S$-ribosylhomocysteinase (LuxS). ${ }^{4} \mathrm{DPD}^{5}$ spontaneously cyclizes and complexes with borate to form a furanosyl borate diester, which acts as a type 2 autoinducer for bacterial interspecies quorum sensing. ${ }^{6}$ Since quorum sensing regulates many bacterial behaviors such as virulence and biofilm formation, LuxS and other proteins involved in quorum sensing have been proposed as attractive targets for novel antibacterial drug design. ${ }^{7}$ Several substrate analogues of SRH (e.g., $\mathbf{1}$ and $\mathbf{2}$ ) showed submicromolar inhibition of LuxS. 4 e, h

\footnotetext{
*Corresponding author. Tel.: +1 305348 6195; fax: +1 305348 3772; e-mail: wnuk@ fiu.edu.

${ }^{\dagger}$ Present address. Azopharma, Inc. Miramar, FL

Publisher's Disclaimer: This is a PDF file of an unedited manuscript that has been accepted for publication. As a service to our customers we are providing this early version of the manuscript. The manuscript will undergo copyediting, typesetting, and review of the resulting proof before it is published in its final citable form. Please note that during the production process errors may be discovered which could affect the content, and all legal disclaimers that apply to the journal pertain.
} 
We have previously observed that SAH hydrolase is capable of the addition of water across $5^{\prime}, 6^{\prime}$ isolated double bond of adenosine analogues $\mathbf{3}$ and $\mathbf{4}$ (Figure 2). ${ }^{1 \mathrm{c}, 8}$ The resulting adduct (or its derivative) caused covalent modification and inactivation $8 \mathrm{~b}$ of the enzyme, a process which required the catalytic activity of the enzyme. Since LuxS catalyzes a similar reaction as SAH hydrolase (i.e., overall elimination of Hcy), we designed analogues of SRH with the vinyl or halovinyl moieties incorporated in place of the carbon-5 and sulfur atoms (e.g., 5). We envisaged that these ribosyl analogues might serve as mechanistic probes to study the mechanism of action of LuxS and evaluate the similarities between SAH hydrolase and LuxS. As mentioned above, LuxS inhibitors may provide a novel class of antibacterial agents. We now describe the syntheses of SRH analogues with the carbon- 5 and sulfur atoms replaced by vinyl or (6-fluoro)vinyl motifs and discuss their interactions with LuxS enzyme.

\section{Chemistry}

Our initial plan to prepare compound $\mathbf{5}$ and its congeners is illustrated in Scheme 1. Treatment of the diacetone 3-O-benzoylglucose $\mathbf{6}$ or allose $\mathbf{7}$ with periodic acid selectively removed the $5,6-O$-isopropylidene group. Subsequent oxidative cleavage of the exposed vicinal diol ${ }^{9 \mathrm{a}}$ gave the corresponding 5-aldehydes $\mathbf{8}$ and $\mathbf{9}$, respectively, in high yields (Scheme 1). Wittig olefination of aldehyde $\mathbf{8}$ with the ylide derived from commercially available [4-ethoxy-4oxobutyl)triphenylphoshonium bromide provided a complex mixture of products. Column chromatography yielded protected 5,6,7,8-tetradeoxy- $\alpha$-D-xylo-non-5(Z)-enofuranuronate 10 (18\% yield). The stereochemistry was assigned as $Z$, based on the magnitude of the coupling constants for olefinic protons $\left({ }^{3} J_{5-6}=11.1 \mathrm{~Hz}\right)$, and literature precedence for the Wittig condensations of aliphatic aldehydes with the nonstabilized ylides. ${ }^{9 \mathrm{~b}}$ Similarly, Wittigtreatment of ribo 5-aldehyde $\mathbf{9}$ gave 11; a nine-carbon analogue of SRH. Unfortunately, our attempts to add bromine $\left(\mathrm{CH}_{2} \mathrm{Cl}_{2} / 0{ }^{\circ} \mathrm{C}\right.$ ) across the double bond of $\mathbf{1 0}$ or $\mathbf{1 1}$ (as well as 16) produced a complex mixture which did not give the desired SRH analogues of type $\mathbf{5}$ bearing a (6-bromo)vinyl unit when treated with DBU. ${ }^{10}$

In an alternative approach, we attempted a synthesis of 6-bromoalkenyl analogues $5(\mathrm{X}=\mathrm{Br})$ via Pd-catalyzed monoalkylation ${ }^{11-13}$ of the readily available ( (gem-dibromo)vinyl sugar precursors (e.g. 12, 13) with the corresponding alkylzinc reagents. Thus, dibromolefination of xylo 5-aldehyde 8 by the Corey-Fuchs procedure ${ }^{14}$ gave 5-(dibromomethylene)-5-

deoxyxylose 12 (81\% from 6; Scheme 2). Analogous treatment of the ribo 5-aldehyde 9 afforded 13. ${ }^{15}$ Treatment of $\mathbf{1 2}$ with 3 equiv. of 4-ethoxy-4-oxobutylzinc bromide in the presence of $\mathrm{Pd}\left(\mathrm{PPh}_{3}\right)_{4}$ at $55^{\circ} \mathrm{C}$ gave monoalkylated 5,6,7,8,9-pentadeoxy- $\alpha$-D-xylo-dec-5 $(E)$-enofuranuronate $14\left(18 \%,{ }^{3} J_{5-6}=15.4 \mathrm{~Hz}\right)$ and dialkylated $18(48 \%)$ products, but did not yield the desired 6-bromoalkenyl product 15. Analogous Negishi coupling of 5-

(dibromomethylene)-5-deoxyribose 13 afforded only dialkylated product $19(54 \%)$. Changing catalyst $\left[\left(\mathrm{Pd}_{2}(\mathrm{dba})_{3}\right)\right]$, solvent (THF), reaction temperature (r.t. to $\left.60^{\circ} \mathrm{C}\right)$ as well as adding additives (CuI, tricyclohexylphosphine) did not lead to the formation of $\mathbf{1 5}$ or $\mathbf{1 7}$ but instead produced dialkylated byproducts 18 and 19 (3-49\%) in agreement with a recent report. ${ }^{13 \mathrm{~b}}$

We next explored stereoselective coupling of the gem-dihalovinyl sugars containing two different halogens. We chose 5-deoxy-5-(fluoroiodomethylene) hexenofuranoses $\mathbf{2 6}$ and $\mathbf{2 7}$ because the iodo and fluoro substituents are known to have quite different reactivity towards oxidative-addition in Pd-mediated couplings. ${ }^{11 \mathrm{~b}, 16,17}$ The precursors 26 and 27 were prepared employing McCarthy's stannyldesulfonylation methodology. ${ }^{18,19}$ Thus, treatment of the xylo aldehyde $\mathbf{8}$ with the enolate generated from the sulfonyl-stabilized fluorophosphonate ${ }^{20}$ gave (fluoro)vinyl sulphones 20 (E/Z, 7:3; 76\%; Scheme 3$)$. The stereoselective radical-mediated stannyldesulfonylation of $\mathbf{2 0}$ with $\mathrm{Bu}_{3} \mathrm{SnH}$ produced (fluoro) vinyl stannanes $\mathbf{2 3}$ (E/Z, 7:3; 95\%). Iododestannylation of $\mathbf{2 3}$ with $N$-iodosuccinimide (NIS) quantitatively afforded 6-fluoro-6-iodo-xylo-hex-5-enofuranoses $\mathbf{2 6}$ with retention of the $E / Z$ 
configuration. The ribo analogue 27 (E/Z, 3:2; 57\% overall yield from 9) was similarly prepared. The isomeric ratio for the fluorinated sugars could be distinguished by the magnitude of the ${ }^{3} J_{\mathrm{F}-\mathrm{H} 5}$ in the NMR spectra.

Pd-mediated cross-coupling of the xylo analogue 26 ( $E / Z, 4: 1)$ with 2 equiv. of 4-ethoxy-4oxobutylzinc bromide resulted in selective consumption of $(E)-\mathbf{2 6}$ to afford $(Z)-\mathbf{2 9}$ in $61 \%$ isolated yield or 76\% based on consumption of $(E)-26$ (Scheme 4). A small amount of (E)-29 was also isolated, although monocoupling with gem-dihalovinyl substrates is considered to be trans selective. ${ }^{12,13 \mathrm{~b}, 16}$ Similar monoalkylation of the ribo analogue $27(E / Z, 3: 2)$ with $\operatorname{BrZn}\left(\mathrm{CH}_{2}\right)_{3} \mathrm{COOEt}$ yielded $(Z)-30$ [54\%, 90\% based on the conversion of $\left.(E)-27\right]^{21}$ and $(E)-\mathbf{3 0}[12 \%, 30 \%$ from $(Z)-27]$. Coupling of the (iodo)vinyl $(E)-28$, prepared as depicted in Scheme $3(\mathbf{9} \rightarrow \mathbf{2 2} \rightarrow \mathbf{2 5} \rightarrow \mathbf{2 8})$, with BrZn $\left(\mathrm{CH}_{2}\right)_{3} \mathrm{COOEt}$ gave the unfluorinated analogue (E)-16 (56\%) with the retention of configuration. Treatment of $(Z)-29$ with $\mathrm{NH}_{3} / \mathrm{MeOH}$ removed the benzoyl group and converted the ethyl ester into a methyl ester (Z)-31 (74\%). Subsequent removal of the isopropylidene group with aqueous trifluoroacetic acid (TFA) at 0 ${ }^{\circ} \mathrm{C}$ gave (Z)-33 $(61 \%$; $\alpha / \beta, 1: 1)$. Successive treatment of $(Z)-30$ with $\mathrm{NH}_{3} / \mathrm{MeOH}$ followed by TFA $/ \mathrm{H}_{2} \mathrm{O}$ gave (Z)-34 (52\% overall yield; $\alpha / \beta, 3: 7$ ); a ten-carbon 6-fluoroalkenyl analogue of SRH.

The 5,6-dideoxy-6-fluorohex-5-enofuranoses $\mathbf{4 2}$ and $\mathbf{4 3}$, depurinated analogues of $\mathbf{3}(\mathrm{X}=\mathrm{F})$, were synthesized by protiodestannylation of the (fluoro)vinyl stannanes $\mathbf{2 3}$ and $\mathbf{2 4}$. Thus, treatment of $23(E / Z, 7: 3)$ with $\mathrm{NH}_{3} / \mathrm{MeOH}$ at $25{ }^{\circ} \mathrm{C}$ resulted in the removal of 3-O-benzoyl group to give 36 (Scheme 5). However, prolonged heating of $\mathbf{3 6}$ (or 23) with $\mathrm{NH}_{3} / \mathrm{MeOH}$ at $65^{\circ} \mathrm{C}$ for $48 \mathrm{~h}$ effected protiodestannylation to yield a separatable mixture of $(E)-\mathbf{3 9}(29 \%)$ and $(Z)-39(48 \%)$. Treatment of $(E)-\mathbf{3 9}$ with TFA $/ \mathrm{H}_{2} \mathrm{O}$ at $0{ }^{\circ} \mathrm{C}$ gave $(E)-\mathbf{4 2}(\alpha / \beta, \sim 1: 1)$. Analogous debenzoylation and protiodestannylation of $\mathbf{2 4}(E / Z, 1: 1)$ with $\mathrm{NH}_{3} / \mathrm{MeOH}$ yielded $(E)-\mathbf{4 0}(32 \%)$ and $(Z)-\mathbf{4 0}(26 \%)$. Acid-catalyzed removal of the isopropylidene group in (E)-40 gave 5,6-dideoxy-6-fluoro-D-ribo-hex-5-enofuranose $(E)-\mathbf{4 3}(67 \% ; \alpha / \beta, \sim 1: 4)$. Alternatively, concomitant protiodestannylation and removal of acetone unit in $\mathbf{3 6}$ or $\mathbf{3 7}$ with TFA also afforded $\mathbf{4 2}$ and $\mathbf{4 3}$.

The 3,5,6-trideoxy 6-fluorohex-5-enofuranose $\mathbf{4 4}$, which lacks a hydroxyl group at C3 and therefore cannot participate in the second enolization step of the LuxS catalyzed reaction, $4 \mathrm{~b}$ was also prepared. Thus, oxidation of the diacetone 3-deoxyglucose ${ }^{22}$ with $\mathrm{H}_{5} \mathrm{IO}_{6} 9 \mathrm{a}$ and in situ treatment of the rather unstable 3-deoxyribose 5-aldehyde with the enolate generated from the sulfonyl-stabilized fluorophosphonate ${ }^{20}$ gave the (fluoro)vinyl sulfones 35 (48\%; E/Z, $2: 1$; ). Subjection of $\mathbf{3 5}$ to the stannyldesulfonylation/protiodestannylation ${ }^{18 \mathrm{~b}}$ sequence afforded 3-deoxy (6-fluoro)vinyl sugar 41, which was deprotected to yield 44 (12\% from 35). Alternatively, treatment of vinyl stannanes $\mathbf{3 8}$ with TFA affected simultaneous protiodestannylation and removal of the acetone unit to give $\mathbf{4 4}$ (23\% from 35; E/Z 1:3, $\alpha / \beta$ $\sim 1: 4)$.

\section{Inhibition of LuxS}

The (6-fluoro)vinyl xylo- (42) and ribo-hexofuranoses (43) and their 3-deoxy analogue 44 as well as (6-fluoro)vinyl xylo- and ribo-decofuranoses ( $\mathbf{3 3}$ and $\mathbf{3 4}$ ) were evaluated ${ }^{4 \mathrm{~h}}$ as potential inhibitors of Bacillus subtilis $S$-ribosylhomocysteinase (LuxS). Compound $\mathbf{4 4}$ exhibited competitive inhibition of moderate potency, with a $K_{\mathrm{I}}$ value of $96 \pm 3 \mu \mathrm{M}$ (Figure 3 ). None of the other compounds showed significant inhibition under the assay conditions.

\section{Summary and Conclusions}

We have developed synthesis of six-, nine- and ten-carbon analogues of ribosyl- and xylosylhomocysteines in which the carbon-5 and sulfur atoms are replaced by a vinyl or (fluoro) 
vinyl unit. These fluoroalkenyl and alkenyl analogues of SRH were synthesized employing either the Wittig reaction or Pd-catalyzed coupling routes. They were evaluated against Bacillus subtilis S-ribosylhomocysteinase (LuxS). Only 3,5,6-trideoxy-6-fluoro-р-erythrohex-5-enofuranose acted as competitive inhibitor of moderate potency with $K_{\mathrm{I}}=96 \mu \mathrm{M}$.

\section{Experimental Section}

${ }^{1} \mathrm{H}\left(\mathrm{Me}_{4} \mathrm{Si}\right)$ NMR spectra were determined with solution in $\mathrm{CDCl}_{3}$ at 400 or $600 \mathrm{MHz},{ }^{13} \mathrm{C}$ $\left(\mathrm{Me}_{4} \mathrm{Si}\right)$ at $100.6 \mathrm{MHz}$ and ${ }^{19} \mathrm{~F}\left(\mathrm{CFCl}_{3}\right)$ at $376.5 \mathrm{MHz}$ unless otherwise noted. Mass spectra (MS) were obtained by atmospheric pressure chemical ionization (APCI) and HRMS by electron impact techniques unless otherwise noted. Reagent grade chemicals were used as received. Solvents were dried by reflux over and distillation from $\mathrm{CaH}_{2}$ under an argon atmosphere except THF (K/benzophenone). TLC was performed on Merck kieselgel 60- $\mathrm{F}_{254}$ with $\mathrm{MeOH} / \mathrm{CHCl}_{3}$ (1:9) and $\mathrm{EtOAc} / \mathrm{MeOH}(95: 5)$ as developing systems, and products were detected with $254 \mathrm{~nm}$ light or by visualization with $\mathrm{Ce}\left(\mathrm{SO}_{4}\right)_{2} /\left(\mathrm{NH}_{4}\right)_{6} \mathrm{Mo}_{7} \mathrm{O}_{24} \bullet 4 \mathrm{H}_{2} \mathrm{O} / \mathrm{H}_{2} \mathrm{SO}_{4} /$ $\mathrm{H}_{2} \mathrm{O}$ reagent. Merck kieselgel 60 (230-400 mesh) was used for column chromatography. Elemental analyses were determined by Galbraith Laboratories, Knoxville, TN.

\section{Ethyl 3-O-Benzoyl-5,6,7,8-tetradeoxy-1,2-O-isopropylidene- $\alpha$-D-xylo-non-5(Z)- enofuranuronate (10)}

Step (a). $\mathrm{H}_{5} \mathrm{IO}_{6}(150 \mathrm{mg}, 0.66 \mathrm{mmol})$ was added to a stirred solution of $\mathbf{6}$ (200 mg, $\left.0.55 \mathrm{mmol}\right)$ in dried EtOAc at ambient temperature. A precipitate appeared within the first five minutes and the resulting solution was stirred for $90 \mathrm{~min}$. The precipitate was filtered off and was washed with EtOAc $(2 \times 5 \mathrm{~mL})$. The combined organic layer was washed with $\mathrm{NaHCO}_{3} / \mathrm{H}_{2} \mathrm{O}$ $(10 \mathrm{~mL}), \mathrm{NaCl} / \mathrm{H}_{2} \mathrm{O}(10 \mathrm{~mL})$, dried $\left(\mathrm{Na}_{2} \mathrm{SO}_{4}\right)$ and evaporated to yield 3-O-benzoyl-1,2-Oisopropylidene- $\alpha$-D-xylo-pentodialdo-1,4-furanose $(\mathbf{8} ; 160 \mathrm{mg}$, 95\%; approx. $90 \%$ pure based on ${ }^{1} \mathrm{H}$ NMR): ${ }^{1} \mathrm{H}$ NMR $\delta 1.35 \& 1.48\left(2 \times \mathrm{s}, 2 \times 3,2 \times \mathrm{CH}_{3}\right), 4.76\left(\mathrm{~d}, J_{4-3}=3.2 \mathrm{~Hz}, 1, \mathrm{H} 4\right)$, $4.88\left(\mathrm{~d}, J_{2-1}=3.1 \mathrm{~Hz}, 1, \mathrm{H} 2\right), 5.77\left(\mathrm{~d}, J_{1-2}=3.1 \mathrm{~Hz}, 1, \mathrm{H} 1\right), 6.18\left(\mathrm{~d}, J_{3-4}=3.3 \mathrm{~Hz}, 1, \mathrm{H} 3\right)$, 7.42-8.01 (m, 5, Ar), 9.78 (s, 1, H5). Step (b). LHMDS (1M/THF; $0.69 \mathrm{~mL}, 0.69 \mathrm{mmol}$ ) was added dropwise to a stirred solution of $\mathrm{Ph}_{3} \mathrm{PCH}_{2} \mathrm{CH}_{2} \mathrm{CH}_{2} \mathrm{CO}_{2} \mathrm{Et} / \mathrm{Br}(314 \mathrm{mg}, 0.69 \mathrm{mmol})$ in anhydrous THF ( $4 \mathrm{~mL})$ in a flame-dried flask under $\mathrm{N}_{2}$ at ambient temperature. After 15 minutes, a solution of the crude, preferentially freshly prepared, aldehyde 8 (160 mg of the material from step a) in THF ( $2 \mathrm{~mL}$ ) was added via syringe and stirring was continued overnight. EtOAc $(30 \mathrm{~mL})$ and $\mathrm{NaHCO}_{3} / \mathrm{H}_{2} \mathrm{O}(10 \mathrm{~mL})$ was added and the separated organic was washed with $\mathrm{NaCl} / \mathrm{H}_{2} \mathrm{O}(10 \mathrm{~mL})$, dried $\left(\mathrm{Na}_{2} \mathrm{SO}_{4}\right)$, and evaporated. Column chromatography $\left(10 \rightarrow 30 \%\right.$ hexanes/EtOAc) gave $10(39 \mathrm{mg}, 18 \%)$ as an oil: ${ }^{1} \mathrm{H}$ NMR $\delta 1.24$ (t, $\left.J=7.2 \mathrm{~Hz}, 3, \mathrm{CH}_{3}\right), 1.37 \& 1.62\left(2 \times \mathrm{s}, 2 \times 3,2 \times \mathrm{CH}_{3}\right), 2.41\left(\mathrm{t}, J_{8-7 / 7^{\prime}}=6.9 \mathrm{~Hz}, 2, \mathrm{H} 8 / 8^{\prime}\right)$, 2.50 ("q", $\left.J_{7-6 / 8 / 8^{\prime}}=7.3 \mathrm{~Hz}, 2, \mathrm{H} 7 / 7^{\prime}\right), 4.15\left(\mathrm{q}, J=7.1 \mathrm{~Hz}, 2, \mathrm{CH}_{2}\right), 4.71\left(\mathrm{~d}, J_{2-1}=3.8 \mathrm{~Hz}, 1\right.$, $\mathrm{H} 2), 5.22\left(\mathrm{dd}, J_{4-5}=7.7 \mathrm{~Hz}, J_{4-3}=2.8 \mathrm{~Hz}, 1, \mathrm{H} 4\right), 5.46\left(\mathrm{~d}, J_{3-4}=2.8 \mathrm{~Hz}, \mathrm{H} 3\right), 5.58\left(\mathrm{dd}, J_{5-6}\right.$ $\left.=11.1 \mathrm{~Hz}, J_{5-4}=7.9 \mathrm{~Hz}, 1, \mathrm{H} 5\right), 5.68\left(\mathrm{dt}, J_{6-5}=11.1 \mathrm{~Hz}, J_{6-7 / 7^{\prime}}=7.1 \mathrm{~Hz}, 1, \mathrm{H6}\right), 6.05(\mathrm{~d}$, $\left.J_{1-2}=3.7 \mathrm{~Hz}, 1, \mathrm{H} 1\right), 7.48-8.04,(\mathrm{~m}, 5, \mathrm{Ar}) ;{ }^{13} \mathrm{C} \mathrm{NMR} \delta 14.62\left(\mathrm{CH}_{3}\right), 24.08(\mathrm{C} 7), 26.62 \&$ $27.19\left(\mathrm{CMe}_{2}\right), 34.23(\mathrm{C} 8), 60.90\left(\mathrm{CH}_{2}\right), 75.54(\mathrm{C} 2), 78.59(\mathrm{C} 3), 84.20(\mathrm{C} 4), 105.02(\mathrm{C} 1)$, $112.47\left(\mathrm{CMe}_{2}\right), 123.90(\mathrm{C} 6), 128.91(\mathrm{Bz}), 129.78(\mathrm{Bz}), 130.15(\mathrm{Bz}), 133.85(\mathrm{Bz}), 134.39(\mathrm{C} 5)$, 165.64 (Bz), 173.09 (C9); MS m/z $391\left(100, \mathrm{MH}^{+}\right)$. HRMS (AP-ESI) $\mathrm{m} / \mathrm{z}$ calcd for $\mathrm{C}_{21} \mathrm{H}_{26} \mathrm{O}_{7} \mathrm{Li}\left(\mathrm{MLi}^{+}\right)$397.1839; found 397.1833.

\section{Ethyl 3-O-Benzoyl-5,6,7,8-tetradeoxy-1,2-O-isopropylidene- $\alpha$-D-ribo-non-5(Z)- enofuranuronate (11)}

Step (a) Oxidation of 7 (200 mg, $0.55 \mathrm{mmol})$ with $\mathrm{H}_{5} \mathrm{IO}_{6}(150 \mathrm{mg}, 0.66 \mathrm{mmol})$, as described for 10, gave 3- $O$-benzoyl-1,2- $O$-isopropylidene- $\alpha$-D-ribo-pentodialdo-1,4-furanose $(\mathbf{9} ; 145$ mg, 85\%; approx. 90\% pure, ${ }^{1} \mathrm{H}$ NMR): ${ }^{1} \mathrm{H}$ NMR $\delta 1.39 \& 1.61\left(2 \times \mathrm{s}, 2 \times 3,2 \times \mathrm{CH}_{3}\right), 4.64$ $\left(\mathrm{dd}, J_{4-5}=2.2 \mathrm{~Hz}, J_{4-3}=9.2 \mathrm{~Hz}, 1, \mathrm{H} 4\right), 5.01\left(\mathrm{t}, J_{2-1 / 3}=4.2 \mathrm{~Hz}, 1, \mathrm{H} 2\right), 5.13\left(\mathrm{dd}, J_{3-4}=9.2\right.$ 
$\left.\mathrm{Hz}, J_{3-2}=4.6 \mathrm{~Hz}, 1, \mathrm{H} 3\right), 6.02\left(\mathrm{~d}, J_{1-2}=3.4 \mathrm{~Hz}, 1, \mathrm{H} 1\right), 7.48-8.03$ (m, 5, Ar), 9.77 (d, $J_{5-4}=$ $2.2 \mathrm{~Hz}, 1, \mathrm{H} 5)$. Step (b). Treatment of the crude $9(145 \mathrm{mg})$ with $\mathrm{Ph}_{3} \mathrm{P}\left(\mathrm{CH}_{2}\right)_{3} \mathrm{CO}_{2} \mathrm{Et} / \mathrm{Br}(275$ $\mathrm{mg}, 0.60 \mathrm{mmol})$ and LHDMS (1M/THF; $0.60 \mathrm{mmol}, 0.60 \mathrm{~mL})$, as described for 10, gave $\mathbf{1 1}$ $(18 \mathrm{mg}, 12 \%):{ }^{1} \mathrm{H}$ NMR $\delta 1.26\left(\mathrm{t}, J=7.1 \mathrm{~Hz}, 3, \mathrm{CH}_{3}\right), 1.36 \& 1.62\left(2 \times \mathrm{s}, 2 \times 3,2 \times \mathrm{CH}_{3}\right)$, $2.38\left(\mathrm{t}, J_{8-7 / 7^{\prime}}=8.2 \mathrm{~Hz}, 2, \mathrm{H} 8 / 8^{\prime}\right), 2.46-2.55$ (m, 1, H7), 2.55-2.67 (m, 1, H7'), 4.15 (q, $J=7.1$ $\left.\mathrm{Hz}, 2, \mathrm{CH}_{2}\right), 4.74\left(\mathrm{dd}, J_{3-4}=9.1 \mathrm{~Hz}, J_{3-2}=4.8 \mathrm{~Hz}, 1, \mathrm{H} 3\right), 4.96$ ("t", $\left.J_{2-1 / 3}=4.3 \mathrm{~Hz}, 1, \mathrm{H} 2\right)$, $5.20\left(\mathrm{t}, J_{4-3 / 5}=8.7 \mathrm{~Hz}, 1, \mathrm{H} 4\right), 5.50\left(\mathrm{ddt}, J_{5-6}=10.9 \mathrm{~Hz}, J_{5-4}=8.7 \mathrm{~Hz}, J_{5-7 / 7^{\prime}}=1.0 \mathrm{~Hz}, 1, \mathrm{H} 5\right)$, $5.72\left(\mathrm{dt}, J_{6-5}=10.9 \mathrm{~Hz}, J_{6-7 / 7^{\prime}}=7.1 \mathrm{~Hz}, 1, \mathrm{H} 6\right), 5.93\left(\mathrm{~d}, J_{1-2}=3.8 \mathrm{~Hz}, 1, \mathrm{H} 1\right), 7.48-8.04$, (m, 5, Ar); ${ }^{13} \mathrm{C}$ NMR $\delta 14.30\left(\mathrm{CH}_{3}\right), 24.01(\mathrm{C} 7), 26.99 \& 27.04\left(\mathrm{CMe}_{2}\right), 34.53(\mathrm{C} 8), 60.89$

$\left(\mathrm{CH}_{2}\right), 73.39(\mathrm{C} 4), 77.34(\mathrm{C} 2), 77.56(\mathrm{C} 3), 104.61(\mathrm{C} 1), 113.40\left(\mathrm{CMe}_{2}\right), 127.26(\mathrm{C} 5), 128.90$ (Bz), 129.80 (Bz), 130.28 (Bz), 133.80 (Bz), 135.14 (C6), 166.25 (Bz), 173.06 (C9). HRMS (AP-ESI) $\mathrm{m} / z$ calcd for $\mathrm{C}_{21} \mathrm{H}_{26} \mathrm{O}_{7} \mathrm{Li}\left(\mathrm{MLi}^{+}\right.$) 397.1839; found 397.1828.

\section{3-O-Benzoyl-5,6-dideoxy-6,6-dibromo-1,2-O-isopropylidene- $\alpha-D-x y l o-h e x-5-e n o f u r a n o s e$ (12)}

(Dibromomethylene)triphenylphosphorane [generated in situ by stirring $\mathrm{CBr}_{4}(8.09 \mathrm{~g}, 24.5$ $\mathrm{mmol}), \mathrm{Ph}_{3} \mathrm{P}(6.46 \mathrm{~g}, 24.5 \mathrm{mmol}$ ) and activated $\mathrm{Zn}$ (dust; $1.60 \mathrm{~g}, 24.5 \mathrm{mmol}$ ) in dried $\mathrm{CH}_{2} \mathrm{Cl}_{2}(100 \mathrm{~mL})$ at $0{ }^{\circ} \mathrm{C}$ (ice-bath) for $30 \mathrm{~min}$ followed by stirring at ambient temperature under $\mathrm{N}_{2}$ for $3 \mathrm{~h}$ ] was added to the solution of freshly prepared aldehyde $\mathbf{8}$ [prepared as described for $\mathbf{1 0}$ (step a) from $\mathbf{6}$ (4.68 g, $12.9 \mathrm{mmol})$ and dried for $1 \mathrm{~h}$ under vacuum prior to use] in $\mathrm{CH}_{2} \mathrm{Cl}_{2}(75 \mathrm{~mL})$. After stirring for $14 \mathrm{~h}$ at ambient temperature, the reaction mixture was partitioned $\left(\mathrm{NaHCO}_{3} / \mathrm{H}_{2} \mathrm{O} / / \mathrm{CHCl}_{3}\right)$, and the organic layer was washed $\left(\mathrm{H}_{2} \mathrm{O}\right.$, brine), dried $\left(\mathrm{MgSO}_{4}\right)$, and the volatiles were evaporated. Column chromatography $(15 \rightarrow 25 \% \mathrm{EtOAc/}$ hexane) gave 12 (4.68 g, 81\% overall from 6) as a solidifying viscous oil: ${ }^{1} \mathrm{H}$ NMR $\delta 1.34 \&$ $1.58\left(2 \times \mathrm{s}, 2 \times 3,2 \times \mathrm{CH}_{3}\right), 4.68\left(\mathrm{~d}, J_{2-1}=3.7 \mathrm{~Hz}, 1, \mathrm{H} 2\right), 5.04\left(\mathrm{dd}, J_{4-5}=7.6 \mathrm{~Hz}, J_{4-3}=3.0\right.$ $\mathrm{Hz}, 1, \mathrm{H} 4), 5.54\left(\mathrm{~d}, J_{3-4}=3.0 \mathrm{~Hz}, 1, \mathrm{H} 3\right), 6.00\left(\mathrm{~d}, J_{1-2}=3.7 \mathrm{~Hz}, 1, \mathrm{H} 1\right), 6.60\left(\mathrm{~d}, J_{5-4}=7.6 \mathrm{~Hz}\right.$, 1, H5), 7.48 (t, $J=7.6 \mathrm{~Hz}, 2 \mathrm{Ar}$ ), 7.60 (tt, $J=1.3,7.6 \mathrm{~Hz}, 1 \mathrm{Ar}$ ), 8.02 ("dd", $J=1.4,7.7 \mathrm{~Hz}, 2$ $\mathrm{Ar}) ;{ }^{13} \mathrm{C}$ NMR $\delta 24.96 \& 25.51(\mathrm{CMe} 2), 75.71$ (C3), 78.18 (C4), 82.04 (C2), 93.26 (C6), 103.30 (C1), $111.26\left(\mathrm{CMe}_{2}\right), 127.31(\mathrm{Bz}), 127.73(\mathrm{Bz}), 128.44(\mathrm{Bz}), 130.49(\mathrm{C} 5), 132.37(\mathrm{Bz}), 163.81$ (Bz); MS m/z 451 (5, $\left.\mathrm{MH}^{+}\left[{ }^{81} \mathrm{Br}_{2}\right]\right), 449\left(10, \mathrm{MH}^{+}\left[{ }^{81 / 79} \mathrm{Br}_{2}\right]\right), 447\left(5, \mathrm{MH}^{+}\left[{ }^{79} \mathrm{Br}_{2}\right]\right)$.

\section{Ethyl 3-O-Benzoyl-5,6,7,8,9-pentadeoxy-1,2-O-isopropylidene- $\alpha-D-x y l o-d e c-5(E)$ - enofuranuronate (14) and Ethyl 3-O-Benzoyl-6-[3-(ethoxycarbonyl)propyl]- 5,6,7,8,9- pentadeoxy-1,2-O-isopropylidene- $\alpha-D-x y l o-d e c-5$-enofuranuronate (18)}

$\mathrm{Pd}\left[\mathrm{P}(\mathrm{Ph})_{3}\right]_{4}(22 \mathrm{mg}, 0.014 \mathrm{mmol})$ was added to a stirred solution of $\mathbf{1 2}(42 \mathrm{mg}, 0.094 \mathrm{mmol})$ in anhydrous benzene $(3 \mathrm{~mL})$ in a flame dried flask under $\mathrm{N}_{2}$ at ambient temperature. After 2 minutes, 4-ethoxy-4-oxobutylzinc bromide (0.5 M/THF; $0.56 \mathrm{~mL}, 129 \mathrm{mg}, 0.28 \mathrm{mmol})$ was added and the resulting mixture was heated at $55^{\circ} \mathrm{C}$ for $6 \mathrm{~h}$. The reaction mixture was cooled down to ambient temperature and was partitioned between EtOAc $(30 \mathrm{~mL})$ and $\mathrm{NaHCO}_{3} /$ $\mathrm{H}_{2} \mathrm{O}(10 \mathrm{~mL})$. The separated organic layer was washed with $\mathrm{H}_{2} \mathrm{O}(10 \mathrm{~mL}), \mathrm{NaCl} / \mathrm{H}_{2} \mathrm{O}(10 \mathrm{~mL})$, dried $\left(\mathrm{Na}_{2} \mathrm{SO}_{4}\right)$, and evaporated. Column chromatography $(10 \rightarrow 30 \%$ EtOAc/hexanes) gave recovered $\mathbf{1 2}$ (7 mg, 13\%), 14 (7 mg, 18\%) and $\mathbf{1 8}(19 \mathrm{mg}, 48 \%)$. Compound $14 \mathrm{had}:{ }^{1} \mathrm{H}$ NMR $\delta 1.23\left(\mathrm{t}, J=7.1 \mathrm{~Hz}, 3, \mathrm{CH}_{3}\right), 1.28 \& 1.58\left(2 \times \mathrm{s}, 2 \times 3,2 \times \mathrm{CH}_{3}\right), 1.68$ (quint, $J_{8-7 / 7^{\prime} / 9 / 9^{\prime}}=7.5$ Hz, 2, H8/8'), 2.07 ("q", $\left.J_{7-6 / 8 / 8^{\prime}}=7.0 \mathrm{~Hz}, 2, \mathrm{H} 7 / 7^{\prime}\right), 2.23$ (t, $\left.J_{9-8 / 8^{\prime}}=7.4 \mathrm{~Hz}, 2, \mathrm{H} 9 / 9^{\prime}\right), 4.15$ (q, $\left.J=7.1 \mathrm{~Hz}, 2, \mathrm{CH}_{2}\right), 4.70\left(\mathrm{~d}, J_{2-1}=3.7 \mathrm{~Hz}, 1, \mathrm{H} 2\right), 4.86\left(\mathrm{dd}, J_{4-5}=7.1 \mathrm{~Hz}, J_{4-3}=2.8 \mathrm{~Hz}, 1\right.$, $\mathrm{H} 4), 5.42\left(\mathrm{~d}, J_{3-4}=2.7 \mathrm{~Hz}, 1, \mathrm{H} 3\right), 5.56\left(\mathrm{dd}, J_{5-6}=15.4 \mathrm{~Hz}, J_{5-4}=7.3 \mathrm{~Hz}, 1, \mathrm{H} 5\right), 5.92(\mathrm{dt}$, $\left.J_{6-5}=15.4 \mathrm{~Hz}, J_{6-7 / 7^{\prime}}=6.9 \mathrm{~Hz}, 1, \mathrm{H} 6\right), 6.03\left(\mathrm{~d}, J_{1-2}=3.7 \mathrm{~Hz}, 1, \mathrm{H1}\right), 7.46-8.05$, (m, 5, $\mathrm{Ar}) ;{ }^{13} \mathrm{C}$ NMR $\delta 14.59\left(\mathrm{CH}_{3}\right), 23.34(\mathrm{C} 8), 26.69 \& 27.16\left(\mathrm{CMe}_{2}\right), 30.10$ (C7), 34.05 (C9), $60.74\left(\mathrm{CH}_{2}\right), 75.90(\mathrm{C} 2), 81.58(\mathrm{C} 3), 85.44(\mathrm{C} 4), 105.00(\mathrm{C} 1), 112.52\left(\mathrm{CMe}_{2}\right), 128.35(\mathrm{C} 5)$, $130.17(\mathrm{Bz}), 130.65(\mathrm{Bz}), 132.47(\mathrm{Bz}), 133.60(\mathrm{Bz}), 135.50(\mathrm{C} 6), 165.89(\mathrm{Bz}), 173.74(\mathrm{C} 10)$; MS $m / z 405\left(100, \mathrm{MH}^{+}\right)$. Compound 18 had: ${ }^{1} \mathrm{H}$ NMR $\delta 1.21\left(\mathrm{t}, J=7.1 \mathrm{~Hz}, 3, \mathrm{CH}_{3}\right), 1.29(\mathrm{t}$, $\left.J=7.1 \mathrm{~Hz}, 3, \mathrm{CH}_{3}\right), 1.36 \& 1.61\left(2 \times \mathrm{s}, 2 \times 3,2 \times \mathrm{CH}_{3}\right), 1.69$ (quint, $\left.J=7.5 \mathrm{~Hz}, 2 \mathrm{H}\right), 1.71-1.80$ 
(m, 2H), $2.05(\mathrm{t}, J=7.5 \mathrm{~Hz}, 2 \mathrm{H}), 2.10-2.26(\mathrm{~m}, 4 \mathrm{H}), 2.33(\mathrm{t}, J=7.2 \mathrm{~Hz}, 2 \mathrm{H}), 4.09$ (q, $J=7.1$ $\left.\mathrm{Hz}, 2, \mathrm{CH}_{2}\right), 4.18\left(\mathrm{q}, J=7.1 \mathrm{~Hz}, 2, \mathrm{CH}_{2}\right), 4.70\left(\mathrm{~d}, J_{2-1}=3.8 \mathrm{~Hz}, 1, \mathrm{H} 2\right), 5.14\left(\mathrm{dd}, J_{4-5}=8.7\right.$ $\left.\mathrm{Hz}, J_{4-3}=2.9 \mathrm{~Hz}, 1, \mathrm{H} 4\right), 5.35\left(\mathrm{~d}, J_{5-4}=8.4 \mathrm{~Hz}, 1, \mathrm{H} 5\right), 5.41\left(\mathrm{~d}, J_{3-4}=2.8 \mathrm{~Hz}, 1, \mathrm{H} 3\right), 6.02(\mathrm{~d}$, $\left.J_{1-2}=3.8 \mathrm{~Hz}, 1, \mathrm{H} 1\right), 7.47-8.06,(\mathrm{~m}, 5, \mathrm{Ar}) ;{ }^{13} \mathrm{C}$ NMR $\delta 14.60\left(\mathrm{CH}_{3}\right), 14.65\left(\mathrm{CH}_{3}\right), 26.65 \&$ $27.15(\mathrm{CMe}), 23.32 \& 23.84$ (C8/8'), $30.53 \& 36.22$ (C7/7'), $34.04 \& 34.08$ (C9/9'), 60.59 $\left(\mathrm{CH}_{2}\right), 60.75\left(\mathrm{CH}_{2}\right), 75.90(\mathrm{C} 4), 78.71(\mathrm{C} 3), 84.24(\mathrm{C} 2), 104.84(\mathrm{C} 1), 112.36\left(\mathrm{CMe}_{2}\right), 119.09$ (C5), 146.90 (C6), $128.92(\mathrm{Bz}), 128.92(\mathrm{Bz}), 129.81$ (Bz), $130.17(\mathrm{Bz}), 133.83(\mathrm{Bz}), 165.70$ (Bz), $173.62 \& 173.75\left(\mathrm{C} 10 / 10^{\prime}\right) ; \mathrm{MS} m / z 519\left(100, \mathrm{MH}^{+}\right)$.

\section{Ethyl 3-O-Benzoyl-5,6,7,8,9-pentadeoxy-1,2-O-isopropylidene- $\alpha$-D-ribo-dec-5(E)- enofuranuronate (16)}

Treatment $\left(55^{\circ} \mathrm{C}, 3 \mathrm{~h}\right.$ ) of $\mathbf{2 8}(E ; 20 \mathrm{mg}, 0.048 \mathrm{mmol})$ with 4-ethoxy-4-oxobutylzinc bromide $(0.5 \mathrm{M} / \mathrm{THF} ; 0.19 \mathrm{~mL}, 65 \mathrm{mg}, 0.096 \mathrm{mmol})$ as described for $\mathbf{1 4} / \mathbf{1 8}$ gave $16(11 \mathrm{mg}, 56 \%):{ }^{1} \mathrm{H}$ NMR $\delta 1.24\left(\mathrm{t}, J=7.1 \mathrm{~Hz}, 3, \mathrm{CH}_{3}\right), 1.35 \& 1.59\left(2 \times \mathrm{s}, 2 \times 3,2 \times \mathrm{CH}_{3}\right), 1.72$ (quint, $\left.J_{8-7 / 7^{\prime} / 9 / 9^{\prime}}=7.4 \mathrm{~Hz}, 2, \mathrm{H} 8 / 8^{\prime}\right), 2.13\left(" \mathrm{q}^{\prime}, J_{7-6 / 8 / 8^{\prime}}=7.2 \mathrm{~Hz}, 2, \mathrm{H} 7 / 7^{\prime}\right), 2.28$ (t, $J_{9-8 / 8^{\prime}}=7.6 \mathrm{~Hz}$, 2, $\left.\mathrm{H} 9 / 9^{\prime}\right), 4.10\left(\mathrm{q}, J=7.1 \mathrm{~Hz}, 2, \mathrm{CH}_{2}\right), 4.65\left(\mathrm{dd}, J_{4-5}=7.6 \mathrm{~Hz}, J_{4-3}=8.9 \mathrm{~Hz}, 1, \mathrm{H} 4\right), 4.74(\mathrm{dd}$, $\left.J_{3-4}=9.2 \mathrm{~Hz}, J_{3-2}=4.6 \mathrm{~Hz}, 1, \mathrm{H} 3\right), 4.96\left(\mathrm{t}, J_{2-1 / 3}=4.3 \mathrm{~Hz}, 1, \mathrm{H} 2\right), 5.53\left(\mathrm{dd}, J_{5-6}=15.4 \mathrm{~Hz}\right.$, $\left.J_{5-4}=7.3 \mathrm{~Hz}, 1, \mathrm{H} 5\right), 5.89\left(\mathrm{~d}, J_{1-2}=4.0 \mathrm{~Hz}, 1, \mathrm{H} 1\right), 5.91\left(\mathrm{dt}, J_{6-5}=15.8 \mathrm{~Hz}, J_{6-7 / 7^{\prime}}=6.8 \mathrm{~Hz}\right.$, 1, H6), 7.46-8.05, (m, 5, Ar); ${ }^{13} \mathrm{C}$ NMR $\delta 14.62\left(\mathrm{CH}_{3}\right), 24.40$ (C8), $26.92 \& 27.00\left(\mathrm{CMe}_{2}\right)$, 31.99 (C7), 33.89 (C9), $60.65\left(\mathrm{CH}_{2}\right), 76.92$ (C2), 77.65 (C3), 78.60 (C4), 104.37 (C1), 113.35 $\left(\mathrm{CMe}_{2}\right), 127.04(\mathrm{C} 5), 128.85(\mathrm{Bz}), 129.83(\mathrm{Bz}), 130.28(\mathrm{Bz}), 133.76(\mathrm{Bz}), 136.28(\mathrm{C} 6), 166.29$ (Bz), 173.84 (C10); MS m/z $405\left(100, \mathrm{MH}^{+}\right)$.

\section{Ethyl 3-O-Benzoyl-5,6,7,8,9-pentadeoxy-6-[3-(ethoxycarbonyl)propyl]-1,2-Oisopropylidene- a-D-ribo-dec-5-enofuranuronate (19)}

Treatment of $\mathbf{1 3}^{15}$ (42 $\left.\mathrm{mg}, 0.094 \mathrm{mmol}\right)$ with $\mathrm{Pd}\left[\mathrm{P}(\mathrm{Ph})_{3}\right]_{4}(22 \mathrm{mg}, 0.014 \mathrm{mmol})$ and 4ethoxy-4-oxobutylzinc bromide $(0.56 \mathrm{~mL}, 129 \mathrm{mg}, 0.28 \mathrm{mmol})$ as described for $\mathbf{1 4} / \mathbf{1 8}$ gave $19(26 \mathrm{mg}, 54 \%):{ }^{1} \mathrm{H}$ NMR $\delta 1.22\left(\mathrm{t}, J=7.1 \mathrm{~Hz}, 6,2 \times \mathrm{CH}_{3}\right), 1.37 \& 1.62(2 \times \mathrm{s}, 2 \times 3,2 \times$ $\mathrm{CH}_{3}$ ), 1.75 (quint, $\left.J=7.5 \mathrm{~Hz}, 4 \mathrm{H}\right), 2.11(\mathrm{t}, J=7.0 \mathrm{~Hz}, 2 \mathrm{H}), 2.24(\mathrm{t}, J=9.0 \mathrm{~Hz}, 2 \mathrm{H}), 2.26$ (t, $J=9.0 \mathrm{~Hz}, 2 \mathrm{H}), 2.32(\mathrm{t}, J=7.2 \mathrm{~Hz}, 2 \mathrm{H}), 4.10\left(\mathrm{q}, J=7.1 \mathrm{~Hz}, 2, \mathrm{CH}_{2}\right), 4.16(\mathrm{q}, J=7.1 \mathrm{~Hz}, 2$, $\left.\mathrm{CH}_{2}\right), 4.74\left(\mathrm{dd}, J_{3-4}=9.0 \mathrm{~Hz}, J_{3-2}=4.8 \mathrm{~Hz}, 1, \mathrm{H} 3\right), 4.95\left(\mathrm{t}, J_{2-3}=4.3 \mathrm{~Hz}, 1, \mathrm{H} 2\right), 5.01(\mathrm{t}$, $\left.J_{4-5}=9.0 \mathrm{~Hz}, 1, \mathrm{H} 4\right), 5.26\left(\mathrm{~d}, J_{5-4}=8.9 \mathrm{~Hz}, 1, \mathrm{H} 5\right), 5.89\left(\mathrm{~d}, J_{1-2}=3.9 \mathrm{~Hz}, 1, \mathrm{H} 1\right), 7.40-8.10$ (m, 5, Ar); ${ }^{13} \mathrm{C}$ NMR $\delta 14.55\left(\mathrm{CH}_{3}\right), 14.61\left(\mathrm{CH}_{3}\right), 21.48\left(\mathrm{C} 8 / 8^{\prime}\right), 23.11 \& 27.03\left(\mathrm{CMe}_{2}\right), 30.08$ \& $30.12\left(\mathrm{C} 7 / 7^{\prime}\right), 32.34 \& 34.04\left(\mathrm{C} 9 / 9^{\prime}\right), 60.73\left(\mathrm{CH}_{2}\right), 60.83\left(\mathrm{CH}_{2}\right), 73.86(\mathrm{C} 4), 78.71(\mathrm{C} 3)$, $84.24(\mathrm{C} 2), 104.37(\mathrm{C} 1), 113.28\left(\mathrm{CMe}_{2}\right), 122.65(\mathrm{C} 5), 128.92(\mathrm{Bz}), 128.92(\mathrm{Bz}), 129.81(\mathrm{Bz})$, $130.17(\mathrm{Bz}), 133.83(\mathrm{Bz}), 143.90(\mathrm{C} 6), 165.70(\mathrm{Bz}), 170.57$ \& $171.62(\mathrm{C} 10 / 10$ '); MS m/z 519 $\left(100, \mathrm{MH}^{+}\right)$.

\section{(E/Z)-3-O-Benzoyl-5,6-dideoxy-6-fluoro-1,2-O-isopropylidene-6-phenylsulfonyl-a-D-xylo- hex-5-enofuranose (20)}

LHMDS (0.84 mL, $140 \mathrm{mg}, 0.84 \mathrm{mmol})$ was added dropwise to a solution of diethyl fluoro (phenylsulfonyl)methylphosphonate ${ }^{20}(260 \mathrm{mg}, 0.84 \mathrm{mmol})$ in anhydrous THF $(8 \mathrm{~mL})$ in a flame dried flask under $\mathrm{N}_{2}$ at $-78{ }^{\circ} \mathrm{C}$. After 30 minutes, a solution of $\mathbf{8}(265 \mathrm{mg}, 0.82 \mathrm{mmol})$ in THF $(4 \mathrm{~mL})$ was added and stirring was continued for $1.5 \mathrm{~h}$. EtOAc $(30 \mathrm{~mL})$ and $\mathrm{NH}_{4} \mathrm{Cl} /$ $\mathrm{H}_{2} \mathrm{O}(10 \mathrm{~mL})$ were added and reaction mixture was allowed to warm to ambient temperature. The separated organic layer was washed with $\mathrm{NaHCO}_{3} / \mathrm{H}_{2} \mathrm{O}(10 \mathrm{~mL}), \mathrm{NaCl} / \mathrm{H}_{2} \mathrm{O}(10 \mathrm{~mL})$, dried $\left(\mathrm{Na}_{2} \mathrm{SO}_{4}\right)$, and evaporated. Column chromatography $(10 \rightarrow 30 \%$ EtOAc/hexanes) gave 20 (166 mg, 76\%; E/Z, 7:3) as inseparable mixture of isomers: HRMS (AP-ESI) $\mathrm{m} / \mathrm{z}$ : calcd for $\mathrm{C}_{22} \mathrm{H}_{22} \mathrm{FO}_{7} \mathrm{~S}\left(\mathrm{MH}^{+}\right) 449.1065$, found $449.1071 ;{ }^{19} \mathrm{~F} \mathrm{NMR} \delta-110.25\left(\mathrm{~d}, J_{\mathrm{F}-\mathrm{H} 5}=18.8 \mathrm{~Hz}\right.$, $0.30 \mathrm{~F}, Z),-119.30\left(\mathrm{~d}, J_{\mathrm{F}-\mathrm{H} 5}=32.1 \mathrm{~Hz}, 0.70 \mathrm{~F}, E\right)$. Compound $(E)-20$ had: ${ }^{1} \mathrm{H}$ NMR $\delta 1.35 \&$ $1.56\left(2 \times \mathrm{s}, 2 \times 3,2 \times \mathrm{CH}_{3}\right), 4.73\left(\mathrm{~d}, J_{2-1}=3.7 \mathrm{~Hz}, 1, \mathrm{H} 2\right), 5.23\left(\mathrm{dt}, J_{4-5}=7.4 \mathrm{~Hz}, J_{4-3 / \mathrm{F}}=2.3\right.$ 
$\mathrm{Hz}, 1, \mathrm{H} 4), 5.49$ (d, J3-4 = 3.1 Hz, 1, H3), 6.03-6.05 (m, 1, H1), 6.43 (dd, $J_{5-\mathrm{F}}=32.4 \mathrm{~Hz}$, $\left.J_{5-4}=7.2 \mathrm{~Hz}, 1, \mathrm{H} 5\right), 7.48-8.03(\mathrm{~m}, 10, \mathrm{Ar}) ;{ }^{13} \mathrm{C}$ NMR $\delta 26.55 \& 27.10\left(\mathrm{CMe}_{2}\right), 73.78(\mathrm{C} 4)$, 78.21 (C3), 83.77 (C2), 105.31 (C1), $113.13\left(\mathrm{CMe}_{2}\right), 112.10\left(\mathrm{~d},{ }^{2} J_{5-\mathrm{F}}=3.3 \mathrm{~Hz}, \mathrm{C} 5\right), 128.99$ (Ph), $129.08(\mathrm{Bz}), 129.13(\mathrm{Bz}), 129.79(\mathrm{Ph}), 129.94(\mathrm{Ph}), 130.12(\mathrm{Ph}), 130.17(\mathrm{Bz}), 134.25$ $(\mathrm{Bz}), 135.02(\mathrm{Ph}), 156.00\left(\mathrm{~d},{ }^{1} J_{6-\mathrm{F}}=300.0 \mathrm{~Hz}, \mathrm{C} 6\right), 165.36(\mathrm{Bz})$. Compound $(\mathrm{Z})-20$ had: ${ }^{1} \mathrm{H}$ NMR $\delta 1.38 \& 1.69\left(2 \times \mathrm{s}, 2 \times 3,2 \times \mathrm{CH}_{3}\right), 4.76\left(\mathrm{~d}, J_{2-1}=3.7 \mathrm{~Hz}, 1, \mathrm{H} 2\right), 5.68\left(\mathrm{~d}, J_{3-4}=2.8\right.$ $\mathrm{Hz}, 1, \mathrm{H} 3), 5.99\left(\mathrm{dd}, J_{5-\mathrm{F}}=19.3 \mathrm{~Hz}, J_{5-4}=8.6 \mathrm{~Hz}, 1, \mathrm{H} 5\right), 6.05-6.07(\mathrm{~m}, 1, \mathrm{H} 1), 6.07-6.09(\mathrm{~m}$, 1, H4), 7.48-8.03 (m, 10, Ar); ${ }^{13} \mathrm{C}$ NMR $\delta 26.98 \& 27.32\left(\mathrm{CMe}_{2}\right), 73.15\left(\mathrm{~d},{ }^{3} J_{4-\mathrm{F}}=10.14 \mathrm{~Hz}\right.$, C4), 79.06 (C3), 83.93 (C2), 105.37 (C1), $113.35\left(\mathrm{CMe}_{2}\right), 114.10\left(\mathrm{~d},{ }^{2} J_{5-\mathrm{F}}=15.0 \mathrm{~Hz}, \mathrm{C} 5\right)$, $128.99(\mathrm{Ph}), 129.08(\mathrm{Bz}), 129.13(\mathrm{Bz}), 129.79(\mathrm{Ph}), 129.94(\mathrm{Ph}), 130.12(\mathrm{Ph}), 130.17(\mathrm{Bz})$, 134.25 (Bz), $135.02(\mathrm{Ph}), 155.58\left(\mathrm{~d},{ }^{1} J_{6-\mathrm{F}}=292.3 \mathrm{~Hz}, \mathrm{C} 6\right), 165.36(\mathrm{Bz})$. Note: Freshly prepared aldehyde 8, dried under vacuum for $2 \mathrm{~h}$ at ambient temperature prior the use, gave the best results.

(E/Z)-3-O-Benzoyl-5,6-dideoxy-6-fluoro-1,2-O-isopropylidene-6-phenylsulfonyl- $\alpha$-D-ribohex-5-enofuranose (21)

Treatment of 9 ( $200 \mathrm{mg}, 0.68 \mathrm{mmol})$ with diethyl fluoro(phenylsulfonyl) methylphosphonate ${ }^{20}(212 \mathrm{mg}, 0.68 \mathrm{mmol})$ and LHMDS (0.68 mL, $\left.114 \mathrm{mg}, 0.68 \mathrm{mmol}\right)$ as described for 20 gave 21 (216 mg, 71\%; E/Z, 6:4): HRMS (AP-ESI) $\mathrm{m} / \mathrm{z}$ : calcd for $\mathrm{C}_{22} \mathrm{H}_{22} \mathrm{FO}_{7} \mathrm{~S}\left(\mathrm{MH}^{+}\right) 449.1065$, found $449.1069 ;{ }^{19} \mathrm{~F} \mathrm{NMR} \delta-108.98\left(\mathrm{~d}, J_{\mathrm{F}-\mathrm{H} 5}=22.6 \mathrm{~Hz}\right.$, $0.40 \mathrm{~F}, Z),-121.25\left(\mathrm{~d}, J_{\mathrm{F}-\mathrm{H} 5}=30.1 \mathrm{~Hz}, 0.60 \mathrm{~F}, E\right)$. Compound $(E)-21$ had: ${ }^{1} \mathrm{H}$ NMR $\delta 1.28 \&$ $1.38\left(2 \times \mathrm{s}, 2 \times 3,2 \times \mathrm{CH}_{3}\right), 4.85\left(\mathrm{dd}, J_{3-4}=9.0 \mathrm{~Hz}, J_{3-2}=4.7 \mathrm{~Hz}, 1, \mathrm{H} 3\right), 5.00\left(" \mathrm{t} ", J_{2-1 / 3}=\right.$ $4.5 \mathrm{~Hz}, 1, \mathrm{H} 2), 5.10\left(\mathrm{t}, J_{4-3 / 5}=8.2 \mathrm{~Hz}, 1, \mathrm{H} 4\right), 5.94\left(\mathrm{~d}, J_{1-2}=3.7 \mathrm{~Hz}, 1, \mathrm{H} 1\right), 6.37\left(\mathrm{dd}, J_{5-\mathrm{F}}=\right.$ $\left.31.3 \mathrm{~Hz}, J_{5-4}=8.3 \mathrm{~Hz}, 1, \mathrm{H} 5\right), 7.44-8.20(\mathrm{~m}, 10, \mathrm{Ar}) ;{ }^{13} \mathrm{C}$ NMR $\delta 26.86 \& 26.93\left(\mathrm{CMe}_{2}\right), 71.36$ $\left(\mathrm{d},{ }^{3} J_{4-\mathrm{F}}=2.2 \mathrm{~Hz}, \mathrm{C} 4\right), 76.64\left(\mathrm{~d},{ }^{4} J_{3-\mathrm{F}}=1.8 \mathrm{~Hz}, \mathrm{C} 3\right), 77.54(\mathrm{C} 2), 104.96(\mathrm{C} 1), 114.10$ $\left(C \mathrm{Me}_{2}\right), 114.22\left(\mathrm{~d},{ }^{2} J_{5-\mathrm{F}}=3.1 \mathrm{~Hz}, \mathrm{C} 5\right), 128.88(\mathrm{Ph}), 129.13(\mathrm{Bz}), 129.18(\mathrm{Bz}), 129.88(\mathrm{Ph})$, $130.28(\mathrm{Ph}), 133.98(\mathrm{Bz}), 135.10(\mathrm{Ph}), 136.96(\mathrm{Ph}), 156.91\left(\mathrm{~d},{ }^{1}{ }_{6}{ }_{6-\mathrm{F}}=306.0 \mathrm{~Hz}, \mathrm{C} 6\right), 165.96$ (Bz). Compound (Z)-21 had: ${ }^{1} \mathrm{H}$ NMR $\delta 1.28 \& 1.38\left(2 \times \mathrm{s}, 2 \times 3,2 \times \mathrm{CH}_{3}\right), 4.84\left(\mathrm{dd}, J_{3-4}=\right.$ $\left.9.2 \mathrm{~Hz}, J_{3-2}=4.6 \mathrm{~Hz}, 1, \mathrm{H} 3\right), 5.01\left(" \mathrm{t} ", J_{2-1 / 3}=4.6 \mathrm{~Hz}, 1, \mathrm{H} 2\right), 5.86\left(\mathrm{dd}, J_{5-\mathrm{F}}=19.8 \mathrm{~Hz}, J_{5-4}\right.$ $=9.9 \mathrm{~Hz}, \mathrm{H} 5), 5.96\left(\mathrm{~d}, J_{1-2}=3.7 \mathrm{~Hz}, 1, \mathrm{H} 1\right), 6.07\left(\mathrm{t}, J_{4-3 / 5}=10.4 \mathrm{~Hz}, 1, \mathrm{H} 4\right), 7.44-8.20(\mathrm{~m}$, 10, Ar); ${ }^{13} \mathrm{C}$ NMR $\delta 27.17 \& 27.39\left(\mathrm{CMe}_{2}\right), 70.71\left(\mathrm{~d},{ }^{3} J_{4-\mathrm{F}}=8.5 \mathrm{~Hz}, \mathrm{C} 4\right), 77.17(\mathrm{C} 3), 77.86$ (C2), 104.82 (C1), $114.37\left(\mathrm{CMe}_{2}\right), 116.23\left(\mathrm{~d},{ }^{2} J_{5-\mathrm{F}}=16.2 \mathrm{~Hz}, \mathrm{C} 5\right), 128.95(\mathrm{Ph}), 129.22(\mathrm{Bz})$, $129.46(\mathrm{Bz}), 129.80(\mathrm{Ph}), 130.02(\mathrm{Ph}), 133.61(\mathrm{Bz}), 134.00(\mathrm{Ph}), 135.19(\mathrm{Ph}), 156.62$ $\left(\mathrm{d},{ }^{1} J_{6-\mathrm{F}}=296.3 \mathrm{~Hz}, \mathrm{C} 6\right), 166.30(\mathrm{Bz})$.

\section{(E)-3-O-Benzoyl-5,6-dideoxy-1,2-O-isopropylidene-6-phenylsulfonyl-a-D-ribo-hex-5- enofuranose (22)}

Treatment of 9 (150 mg, $0.50 \mathrm{mmol})$ with diethyl (phenylsulfonyl)methylphosphonate ${ }^{20}$ (146 $\mathrm{mg}, 0.50 \mathrm{mmol}$ ) and LHMDS ( $0.50 \mathrm{~mL}, 84 \mathrm{mg}, 0.50 \mathrm{mmol}$ ) as described for $\mathbf{2 0}$ gave $\mathbf{2 2}$ (166 $\mathrm{mg}, 82 \%):{ }^{1} \mathrm{H}$ NMR $\delta 1.33 \& 1.55\left(2 \times \mathrm{s}, 2 \times 3,2 \times \mathrm{CH}_{3}\right), 4.76\left(\mathrm{dd}, J_{3-4}=9.5 \mathrm{~Hz}, J_{3-2}=4.6\right.$ $\mathrm{Hz}, 1, \mathrm{H} 3$ ), $4.92\left(\mathrm{ddd}, J_{4-5}=3.7 \mathrm{~Hz}, J_{4-6}=1.7 \mathrm{~Hz}, J_{4-3}=9.5 \mathrm{~Hz}, 1, \mathrm{H} 4\right), 5.01\left(" \mathrm{t} ", J_{2-3 / 1}=4.2\right.$ $\mathrm{Hz}, 1, \mathrm{H} 2), 5.90\left(\mathrm{~d}, J_{1-2}=3.7 \mathrm{~Hz}, 1, \mathrm{H} 1\right), 6.79$ (dd, $\left.J_{6-4}=1.8 \mathrm{~Hz}, J_{6-5}=15.0 \mathrm{~Hz}, 1, \mathrm{H} 6\right), 7.09$ $\left(\mathrm{dd}, J_{5-6}=15.0 \mathrm{~Hz}, J_{5-4}=3.8 \mathrm{~Hz}, 1, \mathrm{H} 5\right), 7.50-8.05(\mathrm{~m}, 10, \mathrm{Ar}) ; \mathrm{MS} \mathrm{m} / z 431\left(100, \mathrm{MH}^{+}\right)$.

\section{(E/Z)-3-O-Benzoyl-5,6-dideoxy-6-fluoro-1,2-O-isopropylidene-6-tributylstannyl-a-D-xylo- hex-5-enofuranose (23)}

$\mathrm{Bu}_{3} \mathrm{SnH}$ ( $407 \mathrm{mg}, 0.38 \mathrm{~mL}, 1.4 \mathrm{mmol}$ ) was added dropwise to a degassed solution of $\mathbf{2 0}$ (300 $\mathrm{mg}, 0.70 \mathrm{mmol} ; E / Z, 7: 3)$ in anhydrous toluene $(5 \mathrm{~mL})$ in a flame-dried flask under $\mathrm{N}_{2}$ at ambient temperature. After an additional 10 minutes of degassing with $\mathrm{N}_{2}$, AIBN ( $86 \mathrm{mg}, 0.53$ $\mathrm{mmol}$ ) was added and the reaction mixture was refluxed at $110^{\circ} \mathrm{C}$ with stirring for $5 \mathrm{~h}$. The volatiles were evaporated and the residue was partitioned between EtOAc $(50 \mathrm{~mL})$ and 
$\mathrm{NaHCO}_{3} / \mathrm{H}_{2} \mathrm{O}(30 \mathrm{~mL})$. The organic layer was washed with $\mathrm{NaCl} / \mathrm{H}_{2} \mathrm{O}(30 \mathrm{~mL})$, dried $\left(\mathrm{Na}_{2} \mathrm{SO}_{4}\right)$, and evaporated. Column chromatography (hexanes $\rightarrow 10 \%$ EtOAc/hexanes) gave 23 (794 $\mathrm{mg}, 95 \% ; E / Z, 7: 3)$ as an inseparable mixture: $\mathrm{MS} \mathrm{m} / 2599\left(89, \mathrm{MH}^{+},{ }^{120} \mathrm{Sn}\right), 597$ (63, $\left.\mathrm{MH}^{+},{ }^{118} \mathrm{Sn}\right), 595\left(33, \mathrm{MH}^{+},{ }^{116} \mathrm{Sn}\right), 541\left(100, \mathrm{M}-57,{ }^{120} \mathrm{Sn}\right), 539\left(78, \mathrm{M}-57,{ }^{118} \mathrm{Sn}\right), 537(42$, M-57, $\left.{ }^{116} \mathrm{Sn}\right) ;{ }^{19} \mathrm{~F}$ NMR $\delta-87.67\left(\mathrm{~d}, J_{\mathrm{F}-\mathrm{H} 5}=34.3 \mathrm{~Hz}, 84 \%\right.$ of $\left.0.30 \mathrm{~F}, Z\right),-87.67\left(\mathrm{dd}, J_{\mathrm{F}-\mathrm{Sn}}=\right.$ $229.5 \mathrm{~Hz}, J_{\mathrm{F}-\mathrm{H} 5}=34.8 \mathrm{~Hz}, 16 \%$ of $\left.0.30 \mathrm{~F}, Z\right),-92.73\left(\mathrm{~d}, J_{\mathrm{F}-\mathrm{H} 5}=52.7 \mathrm{~Hz}, 84 \%\right.$ of $\left.0.70 \mathrm{~F}, E\right)$, $-92.73\left(\mathrm{ddd}, J_{\mathrm{F}-\mathrm{Sn}}=213.1 \mathrm{~Hz}, J_{\mathrm{F}-\mathrm{H} 5}=52.7 \mathrm{~Hz}, J_{\mathrm{F}-\mathrm{H} 4}=4.9 \mathrm{~Hz}, 16 \%\right.$ of $\left.0.70 \mathrm{~F}, E\right)$. Compound (E)-23 had: ${ }^{1} \mathrm{H}$ NMR $\delta 0.90-1.60(\mathrm{~m}, 27,3 \times \mathrm{Bu}), 1.34 \& 1.36\left(2 \times \mathrm{s}, 2 \times 3,2 \times \mathrm{CH}_{3}\right), 4.71(\mathrm{~d}$, $\left.J_{2-1}=3.8 \mathrm{~Hz}, 1, \mathrm{H} 2\right), 5.10\left(\mathrm{dd}, J_{5-\mathrm{F}}=52.6 \mathrm{~Hz}, J_{5-4}=7.4 \mathrm{~Hz}, 1, \mathrm{H} 5\right), 5.32\left(\mathrm{~d}, J_{3-4}=3.0 \mathrm{~Hz}, 1\right.$, $\mathrm{H} 3), 5.47-5.49(\mathrm{~m}, 1, \mathrm{H} 4), 6.02\left(\mathrm{~d}, J_{1-2}=3.8 \mathrm{~Hz}, 1, \mathrm{H} 1\right), 7.47-8.06(\mathrm{~m}, 5, \mathrm{Ar}) ;{ }^{13} \mathrm{C}$ NMR $\delta$ $10.33(\mathrm{Bu}), 11.15(\mathrm{Bu}), 17.90(\mathrm{Bu}), 27.42 \& 27.54\left(\mathrm{CMe}_{2}\right), 28.24(\mathrm{Bu}), 70.56\left(\mathrm{~d},{ }^{3} J_{4-\mathrm{F}}=17.6\right.$ $\mathrm{Hz}, \mathrm{C} 4), 77.21$ (C3), 77.52 (C2), 104.31 (C1), $113.07\left(\mathrm{CMe}_{2}\right), 120.53\left(\mathrm{~d},{ }^{2} J_{5-\mathrm{F}}=3.9 \mathrm{~Hz}, \mathrm{C} 5\right)$, 128.75 (Bz), $129.83(\mathrm{Bz}), 130.25(\mathrm{Bz}), 133.61(\mathrm{Bz}), 166.16(\mathrm{Bz}), 177.14\left(\mathrm{~d},{ }^{2} J_{6-\mathrm{F}}=262.0 \mathrm{~Hz}\right.$, C6). Compound (Z)-23 had: ${ }^{1} \mathrm{H}$ NMR $\delta$ 0.90-1.60 (m, 27, $\left.3 \times \mathrm{Bu}\right), 1.38 \& 1.69(2 \times \mathrm{s}, 2 \times 3$, $\left.2 \times \mathrm{CH}_{3}\right), 4.69\left(\mathrm{~d}, J_{1-2}=3.9 \mathrm{~Hz}, 1, \mathrm{H} 2\right), 4.75\left(\mathrm{~d}, J_{3-4}=7.9 \mathrm{~Hz}, 1, \mathrm{H} 3\right), 5.47-5.49(\mathrm{~m}, 1, \mathrm{H} 4)$, $5.98\left(\mathrm{~d}, J_{1-2}=3.8 \mathrm{~Hz}, 1, \mathrm{H} 1\right), 6.02\left(\mathrm{dd}, J_{5-\mathrm{F}}=34.3 \mathrm{~Hz}, J_{5-4}=9.2 \mathrm{~Hz}, 1, \mathrm{H} 5\right), 7.47-8.06$ (m, 5 , $\mathrm{Ar}) ;{ }^{13} \mathrm{C}$ NMR $\delta 10.33(\mathrm{Bu}), 11.15(\mathrm{Bu}), 17.90(\mathrm{Bu}), 27.42 \& 27.54(\mathrm{CMe}), 28.24(\mathrm{Bu}), 74.73$ $\left(\mathrm{d},{ }^{3} J_{4-\mathrm{F}}=22.2 \mathrm{~Hz}, \mathrm{C} 4\right), 77.38\left(\mathrm{~d},{ }^{4} J_{3-\mathrm{F}}=1.4 \mathrm{~Hz}, \mathrm{C} 3\right), 77.52(\mathrm{C} 2), 104.53(\mathrm{C} 1), 113.47$ $\left(\mathrm{CMe}_{2}\right), 121.24\left(\mathrm{~d},{ }^{2} J_{5-\mathrm{F}}=9.5 \mathrm{~Hz}, \mathrm{C} 5\right), 128.75(\mathrm{Bz}), 129.88(\mathrm{Bz}), 130.34(\mathrm{Bz}), 133.73(\mathrm{Bz})$, $166.35(\mathrm{Bz}), 180.03\left(\mathrm{~d},{ }^{2} J_{6-\mathrm{F}}=254.3 \mathrm{~Hz}, \mathrm{C} 6\right)$.

\section{(E/Z)-3-O-Benzoyl-5,6-dideoxy-6-fluoro-1,2-O-isopropylidene-6-tributylstannyl-a-D-ribo- hex-5-enofuranose (24)}

Treatment of 21 (300 mg, $0.70 \mathrm{mmol}$; $E / Z, 3: 2)$ with $\mathrm{Bu} 3 \mathrm{SnH}(407 \mathrm{mg}, 0.38 \mathrm{~mL}, 1.4 \mathrm{mmol})$ and AIBN ( $86 \mathrm{mg}, 0.53 \mathrm{mmol}$ ) as described for $\mathbf{2 3}$ gave 24 (397 mg, 95\%; E/Z, 3:2): MS m/ $z 599\left(89, \mathrm{MH}^{+},{ }^{120} \mathrm{Sn}\right), 597\left(63, \mathrm{MH}^{+},{ }^{118} \mathrm{Sn}\right), 595\left(33, \mathrm{MH}^{+},{ }^{116} \mathrm{Sn}\right), 541\left(100, \mathrm{M}-57,{ }^{120} \mathrm{Sn}\right)$, $539\left(78, \mathrm{M}-57,{ }^{118} \mathrm{Sn}\right), 537\left(42, \mathrm{M}-57,{ }^{116} \mathrm{Sn}\right) ;{ }^{19} \mathrm{~F}$ NMR $\delta-87.58\left(\mathrm{~d}, J_{\mathrm{F}-\mathrm{H} 5}=33.1 \mathrm{~Hz}, 84 \%\right.$ of $0.40 \mathrm{~F}, Z),-87.58$ (ddd, $J_{\mathrm{F}-\mathrm{Sn}}=226.7 \mathrm{~Hz}, J_{\mathrm{F}-\mathrm{H} 5}=32.8 \mathrm{~Hz}, J_{\mathrm{F}-\mathrm{H} 4}=4.1 \mathrm{~Hz}, 16 \%$ of $0.40 \mathrm{~F}$ ), $-94.80\left(\mathrm{~d}, J_{\mathrm{F}-\mathrm{H} 5}=51.1 \mathrm{~Hz}, 84 \%\right.$ of $\left.0.60 \mathrm{~F}, E\right),-94.80\left(\mathrm{ddd}, J_{\mathrm{F}-\mathrm{Sn}}=213.9 \mathrm{~Hz}, J_{\mathrm{F}-\mathrm{H} 5}=50.8 \mathrm{~Hz}\right.$, $J_{\mathrm{F}-\mathrm{H} 4}=4.5 \mathrm{~Hz}, 16 \%$ of $\left.0.60 \mathrm{~F}, E\right)$. Compound $(E)-24$ had: ${ }^{1} \mathrm{H}$ NMR $\delta 0.70-1.70(\mathrm{~m}, 27,3 \times$ $\mathrm{Bu}), 1.24 \& 1.26\left(2 \times \mathrm{s}, 2 \times 3,2 \times \mathrm{CH}_{3}\right), 4.62\left(\mathrm{dd}, J_{3-4}=9.3 \mathrm{~Hz}, J_{3-2}=4.7 \mathrm{~Hz}, 1, \mathrm{H} 3\right), 4.86-4.87$ (m, 1, H2), 4.90 (dd, $\left.J_{5-\mathrm{F}}=51.0 \mathrm{~Hz}, J_{5-4}=8.4 \mathrm{~Hz}, 1, \mathrm{H} 5\right), 5.28$ ("t", $\left.J_{4-3 / 5}=8.9 \mathrm{~Hz}, 1, \mathrm{H} 4\right)$, $5.79\left(\mathrm{~d}, J_{1-2}=3.9 \mathrm{~Hz}, 1, \mathrm{H} 1\right), 7.57-8.06(\mathrm{~m}, 5, \mathrm{Ar}) ;{ }^{13} \mathrm{C}$ NMR $\delta 11.15(\mathrm{Bu}), 14.03(\mathrm{Bu}), 29.96$ (Bu), $27.48 \& 27.59(\mathrm{CMe}), 29.23(\mathrm{Bu}), 70.55\left(\mathrm{~d},{ }^{3} J_{4-\mathrm{F}}=18.1 \mathrm{~Hz}, \mathrm{C} 4\right), 77.36(\mathrm{C} 3), 77.48$ (C2), $104.50(\mathrm{C} 1), 113.54\left(\mathrm{CMe}_{2}\right), 120.59\left(\mathrm{~d},{ }^{2} J_{5-\mathrm{F}}=3.8 \mathrm{~Hz}, \mathrm{C} 5\right), 128.77(\mathrm{Bz}), 129.81(\mathrm{Bz})$, 130.38 (Bz), 133.69 (Bz), $166.44(\mathrm{Bz}), 176.10\left(\mathrm{~d},{ }^{1} J_{6-\mathrm{F}}=260.0 \mathrm{~Hz}, \mathrm{C} 6\right)$. Compound $(\mathrm{Z})-\mathbf{2 4}$ had: ${ }^{1} \mathrm{H}$ NMR $\delta$ 0.70-1.70 (m, 27, $\left.3 \times \mathrm{Bu}\right), 1.28 \& 1.30\left(2 \times \mathrm{s}, 2 \times 3,2 \times \mathrm{CH}_{3}\right), 4.47$ ("t", $\left.J_{4-3 / 5}=9.3 \mathrm{~Hz}, 1, \mathrm{H} 4\right), 4.71$ (dd, $\left.J_{3-4}=9.0 \mathrm{~Hz}, J_{3-2}=4.8 \mathrm{~Hz}, 1, \mathrm{H} 3\right), 4.85-4.86(\mathrm{~m}, 1, \mathrm{H} 2)$, $5.81\left(\mathrm{~d}, J_{1-2}=3.8 \mathrm{~Hz}, 1, \mathrm{H} 1\right), 5.83\left(\mathrm{dd}, J_{5-\mathrm{F}}=33.7 \mathrm{~Hz}, J_{5-4}=9.5 \mathrm{~Hz}, 1, \mathrm{H} 5\right), 7.57-8.06(\mathrm{~m}, 5$, Ar) ${ }^{13} \mathrm{C}$ NMR $\delta 11.15(\mathrm{Bu}), 14.03(\mathrm{Bu}), 29.96(\mathrm{Bu}), 27.48 \& 27.59(\mathrm{CMe}), 29.23(\mathrm{Bu}), 74.72$ $\left(\mathrm{d},{ }^{3} J_{4-\mathrm{F}}=22.0 \mathrm{~Hz}, \mathrm{C} 4\right), 77.16(\mathrm{C} 3), 77.67(\mathrm{C} 2), 104.28(\mathrm{C} 1), 113.13\left(\mathrm{CMe}_{2}\right), 121.18$ $\left(\mathrm{d},{ }^{2} J_{5-\mathrm{F}}=9.9 \mathrm{~Hz}, \mathrm{C} 5\right), 128.77(\mathrm{Bz}), 129.76(\mathrm{Bz}), 130.28(\mathrm{Bz}), 130.80(\mathrm{Bz}), 166.24(\mathrm{Bz}), 177.00$ $\left(\mathrm{d},{ }^{1} J_{6-\mathrm{F}}=255.0 \mathrm{~Hz}, \mathrm{C} 6\right)$.

\section{(E)-3-O-Benzoyl-5,6-dideoxy-1,2-O-isopropylidene-6-tributylstannyl- $\alpha$-D-ribo-hex-5- enofuranose (25)}

Treatment of $22(E ; 300 \mathrm{mg}, 0.70 \mathrm{mmol})$ with $\mathrm{Bu}_{3} \mathrm{SnH}(407 \mathrm{mg}, 0.38 \mathrm{~mL}, 1.4 \mathrm{mmol})$ and AIBN ( $86 \mathrm{mg}, 0.53 \mathrm{mmol}$ ) as described for $\mathbf{2 3}$ gave 25 (385 mg, 95\%): ${ }^{1} \mathrm{H}$ NMR $\delta 1.51-1.90$ (m, 33, $\left.3 \times \mathrm{Bu} \& 2 \times \mathrm{CH}_{3}\right), 4.66\left(\mathrm{dd}, J_{4-5}=6.5 \mathrm{~Hz}, J_{4-3}=8.4 \mathrm{~Hz}, 1, \mathrm{H} 4\right), 4.77\left(\mathrm{dd}, J_{3-4}=9.2 \mathrm{~Hz}\right.$, $\left.J_{3-2}=4.7 \mathrm{~Hz}, 1, \mathrm{H} 3\right), 4.97\left(\mathrm{t}, J_{2-1 / 3}=3.6 \mathrm{~Hz}, 1, \mathrm{H} 2\right), 5.93\left(\mathrm{~d}, J_{1-2}=3.8 \mathrm{~Hz}, 1, \mathrm{H} 1\right), 6.10(\mathrm{dd}$, $\left.J_{5-6}=19.1 \mathrm{~Hz}, J_{5-4}=6.5 \mathrm{~Hz} 1, \mathrm{H} 5\right), 6.50\left(\mathrm{dd}, J_{6-5}=19.1 \mathrm{~Hz}, J_{6-4}=0.9 \mathrm{~Hz}, 1, \mathrm{H} 6\right), 7.57-8.06$ 
(m, 5, Ar); MS m/z $581\left(89, \mathrm{MH}^{+},{ }^{120} \mathrm{Sn}\right), 579\left(63, \mathrm{MH}^{+},{ }^{118} \mathrm{Sn}\right), 577\left(33, \mathrm{MH}^{+},{ }^{116} \mathrm{Sn}\right), 523$ $\left(100, \mathrm{M}-57,{ }^{120} \mathrm{Sn}\right), 521\left(78, \mathrm{M}-57,{ }^{118} \mathrm{Sn}\right), 519\left(42, \mathrm{M}-57,{ }^{116} \mathrm{Sn}\right)$.

\section{(E/Z)-3-O-Benzoyl-5,6-dideoxy-6-fluoro-6-iodo-1,2-O-isopropylidene- $\alpha$-D-xylo-hex-5- enofuranose (26)}

A solution of NIS (50 mg, $0.23 \mathrm{mmol})$ in anhydrous $\mathrm{CH}_{2} \mathrm{Cl}_{2}(3 \mathrm{~mL})$ was added dropwise to a stirred solution of $23(90 \mathrm{mg}, 0.15 \mathrm{mmol} ; E / Z, 7: 3)$ in $\mathrm{CH}_{2} \mathrm{Cl}_{2}(5 \mathrm{~mL})$ under $\mathrm{N}_{2}$ at $-20{ }^{\circ} \mathrm{C}$.

After $1 \mathrm{~h}, \mathrm{CHCl}_{3}(30 \mathrm{~mL})$ and diluted $\mathrm{NaHSO}_{3} / \mathrm{H}_{2} \mathrm{O}(10 \mathrm{~mL})$ were added. The separated organic layer was washed with $\mathrm{NaHCO}_{3} / \mathrm{H}_{2} \mathrm{O}(10 \mathrm{~mL}), \mathrm{NaCl} / \mathrm{H}_{2} \mathrm{O}(10 \mathrm{~mL})$, dried $\left(\mathrm{Na}_{2} \mathrm{SO}_{4}\right)$, and evaporated. Column chromatography (hexanes $\rightarrow 30 \%$ EtOAc/hexanes) gave 26 ( $155 \mathrm{mg}$, $83 \% ; E / Z, 8: 2)$ as an inseparable mixture: $\mathrm{MS} m / z 435\left(100, \mathrm{MH}^{+}\right) ;{ }^{19} \mathrm{~F}$ NMR $\delta-56.54(\mathrm{~d}$, $\left.J_{\mathrm{F}-\mathrm{H} 5}=15.8 \mathrm{~Hz}, 0.20 \mathrm{~F}, Z\right),-60.98\left(\mathrm{~d}, J_{\mathrm{F}-\mathrm{H} 5}=33.1 \mathrm{~Hz}, 0.80 \mathrm{~F}, E\right)$. Compound $(E)-26$ had: ${ }^{1} \mathrm{H}$ NMR $\delta 1.35 \& 1.38\left(2 \times \mathrm{s}, 2 \times 3,2 \times \mathrm{CH}_{3}\right), 4.69\left(\mathrm{~d}, J_{2-1}=3.8 \mathrm{~Hz}, 1, \mathrm{H} 2\right), 5.28\left(\mathrm{ddd}, J_{4-5}=\right.$ $\left.9.8 \mathrm{~Hz}, J_{4-3}=2.9 \mathrm{~Hz}, J_{4-6}=1.6 \mathrm{~Hz}, 1, \mathrm{H} 4\right), 5.45\left(\mathrm{~d}, J_{3-4}=3.0 \mathrm{~Hz}, 1, \mathrm{H} 3\right), 5.58\left(\mathrm{dd}, J_{5-\mathrm{F}}=33.0\right.$ $\left.\mathrm{Hz}, J_{5-4}=8.7 \mathrm{~Hz}, 1, \mathrm{H} 5\right), 5.99\left(\mathrm{~d}, J_{1-2}=3.7 \mathrm{~Hz}, 1, \mathrm{H} 1\right), 7.47-8.06(\mathrm{~m}, 5, \mathrm{Ar}) ;{ }^{13} \mathrm{C} \mathrm{NMR} \delta 26.60$ \& $27.12\left(\mathrm{CMe}_{2}\right), 74.04\left(\mathrm{~d},{ }^{3} J_{4-\mathrm{F}}=4.4 \mathrm{~Hz}, \mathrm{C} 4\right), 77.88(\mathrm{C} 3), 83.73(\mathrm{C} 2), 104.74(\mathrm{C} 1), 107.89$ $\left(\mathrm{d},{ }^{1} J_{6-\mathrm{F}}=338.7 \mathrm{~Hz}, \mathrm{C} 6\right), 112.85\left(\mathrm{CMe}_{2}\right), 116.80\left(\mathrm{~d},{ }^{2} J_{5-\mathrm{F}}=5.4 \mathrm{~Hz}, \mathrm{C} 5\right), 129.04(\mathrm{Bz}), 129.50$ (Bz), $130.18(\mathrm{Bz}), 134.09(\mathrm{Bz}), 165.54(\mathrm{Bz})$. Compound $(Z)-26$ had: ${ }^{1} \mathrm{H}$ NMR $\delta 1.35 \& 1.68$ $\left(2 \times \mathrm{s}, 2 \times 3,2 \times \mathrm{CH}_{3}\right), 4.71\left(\mathrm{~d}, J_{1-2}=3.7 \mathrm{~Hz}, 1, \mathrm{H} 2\right), 4.84\left(\mathrm{dd}, J_{4-5}=8.7 \mathrm{~Hz}, J_{4-3}=2.7 \mathrm{~Hz}\right.$, 1, H4), $5.48\left(\mathrm{~d}, J_{3-4}=3.0 \mathrm{~Hz}, 1, \mathrm{H} 3\right), 5.77\left(\mathrm{dd}, J_{5-\mathrm{F}}=15.4 \mathrm{~Hz}, J_{5-4}=8.8 \mathrm{~Hz}, 1, \mathrm{H} 5\right), 6.03(\mathrm{~d}$, $\left.J_{1-2}=3.7 \mathrm{~Hz}, 1, \mathrm{H} 1\right), 7.47-8.06(\mathrm{~m}, 5, \mathrm{Ar}) ;{ }^{13} \mathrm{C} \mathrm{NMR} \delta 26.78 \& 27.27(\mathrm{CMe}), 77.88(\mathrm{C} 3)$, $80.06\left(\mathrm{~d},{ }^{3} J_{4-\mathrm{F}}=8.2 \mathrm{~Hz}, \mathrm{C} 4\right), 83.84(\mathrm{C} 2), 105.04(\mathrm{C} 1), 112.94\left(\mathrm{~d},{ }^{2} J_{5-\mathrm{F}}=16.9 \mathrm{~Hz}, \mathrm{C} 5\right), 112.95$ $\left(C \mathrm{Me}_{2}\right), 114.78\left(\mathrm{~d},{ }^{1} J_{6-\mathrm{F}}=332.0 \mathrm{~Hz}, \mathrm{C} 6\right), 129.04(\mathrm{Bz}), 129.40(\mathrm{Bz}), 130.18(\mathrm{Bz}), 134.14(\mathrm{Bz})$, $165.54(\mathrm{Bz})$.

\section{(E/Z)-3-O-Benzoyl-5,6-dideoxy-6-fluoro-6-iodo-1,2-O-isopropylidene-a-D-ribo-hex-5- enofuranose (27)}

Treatment of 24 (250 mg, $0.42 \mathrm{mmol} ; E / Z, 3: 2)$ with NIS (142 $\mathrm{mg}, 0.63 \mathrm{mmol})$ as described for $\mathbf{2 6}$ gave $\mathbf{2 7}(155 \mathrm{mg}, 85 \%$; $E / Z, 3: 2)$ as an inseparable mixture: HRMS (AP-FAB) $\mathrm{m} / z$ : calcd for $\mathrm{C}_{16} \mathrm{H}_{16} \mathrm{FIO}_{5} \mathrm{Li}\left(\mathrm{MLi}^{+}\right) 441.0181$; found $441.0192 ;{ }^{19} \mathrm{~F} \mathrm{NMR} \delta-56.42\left(\mathrm{~d}, J_{\mathrm{F}-\mathrm{H} 5}=15.1 \mathrm{~Hz}\right.$, $0.40 \mathrm{~F}, Z),-63.30\left(\mathrm{~d}, J_{\mathrm{F}-\mathrm{H} 5}=33.5 \mathrm{~Hz}, 0.60 \mathrm{~F}, E\right)$. Compound $(E)-27$ had: ${ }^{1} \mathrm{H}$ NMR $\delta 1.36 \&$ $1.60\left(2 \times \mathrm{s}, 2 \times 3,2 \times \mathrm{CH}_{3}\right), 4.75\left(\mathrm{dd}, J_{3-4}=9.2 \mathrm{~Hz}, J_{3-2}=4.7 \mathrm{~Hz}, 1, \mathrm{H3}\right), 4.98\left(\mathrm{t}, J_{2-1 / 3}=4.5\right.$ $\mathrm{Hz}, 1, \mathrm{H} 2), 5.16\left(\mathrm{t}, J_{4-3 / 5}=9.0 \mathrm{~Hz}, 1, \mathrm{H} 4\right), 5.49\left(\mathrm{dd}, J_{5-\mathrm{F}}=32.7 \mathrm{~Hz}, J_{5-4}=8.7 \mathrm{~Hz}, 1, \mathrm{H} 5\right), 5.89$ $\left(\mathrm{d}, J_{1-2}=3.8 \mathrm{~Hz}, 1, \mathrm{H} 1\right), 7.50-8.10(\mathrm{~m}, 5, \mathrm{Ar}) ;{ }^{13} \mathrm{C}$ NMR $\delta 26.96 \& 27.11\left(\mathrm{CMe}_{2}\right), 72.45$ $\left(\mathrm{d},{ }^{3} J_{4-\mathrm{F}}=4.3 \mathrm{~Hz}, \mathrm{C} 4\right), 76.74\left(\mathrm{~d},{ }^{4} J_{3-\mathrm{F}}=2.1 \mathrm{~Hz}, \mathrm{C} 3\right), 77.32(\mathrm{C} 2), 104.39(\mathrm{C} 1), 113.78$ $\left(C \mathrm{Me}_{2}\right), 114.96\left(\mathrm{~d},{ }^{1} J_{6-\mathrm{F}}=331.5 \mathrm{~Hz}, \mathrm{C} 6\right), 119.90\left(\mathrm{~d},{ }^{2} J_{5-\mathrm{F}}=5.5 \mathrm{~Hz}, \mathrm{C} 5\right), 128.92(\mathrm{Bz}), 129.46$ (Bz), $130.50(\mathrm{Bz}), 133.94(\mathrm{Bz}), 166.21(\mathrm{Bz})$. Compound (Z)-27 had: ${ }^{1} \mathrm{H}$ NMR $\delta 1.38$ \& 1.64 $\left(2 \times \mathrm{s}, 2 \times 3,2 \times \mathrm{CH}_{3}\right), 4.72-4.75(\mathrm{~m}, 1, \mathrm{H} 4), 4.84\left(\mathrm{dd}, J_{3-4}=9.2 \mathrm{~Hz}, J_{3-2}=4.6 \mathrm{~Hz}, 1, \mathrm{H} 3\right)$, $4.98\left(\mathrm{t}, J_{2-3 / 1}=4.5 \mathrm{~Hz}, 1, \mathrm{H} 2\right), 5.68\left(\mathrm{dd}, J_{5-\mathrm{F}}=15.3 \mathrm{~Hz}, J_{5-4}=8.9 \mathrm{~Hz}, 1, \mathrm{H} 5\right), 5.91\left(\mathrm{~d}, J_{1-2}=\right.$ $3.8 \mathrm{~Hz}, 1, \mathrm{H} 1), 7.50-8.14(\mathrm{~m}, 5, \mathrm{Ar}) ;{ }^{13} \mathrm{C}$ NMR $\delta 26.96 \& 27.11(\mathrm{CMe}), 76.85\left(\mathrm{~d},{ }^{4} J_{3-\mathrm{F}}=2.1\right.$ $\mathrm{Hz}, \mathrm{C} 3), 77.63(\mathrm{C} 2), 78.13\left(\mathrm{~d},{ }^{3} J_{4-\mathrm{F}}=8.3 \mathrm{~Hz}, \mathrm{C} 4\right), 104.54(\mathrm{C} 1), 108.75\left(\mathrm{~d},{ }^{1} J_{6-\mathrm{F}}=339.4 \mathrm{~Hz}\right.$, C6), $113.90\left(\mathrm{CMe}_{2}\right), 115.77\left(\mathrm{~d},{ }^{2} J_{5-\mathrm{F}}=16.2 \mathrm{~Hz}, \mathrm{C} 5\right), 128.91(\mathrm{Bz}), 129.49(\mathrm{Bz}), 130.37(\mathrm{Bz})$, $133.95(\mathrm{Bz}), 166.21(\mathrm{Bz})$.

\section{(E)-3-O-Benzoyl-5,6-dideoxy-6-iodo-1,2-O-isopropylidene-a-D-ribo-hex-5-enofuranose (28)}

Treatment of $\mathbf{2 5}(150 \mathrm{mg}, 0.25 \mathrm{mmol})$ with NIS ( $85 \mathrm{mg}, 0.38 \mathrm{mmol})$ as described for $\mathbf{2 6}$ gave $28(93 \mathrm{mg}, 87 \%):{ }^{1} \mathrm{H}$ NMR $\delta 1.35 \& 1.62\left(2 \times \mathrm{s}, 2 \times 3,2 \times \mathrm{CH}_{3}\right), 4.67\left(\mathrm{dd}, J_{2-3}=9.2 \mathrm{~Hz}\right.$, $\left.J_{2-1}=4.6 \mathrm{~Hz}, 1, \mathrm{H} 2\right), 4.77\left(\mathrm{dd}, J_{3-4}=3.4 \mathrm{~Hz}, J_{3-2}=9.2 \mathrm{~Hz}, 1, \mathrm{H} 3\right), 4.97\left(\mathrm{t}, J_{4-3 / 5}=4.2 \mathrm{~Hz}, 1\right.$, $\mathrm{H} 4), 5.91\left(\mathrm{~d}, J_{1-2}=3.8 \mathrm{~Hz}, 1, \mathrm{H} 1\right), 6.61-6.70$ (m, 2, H5/6), 7.49-8.08 (m, 5, Ar); ${ }^{13} \mathrm{C}$ NMR $\delta$ $26.95 \& 26.96$ (CMe $), 76.37$ (C4), 77.59 (C3), 79.61 (C2), 81.32 (C6), 104.43 (C1), 113.68 
$\left(\mathrm{CMe}_{2}\right), 128.89$ (Bz), $129.60(\mathrm{Bz}), 130.94(\mathrm{Bz}), 133.89$ (Bz), 141.58 (C5), 166.08 (Bz); MS $\mathrm{m} / \mathrm{z} 417\left(100, \mathrm{MH}^{+}\right)$.

\section{Ethyl 3-O-Benzoyl-5,6,7,8,9-pentadeoxy-6-fluoro-1,2-O-isopropylidene- $\alpha-D-x y l o-d e c-5-(E / Z)-$ enofuranuronate (29)}

$\mathrm{Pd}\left[\mathrm{P}(\mathrm{Ph})_{3}\right]_{4}(5 \mathrm{mg}, 0.004 \mathrm{mmol})$ was added to a stirred solution of 26 (30 mg, $0.07 \mathrm{mmol} ; E /$ $Z, 4: 1)$ in anhydrous benzene ( $3 \mathrm{~mL}$ ) under $\mathrm{N}_{2}$ at ambient temperature. After 2 minutes, 4ethoxy-4-oxobutylzinc bromide (0.5M/THF; $0.28 \mathrm{~mL}, 65 \mathrm{mg}, 0.14 \mathrm{mmol})$ was added and the resulting mixture was heated at $55^{\circ} \mathrm{C}$ for $5 \mathrm{~h}$. EtOAc $(30 \mathrm{~mL})$ and $\mathrm{NaHCO}_{3} / \mathrm{H}_{2} \mathrm{O}(10 \mathrm{~mL})$ were added and the separated organic layer was washed with $\mathrm{H}_{2} \mathrm{O}(10 \mathrm{~mL}), \mathrm{NaCl} / \mathrm{H}_{2} \mathrm{O}(10$ $\mathrm{mL})$, dried $\left(\mathrm{Na}_{2} \mathrm{SO}_{4}\right)$, and then was evaporated. Column chromatography $(10 \rightarrow 30 \%$ EtOAc/ hexanes) gave (Z)-29 (18 mg, 61\%, 76\% based on the conversion of the $E$-isomer), (E)-29 (2 $\mathrm{mg}, 7 \%, 35 \%$ based on the conversion of the $Z$-isomer) and more polar byproduct tentatively assigned as 3-O-debenzoylated-(Z)-26 $\left[\sim 5 \%\right.$, TLC; $\left.{ }^{19} \mathrm{~F} \mathrm{NMR} \delta-57.21\left(J_{\mathrm{F}-\mathrm{H} 5}=16.4 \mathrm{~Hz}\right)\right]$. Compound (Z)-29 had: ${ }^{1} \mathrm{H}$ NMR $\delta 1.22\left(\mathrm{t}, J=7.1 \mathrm{~Hz}, 3, \mathrm{CH}_{3}\right), 1.36 \& 1.61(2 \times \mathrm{s}, 2 \times 3,2 \times$ $\left.\mathrm{CH}_{3}\right), 1.81$ ("quint", $\left.J_{8-7 / 7^{\prime} / 9 / 9^{\prime}}=7.4 \mathrm{~Hz}, 2, \mathrm{H} 8 / 8^{\prime}\right), 2.26\left(\mathrm{dt}, J_{7-\mathrm{F}}=18.1 \mathrm{~Hz}, J_{7-8 / 8^{\prime}}=7.4 \mathrm{~Hz}, 2\right.$, $\left.\mathrm{H} 7 / 7^{\prime}\right), 2.30\left(\mathrm{t}, J_{9-8 / 8^{\prime}}=7.4 \mathrm{~Hz}, 2, \mathrm{H} 9 / 9^{\prime}\right), 4.09\left(\mathrm{q}, J=7.1 \mathrm{~Hz}, 2, \mathrm{CH}_{2}\right), 4.69\left(\mathrm{~d}, J_{2-1}=3.7 \mathrm{~Hz}\right.$, $1, \mathrm{H} 2), 4.84\left(\mathrm{dd}, J_{5-\mathrm{F}}=35.8 \mathrm{~Hz}, J_{5-4}=8.4 \mathrm{~Hz}, \mathrm{H} 5\right), 5.33\left(\mathrm{dd}, J_{4-5}=8.5 \mathrm{~Hz}, J_{4-3}=2.8 \mathrm{~Hz}, 1\right.$, $\mathrm{H} 4), 5.45\left(\mathrm{~d}, J_{3-4}=2.8 \mathrm{~Hz}, 1, \mathrm{H} 3\right), 6.00\left(\mathrm{~d}, J_{1-2}=3.7 \mathrm{~Hz}, 1, \mathrm{H} 1\right), 7.48-8.04,(\mathrm{~m}, 5, \mathrm{Ar}) ;{ }^{13} \mathrm{C}$ NMR $\delta 14.59\left(\mathrm{CH}_{3}\right), 21.49(\mathrm{C} 8), 26.64 \& 27.11\left(\mathrm{CMe}_{2}\right), 31.61\left(\mathrm{~d},{ }^{2} J_{7-\mathrm{F}}=25.4 \mathrm{~Hz}, \mathrm{C} 7\right), 33.34$ (C9), $60.75\left(\mathrm{CH}_{2}\right), 73.37\left(\mathrm{~d},{ }^{3} J_{4-\mathrm{F}}=6.6 \mathrm{~Hz}, \mathrm{C} 4\right), 77.63(\mathrm{C} 2), 78.33(\mathrm{C} 3), 100.03\left(\mathrm{~d},{ }^{2} J_{5-\mathrm{F}}=\right.$ $10.9 \mathrm{~Hz}, \mathrm{C} 5), 104.78$ (C1), $112.60\left(\mathrm{CMe}_{2}\right), 128.97(\mathrm{Bz}), 129.70(\mathrm{Bz}), 130.16(\mathrm{Bz}), 133.93$ (Bz), $162.94\left(\mathrm{~d},{ }^{1} J_{6-\mathrm{F}}=260.7 \mathrm{~Hz}, \mathrm{C} 6\right), 165.61(\mathrm{Bz}), 173.32(\mathrm{C} 10) ;{ }^{19} \mathrm{~F} \mathrm{NMR} \delta-99.93(\mathrm{dt}$, $\left.J_{\mathrm{F}-\mathrm{H} 5}=35.8 \mathrm{~Hz}, J=18.0 \mathrm{~Hz}\right)$; HRMS $\left(\mathrm{AP}-\mathrm{FAB}^{+}\right) \mathrm{m} / z$ calcd for $\mathrm{C}_{22} \mathrm{H}_{27} \mathrm{FO}_{7} \mathrm{Li}\left(\mathrm{MLi}^{+}\right)$ 429.1910; found 429.1900. Compound (E)-29 had: ${ }^{1} \mathrm{H}$ NMR $\delta 1.28\left(\mathrm{t}, J=7.1 \mathrm{~Hz}, 3, \mathrm{CH}_{3}\right)$, $1.35 \& 1.61\left(2 \times \mathrm{s}, 2 \times 3,2 \times \mathrm{CH}_{3}\right), 1.85-1.95\left(\mathrm{~m}, 2, \mathrm{H} 8 / 8^{\prime}\right), 2.38$ (t, $\left.J_{9-8 / 8^{\prime}}=7.2 \mathrm{~Hz}, 2, \mathrm{H} 9 / 9^{\prime}\right)$, 2.39-2.50 (m, 2, H7/7'), 4.15 (q, J = 7.1 Hz, 2, $\mathrm{CH}_{2}$ ), 4.69 (d, $\left.J_{2-1}=3.8 \mathrm{~Hz}, 1, \mathrm{H} 2\right), 4.93$ ("dt", $\left.J_{4-5}=9.3 \mathrm{~Hz}, J_{4-\mathrm{F} / 3}=2.5 \mathrm{~Hz}, 1, \mathrm{H} 4\right), 5.30\left(\mathrm{dd}, J_{5-\mathrm{F}}=18.6 \mathrm{~Hz}, J_{5-4}=9.4 \mathrm{~Hz}, \mathrm{H} 5\right), 5.38(\mathrm{~d}$, $\left.J_{3-4}=2.9 \mathrm{~Hz}, 1, \mathrm{H} 3\right), 6.00\left(\mathrm{~d}, J_{1-2}=3.8 \mathrm{~Hz}, 1, \mathrm{H} 1\right), 7.48-8.04(\mathrm{~m}, 5, \mathrm{Ar}) ;{ }^{19} \mathrm{~F}$ NMR $\delta-94.53$ ("q", $J=22.1 \mathrm{~Hz}$ ). HRMS $\left(\mathrm{AP}^{\mathrm{FAAB}}{ }^{+}\right) \mathrm{m} / z$ calcd for $\mathrm{C}_{22} \mathrm{H}_{27} \mathrm{FO}_{7} \mathrm{Li}\left(\mathrm{MLi}^{+}\right) 429.1910$; found 429.1903.

\section{Ethyl 3-O-Benzoyl-5,6,7,8,9-pentadeoxy-6-fluoro-1,2-O-isopropylidene- $\alpha$-D-ribo-dec-5(E/Z)- enofuranuronate (30)}

Treatment of 27 (42 mg, $0.097 \mathrm{mmol} ; E / Z, 3: 2)$ with $\mathrm{Pd}\left[\mathrm{P}(\mathrm{Ph})_{3}\right]_{4}(22 \mathrm{mg}, 0.01 \mathrm{mmol})$ and 4ethoxy-4-oxobutylzinc bromide $(0.5 \mathrm{M} / \mathrm{THF} ; 0.30 \mathrm{mmol}, 0.60 \mathrm{~mL})$ as described for 29 followed by column chromatography $(10 \rightarrow 40 \%$ EtOAc/hexanes) gave $(Z)-\mathbf{3 0}$ ( $22 \mathrm{mg}, 54 \%$; $90 \%$ based on the conversion of $E$-isomer), $(E)-30$ ( $5 \mathrm{mg}, 12 \% ; 30 \%$ based on the conversion of the $Z$ isomer), and more polar 3-O-debenzoylated-(Z)-27 (3 mg, 10\%). Compound $(Z)-30$ had: ${ }^{1} \mathrm{H}$ NMR $\delta 1.24\left(\mathrm{t}, J=7.1 \mathrm{~Hz}, 3, \mathrm{CH}_{3}\right), 1.37 \& 1.60\left(2 \times \mathrm{s}, 2 \times 3,2 \times \mathrm{CH}_{3}\right), 1.84$ ("quint", $\left.J_{8-7 / 7^{\prime} / 9 / 9^{\prime}}=7.4 \mathrm{~Hz}, 2, \mathrm{H} 8 / 8^{\prime}\right), 2.25\left(\mathrm{dt}, J_{7-\mathrm{F}}=17.6 \mathrm{~Hz}, J_{7-8 / 8^{\prime}}=7.5 \mathrm{~Hz}, 2, \mathrm{H} 7 / 7^{\prime}\right), 2.32(\mathrm{t}$, $\left.J_{9-8 / 8^{\prime}}=7.4 \mathrm{~Hz}, 2, \mathrm{H} 9 / 9^{\prime}\right), 4.09\left(\mathrm{q}, J=7.1 \mathrm{~Hz}, 2, \mathrm{CH}_{2}\right), 4.72\left(\mathrm{dd}, J_{3-4}=9.2 \mathrm{~Hz}, J_{3-2}=4.7 \mathrm{~Hz}\right.$, $1, \mathrm{H} 3), 4.75\left(\mathrm{dd}, J_{5-\mathrm{F}}=35.0 \mathrm{~Hz}, J_{5-4}=8.9 \mathrm{~Hz}, 1, \mathrm{H} 5\right), 4.95\left(\mathrm{t}, J_{2-1 / 3}=4.3 \mathrm{~Hz}, 1, \mathrm{H} 2\right), 5.19$ (t, $\left.J_{4-3 / 5}=9.1 \mathrm{~Hz}, 1, \mathrm{H} 4\right), 5.89\left(\mathrm{~d}, J_{1-2}=3.8 \mathrm{~Hz}, 1, \mathrm{H} 1\right), 7.48-8.09(\mathrm{~m}, 5, \mathrm{Ar}) ;{ }^{13} \mathrm{C}$ NMR $\delta 14.60$ $\left(\mathrm{CH}_{3}\right), 21.45(\mathrm{C} 8), 26.95 \& 27.00\left(\mathrm{CMe}_{2}\right), 31.63\left(\mathrm{~d},{ }^{2} J_{7-\mathrm{F}}=26.5 \mathrm{~Hz}, \mathrm{C} 7\right), 33.32(\mathrm{C} 9), 60.79$ $\left(\mathrm{CH}_{2}\right), 71.39\left(\mathrm{~d},{ }^{3} J_{4-\mathrm{F}}=6.3 \mathrm{~Hz}, \mathrm{C} 4\right), 77.54(\mathrm{C} 2), 73.63(\mathrm{C} 3), 103.40\left(\mathrm{~d},{ }^{2} J_{5-\mathrm{F}}=11.8 \mathrm{~Hz}, \mathrm{C} 5\right)$, 104.39 (C1), $113.52\left(\mathrm{CMe}_{2}\right), 128.84(\mathrm{Bz}), 129.71(\mathrm{Bz}), 130.33(\mathrm{Bz}), 133.77(\mathrm{Bz}), 164.13$ $\left(\mathrm{d},{ }^{1} J_{6-\mathrm{F}}=272.7 \mathrm{~Hz}, \mathrm{C} 6\right), 165.33(\mathrm{Bz}), 173.30(\mathrm{C} 10) ;{ }^{19} \mathrm{~F}$ NMR $\delta-102.14\left(\mathrm{dt}, J_{\mathrm{F}-\mathrm{H} 5}=34.1\right.$ $\mathrm{Hz}, J_{\mathrm{F}-\mathrm{H} 7 / 7^{\prime}}=17.6 \mathrm{~Hz}$ ). HRMS (AP-ESI) $\mathrm{m} / z$ calcd for $\mathrm{C}_{22} \mathrm{H}_{28} \mathrm{FO}_{7}\left(\mathrm{MH}^{+}\right) 423.1814$; found 423.1815. Compound (E)-30 had: ${ }^{1} \mathrm{H}$ NMR $\delta 1.26\left(\mathrm{t}, J=7.1 \mathrm{~Hz}, 3, \mathrm{CH}_{3}\right), 1.36 \& 1.61(2 \times \mathrm{s}$, $2 \times 3,2 \times \mathrm{CH}_{3}$ ), 1.90 ("quint", $J_{8-7 / 7^{\prime} / 9 / 9^{\prime}}=6.9 \mathrm{~Hz}, 2, \mathrm{H} 8 / 8^{\prime}$ ), 2.38 (t, $J_{9-8 / 8^{\prime}}=6.9 \mathrm{~Hz}, 2, \mathrm{H} 9 / 9^{\prime}$ ), $2.50\left(\mathrm{dt}, J_{7-\mathrm{F}}=23.0 \mathrm{~Hz}, J_{7-8 / 8^{\prime}}=7.3 \mathrm{~Hz}, 2, \mathrm{H} 7 / 7^{\prime}\right), 4.14\left(\mathrm{q}, J=7.1 \mathrm{~Hz}, 2, \mathrm{CH}_{2}\right), 4.75-4.80(\mathrm{~m}$, 
2, H3/4), $4.95\left(\mathrm{t}, J_{2-1 / 3}=4.0 \mathrm{~Hz}, 1, \mathrm{H} 2\right), 5.17\left(\mathrm{dd}, J_{5-\mathrm{F}}=19.2 \mathrm{~Hz}, J_{5-4}=8.7 \mathrm{~Hz}, 1, \mathrm{H} 5\right), 5.88$ $\left(\mathrm{d}, J_{1-2}=3.8 \mathrm{~Hz}, 1, \mathrm{H} 1\right), 7.48-8.09(\mathrm{~m}, 5, \mathrm{Ar}) ;{ }^{13} \mathrm{C} \mathrm{NMR} \delta 14.63\left(\mathrm{CH}_{3}\right), 21.99(\mathrm{C} 8), 26.92 \&$ $27.00(\mathrm{CMe}), 28.49\left(\mathrm{~d},{ }^{2} J_{7-\mathrm{F}}=27.0 \mathrm{~Hz}, \mathrm{C} 7\right), 33.67(\mathrm{C} 9), 60.78\left(\mathrm{CH}_{2}\right), 73.65\left(\mathrm{~d},{ }^{3} J_{4-\mathrm{F}}=14.7\right.$ $\mathrm{Hz}, \mathrm{C} 4), 77.50$ (C2), $77.61(\mathrm{C} 3), 104.58\left(\mathrm{~d},{ }^{2} J_{5-\mathrm{F}}=25.8 \mathrm{~Hz}, \mathrm{C} 5\right), 104.37$ (C1), 113.39 $\left(\mathrm{CMe}_{2}\right), 128.88(\mathrm{Bz}), 129.64(\mathrm{Bz}), 130.25(\mathrm{Bz}), 133.83(\mathrm{Bz}), 165.15\left(\mathrm{~d},{ }^{1} J_{6-\mathrm{F}}=256.5 \mathrm{~Hz}, \mathrm{C} 6\right)$, $165.99(\mathrm{Bz}), 173.21(\mathrm{C} 10) ;{ }^{19} \mathrm{~F}$ NMR $\delta$ - $94.73\left(" \mathrm{q} ", J_{\mathrm{F}-\mathrm{H} 5 / 7 / 7^{\prime}}=22.8 \mathrm{~Hz}\right.$ ). HRMS (AP-ESI) $\mathrm{m} / z$ calcd for $\mathrm{C}_{22} \mathrm{H}_{28} \mathrm{FO}_{7}\left(\mathrm{MH}^{+}\right)$423.1814; found 423.1819. The 3-O-debenzoylated-( $\left.\mathrm{Z}\right)-27$ had: ${ }^{1} \mathrm{H}$ NMR $\delta 1.27 \& 1.58\left(2 \times \mathrm{s}, 2 \times 3,2 \times \mathrm{CH}_{3}\right), 3.82-3.84(\mathrm{~m}, 1, \mathrm{H} 3), 4.18\left(\mathrm{t}, J_{4-3 / 5}=8.8\right.$ $\mathrm{Hz}, 1, \mathrm{H} 4), 4.60-4.62(\mathrm{~m}, 1, \mathrm{H} 2), 5.61$ (dd, $\left.J_{5-\mathrm{F}}=15.1 \mathrm{~Hz}, J_{5-4}=8.9 \mathrm{~Hz}, 1, \mathrm{H} 5\right), 5.83$ (d, $\left.J_{1-2}=3.7 \mathrm{~Hz}, 1, \mathrm{H} 1\right) ;{ }^{13} \mathrm{C}$ NMR $\delta 26.99 \& 27.07\left(\mathrm{CMe}_{2}\right), 76.63(\mathrm{C} 3), 78.56(\mathrm{C} 2), 80.47$ $\left(\mathrm{d},{ }^{3} J_{4-\mathrm{F}}=8.0 \mathrm{~Hz}, \mathrm{C} 4\right), 104.16(\mathrm{C} 1), 115.85\left(\mathrm{~d},{ }^{1} J_{6-\mathrm{F}}=344.1 \mathrm{~Hz}, \mathrm{C} 6\right), 113.70\left(\mathrm{CMe}_{2}\right), 115.85$ $\left(\mathrm{d},{ }^{2} J_{5-\mathrm{F}}=15.7 \mathrm{~Hz}, \mathrm{C} 5\right) ;{ }^{19} \mathrm{~F}$ NMR $\delta-56.50\left(\mathrm{~d}, J_{\mathrm{F}-\mathrm{H} 5}=15.1 \mathrm{~Hz}\right) ; \mathrm{MS} m / z 331\left(100, \mathrm{MH}^{+}\right)$.

\section{Methyl 5,6,7,8,9-Pentadeoxy-6-fluoro-1,2-O-isopropylidene- $\alpha-D-x y l o-d e c-5(Z)-$ enofuranuronate (31)}

Compound (Z)-29 (26 mg, $0.062 \mathrm{mmol})$ was dissolved in $\mathrm{MeOH}(6 \mathrm{~mL})$ and saturated $\mathrm{NH}_{3} /$ $\mathrm{MeOH}(3 \mathrm{~mL})$ was added at $0{ }^{\circ} \mathrm{C}$ (ice bath). The resulting mixture was stirred for $48 \mathrm{~h}\left(0^{\circ} \mathrm{C}\right.$ $\rightarrow$ ambient temperature). The volatiles were evaporated and the residue was column chromatographed $\left(15 \rightarrow 50 \%\right.$ EtOAc/hexanes) to give $31(14 \mathrm{mg}, 74 \%):{ }^{1} \mathrm{H}$ NMR $\delta 1.35 \&$ $1.55\left(2 \times \mathrm{s}, 2 \times 3,2 \times \mathrm{CH}_{3}\right), 1.90$ (quint, $\left.J_{8-7 / 7^{\prime} / 9 / 9^{\prime}}=7.2 \mathrm{~Hz}, 2, \mathrm{H} 8 / 8^{\prime}\right), 2.23-2.40$ (m, 2, H7/7'), $2.41\left(\mathrm{t}, J_{9-8 / 8^{\prime}}=7.2 \mathrm{~Hz}, 2, \mathrm{H} 9 / 9^{\prime}\right), 3.70\left(\mathrm{~s}, 3, \mathrm{CH}_{3}\right), 4.17\left(\mathrm{~d}, J_{3-4}=2.6 \mathrm{~Hz}, 1, \mathrm{H} 3\right) ; 4.59(\mathrm{~d}$, $\left.J_{2-1}=3.7 \mathrm{~Hz}, 1, \mathrm{H} 2\right), 4.84\left(\mathrm{dd}, J_{5-\mathrm{F}}=37.6 \mathrm{~Hz}, J_{5-4}=7.7 \mathrm{~Hz}, 1, \mathrm{H} 5\right), 5.08$ ("dm", $J_{4-5}=7.6$ $\mathrm{Hz}, 1, \mathrm{H} 4), 5.95\left(\mathrm{~d}, J_{1-2}=3.7 \mathrm{~Hz}, 1, \mathrm{H} 1\right) ;{ }^{13} \mathrm{C} \mathrm{NMR} \delta 21.40$ (C8), $26.59 \& 27.12\left(\mathrm{CMe}_{2}\right)$, $31.65\left(\mathrm{~d},{ }^{2} J_{7-\mathrm{F}}=26.6 \mathrm{~Hz}, \mathrm{C} 7\right), 33.29(\mathrm{C} 9), 52.08\left(\mathrm{CH}_{3}\right), 75.29\left(\mathrm{~d},{ }^{3} J_{4-\mathrm{F}}=4.9 \mathrm{~Hz}, \mathrm{C} 4\right), 76.74$ $\left(\mathrm{d},{ }^{4} J_{3-\mathrm{F}}=1.0 \mathrm{~Hz}, \mathrm{C} 3\right), 85.51(\mathrm{C} 2), 101.15\left(\mathrm{~d},{ }^{2} J_{5-\mathrm{F}}=11.0 \mathrm{~Hz}, \mathrm{C} 5\right), 104.74(\mathrm{C} 1), 112.08$ $\left(\mathrm{CMe}_{2}\right), 161.86\left(\mathrm{~d},{ }^{1} J_{6-\mathrm{F}}=261.8 \mathrm{~Hz}, \mathrm{C} 6\right), 174.02(\mathrm{C} 10) ;{ }^{19} \mathrm{~F} \mathrm{NMR} \delta-100.23\left(\mathrm{dt}, J_{\mathrm{F}-\mathrm{H} 5}=38.0\right.$ $\left.\mathrm{Hz}, J_{\mathrm{F}-\mathrm{H} 7}=18.0 \mathrm{~Hz}\right) ; \mathrm{MS} m / z 305\left(100, \mathrm{MH}^{+}\right)$.

\section{Methyl 5,6,7,8,9-Pentadeoxy-6-fluoro-1,2-O-isopropylidene- $\alpha$-D-ribo-dec-5(Z)- enofuranuronate (32)}

Saturated $\mathrm{NH}_{3} / \mathrm{MeOH}(3 \mathrm{~mL})$ was added to a solution of $(\mathrm{Z})$-30 $(26 \mathrm{mg}, 0.062 \mathrm{mmol})$ in $\mathrm{MeOH}$ $(3 \mathrm{~mL})$ and the mixture was stirred at $0{ }^{\circ} \mathrm{C}$ for $48 \mathrm{~h}$ to ambient temperature. The volatiles were evaporated and the residue was column chromatographed $(15 \rightarrow 60 \%$ EtOAc/hexanes) to give $32(13 \mathrm{mg}, 69 \%):{ }^{1} \mathrm{H}$ NMR $\delta 1.39 \& 1.62\left(2 \times \mathrm{s}, 2 \times 3,2 \times \mathrm{CH}_{3}\right), 1.90$ (quint, $J_{8-7 / 7 / 9 / 9}=7.3$ $\left.\mathrm{Hz}, 2, \mathrm{H} 8 / 8^{\prime}\right), 2.31$ (dt, $\left.J_{7-\mathrm{F}}=17.6 \mathrm{~Hz}, J_{7-8 / 8^{\prime}}=7.4 \mathrm{~Hz}, 2, \mathrm{H} 7 / 7^{\prime}\right), 2.40\left(\mathrm{t}, J_{9-8 / 8^{\prime}}=6.9 \mathrm{~Hz}, 2\right.$, H9/9'), 3.75 (s, 3, $\mathrm{CH}_{3}$ ), 4.56-4.72 (m, 4, H2/3/4/5), 5.82 (d, $\left.J_{1-2}=3.9 \mathrm{~Hz}, 1, \mathrm{H} 1\right) ;{ }^{13} \mathrm{C}$ NMR $\delta 21.44(\mathrm{C} 8), 26.81 \& 26.94(\mathrm{CMe} 2), 31.74\left(\mathrm{~d},{ }^{2} J_{7-\mathrm{F}}=26.1 \mathrm{~Hz}, \mathrm{C} 7\right), 33.20(\mathrm{C} 9), 52.07$ $\left(\mathrm{CH}_{3}\right), 73.94\left(\mathrm{~d},{ }^{3} J_{4-\mathrm{F}}=5.1 \mathrm{~Hz}, \mathrm{C} 4\right), 76.80(\mathrm{C} 2), 78.62(\mathrm{C} 3), 103.63\left(\mathrm{~d},{ }^{2} J_{5-\mathrm{F}}=11.6 \mathrm{~Hz}, \mathrm{C} 5\right)$, $104.00(\mathrm{C} 1), 113.07\left(\mathrm{CMe}_{2}\right), 163.91\left(\mathrm{~d},{ }^{1} J_{6-\mathrm{F}}=262.70 \mathrm{~Hz}, \mathrm{C} 6\right), 173.90(\mathrm{C} 10) ;{ }^{19} \mathrm{~F}$ NMR $\delta$ $-100.23\left(\mathrm{dt}, J_{\mathrm{F}-\mathrm{H} 5}=37.1 \mathrm{~Hz}, J_{\mathrm{F}-\mathrm{H} 7 / 7^{\prime}}=18.1 \mathrm{~Hz}\right)$. HRMS $($ AP-ESI $) \mathrm{m} / z$ calcd for $\mathrm{C}_{14} \mathrm{H}_{22} \mathrm{FO}_{6}$ $\left(\mathrm{MH}^{+}\right)$305.1395; found 305.1396.

\section{Methyl 5,6,7,8,9-Pentadeoxy-6-fluoro- $\alpha / \beta-D-x y l o-d e c-5(Z)$-enofuranuronate (33)}

A solution of $31(17 \mathrm{mg}, 0.056 \mathrm{mmol})$ in TFA/ $\mathrm{H}_{2} \mathrm{O}(9: 1,3 \mathrm{~mL})$ was stirred for $45 \mathrm{~min}$ at $0{ }^{\circ} \mathrm{C}$ and was evaporated and coevaporated [toluene $(3 \times), \mathrm{CH}_{3} \mathrm{CN}(2 \times)$ ]. The residue was dissolved in $\mathrm{H}_{2} \mathrm{O}$ and the aqueous layer was extracted with ether $(2 \times)$. The water layer was evaporated to give 33 (9 mg, $61 \%$; $\alpha / \beta, 1: 1):{ }^{1} \mathrm{H}$ NMR $\left(\mathrm{MeOH}-d_{4}\right) \delta 1.81-1.94\left(\mathrm{~m}, 2, \mathrm{H} 8 / 8^{\prime}\right), 2.27-2.38$ (m, 2, H7/7'), 2.38-2.45 (m, 2, H9/9'), $3.67\left(\mathrm{~m}, 3, \mathrm{CH}_{3}\right), 3.92$ (dd, $J_{3-4}=3.8 \mathrm{~Hz}, J_{3-2}=1.8 \mathrm{~Hz}$, $0.5, \mathrm{H} 3), 3.97\left(\mathrm{dd}, J_{3-4}=3.9 \mathrm{~Hz}, J_{3-2}=2.6 \mathrm{~Hz}, 0.5, \mathrm{H} 3\right), 4.00-4.04(\mathrm{~m}, 1, \mathrm{H} 2), 4.91\left(\mathrm{~d}, J_{4-5}=\right.$ $8.9 \mathrm{~Hz}, 0.5, \mathrm{H} 4), 4.99$ (d, $\left.J_{4-5}=9.1 \mathrm{~Hz}, 0.5, \mathrm{H} 4\right), 5.04-5.12$ (m, 1, H5), 5.08 (s, 0.5, H1 $\beta$ ), 5.37 $\left(\mathrm{d}, J_{1-2}=4.0 \mathrm{~Hz}, 0.5, \mathrm{H} 1 \alpha\right) ;{ }^{19} \mathrm{~F} \mathrm{NMR} \delta-106.29\left(\mathrm{dt}, J_{\mathrm{F}-\mathrm{H} 5}=37.2 \mathrm{~Hz}, J_{\mathrm{F}-\mathrm{H} 7}=17.6 \mathrm{~Hz}, 0.5 \mathrm{~F}\right)$, 
$-106.87\left(\mathrm{dt}, J_{\mathrm{F}-\mathrm{H} 5}=37.8 \mathrm{~Hz}, J_{\mathrm{F}-\mathrm{H} 7}=18.2 \mathrm{~Hz}, 0.5 \mathrm{~F}\right)$. HRMS (AP-ESI) $\mathrm{m} / z$ calcd for $\mathrm{C}_{11} \mathrm{H}_{18} \mathrm{FO}_{6}\left(\mathrm{MH}^{+}\right)$265.1082; found 265.1088.

\section{Methyl 5,6,7,8,9-Pentadeoxy-6-fluoro- $\alpha / \beta-D-r i b o-d e c-5(Z)$-enofuranuronate (34)}

A solution of $32(12 \mathrm{mg}, 0.04 \mathrm{mmol})$ in TFA $/ \mathrm{H}_{2} \mathrm{O}(9: 1,3 \mathrm{~mL})$ was stirred for $30 \mathrm{~min}$ at $0{ }^{\circ} \mathrm{C}$ and was evaporated and coevaporated [toluene ( $3 \times)$ ]. The residue was dissolved in $\mathrm{H}_{2} \mathrm{O}$ and the aqueous layer was extracted with ether $(2 x)$. The water layer was evaporated to give $\mathbf{3 4}(8$ $\mathrm{mg}, 76 \% ; \alpha / \beta, 3: 7):{ }^{1} \mathrm{H}$ NMR $\left(\mathrm{D}_{2} \mathrm{O}\right) \delta 1.72-1.76\left(\mathrm{~m}, 2, \mathrm{H} 8 / 8^{\prime}\right), 2.20\left(\mathrm{dt}, J_{7-\mathrm{F}}=18.1 \mathrm{~Hz}\right.$, $\left.J_{7-8 / 8^{\prime}}=8.4 \mathrm{~Hz}, 2, \mathrm{H} 7 / 7^{\prime}\right), 2.31-2.38\left(\mathrm{~m}, 2, \mathrm{H} 9 / 9^{\prime}\right), 3.59$ (d, $\left.J_{2-3}=2.4 \mathrm{~Hz}, 0.7, \mathrm{H} 2\right), 3.82-3.85$ (m, 0.3, H2), 3.90-3.93 (s, 0.7, H3), 3.90-4.06 (m, 4.3, H3/H4/CH 3 ), 4.64-4.77 (m, 1, H5), 5.12 $(\mathrm{s}, 0.7, \mathrm{H} 1), 5.28\left(\mathrm{~d}, J_{1-2}=3.7 \mathrm{~Hz}, 0.3, \mathrm{H} 1\right) ;{ }^{19} \mathrm{~F} \mathrm{NMR} \delta-104.06\left(\mathrm{dt}, J_{\mathrm{F}-\mathrm{H} 5}=36.4 \mathrm{~Hz}\right.$, $\left.J_{\mathrm{F}-\mathrm{H} 7 / 7^{\prime}}=17.8 \mathrm{~Hz}, 0.3, \alpha\right) ;-105.04\left(\mathrm{dt}, J_{\mathrm{F}-\mathrm{H} 5}=35.8 \mathrm{~Hz}, J_{\mathrm{F}-\mathrm{H} 7 / 7^{\prime}}=18.8 \mathrm{~Hz}, 0.7 \mathrm{~F}, \beta\right)$. HRMS (AP-ESI) $\mathrm{m} / z$ calcd for $\mathrm{C}_{11} \mathrm{H}_{18} \mathrm{FO}_{6}\left(\mathrm{MH}^{+}\right)$265.1082; found 265.1090 .

\section{(E/Z)-3,5,6-Trideoxy-6-fluoro-1,2-O-isopropylidene-6-phenylsulfonyl-a-D-erythro-hex-5- enofuranose (35)}

Step (a). Treatment of diacetone 3-deoxyglucose ${ }^{22}$ (204 mg, $0.83 \mathrm{mmol}$ ) with $\mathrm{H}_{5} \mathrm{IO}_{6}(228 \mathrm{mg}$, $1.00 \mathrm{mmol}$ ), as described for $\mathbf{1 0}$ (Step $a$, except no aqueous workup was performed) gave 3deoxy-1,2- $O$-isopropylidene- $\alpha$-D-erythro-pentdialdo-1,4-furanose $\left[\sim 85 \%\right.$ pure; ${ }^{1} \mathrm{H}$ NMR $\delta$ $\left.9.75\left(\mathrm{~d}, J_{5-4}=4.8 \mathrm{~Hz}, \mathrm{H} 5\right)\right]$ which was directly used in the next step. Step (b) Treatment of the crude aldehyde with diethyl fluoro(phenylsulfonyl)methylphosphonate ${ }^{20}(297 \mathrm{mg}, 0.96$ $\mathrm{mmol}$ ) and LHMDS (0.96 mL, $0.96 \mathrm{mmol}$ ), as described for $\mathbf{2 0}$, gave 35 (150 mg, 48\%; E/Z, $2: 1)$ as an inseparable mixture of isomers. Compound $(E)-35$ had: ${ }^{1} \mathrm{H}$ NMR $\delta 1.30 \& 1.47$ (2 $\left.\times \mathrm{s}, 2 \times 3,2 \times \mathrm{CH}_{3}\right), 1.71\left(\mathrm{ddd}, J_{3-4}=10.9 \mathrm{~Hz}, J_{3-3^{\prime}}=15.5 \mathrm{~Hz}, J_{3-2}=4.6 \mathrm{~Hz}, 1, \mathrm{H} 3\right), 2.28(\mathrm{dd}$, $\left.J_{3^{\prime}-4}=4.5 \mathrm{~Hz}, J_{3^{\prime}-3}=13.4 \mathrm{~Hz}, 1, \mathrm{H} 3^{\prime}\right), 4.77\left(\mathrm{t}, J_{2-1 / 3}=4.0 \mathrm{~Hz}, 1, \mathrm{H} 2\right), 4.93-4.97$ (m, 1, H4), $5.85\left(\mathrm{~d}, J_{1-2}=3.6 \mathrm{~Hz}, 1, \mathrm{H} 1\right), 6.31\left(\mathrm{dd}, J_{5-\mathrm{F}}=32.4 \mathrm{~Hz}, J_{5-4}=7.5 \mathrm{~Hz}, 1, \mathrm{H} 5\right), 7.56-7.97(\mathrm{~m}, 5$, $\mathrm{Ar}) ;{ }^{13} \mathrm{C}$ NMR $\delta 26.42 \& 27.00\left(\mathrm{CMe}_{2}\right), 39.25\left(\mathrm{~d},{ }^{4} J_{3-\mathrm{F}}=2.0 \mathrm{~Hz}, \mathrm{C} 3\right), 71.26\left(\mathrm{~d},{ }^{3} J_{4-\mathrm{F}}=2.4\right.$ $\mathrm{Hz}, \mathrm{C} 4), 80.69$ (C2), $105.90(\mathrm{C} 1), 112.01\left(\mathrm{CMe}_{2}\right), 116.77\left(\mathrm{~d},{ }^{2} J_{5-\mathrm{F}}=3.7 \mathrm{~Hz}, \mathrm{C} 5\right), 129.17(\mathrm{Ph})$, $129.91(\mathrm{ph}), 135.08(\mathrm{Ph}), 137.22(\mathrm{Ph}), 155.54\left(\mathrm{~d},{ }^{1} J_{6-\mathrm{F}}=301.9 \mathrm{~Hz}, \mathrm{C} 6\right) ;{ }^{19} \mathrm{~F}$ NMR $\delta-122.72$ $\left(\mathrm{d}, J_{\mathrm{F}-\mathrm{H} 5}=32.5 \mathrm{~Hz}, 0.66\right)$. Compound $(Z)-35$ had: ${ }^{1} \mathrm{H}$ NMR $\delta 1.34 \& 1.60(2 \times \mathrm{s}, 2 \times 3,2 \times$ $\mathrm{CH}_{3}$ ), 1.68 (ddd, $J_{3-4}=10.5 \mathrm{~Hz}, J_{3-3^{\prime}}=15.2 \mathrm{~Hz}, J_{3-2}=4.7 \mathrm{~Hz}, 1, \mathrm{H} 3$ ), 2.46 (ddd, $J_{3^{\prime}-4}=4.6$ $\left.\mathrm{Hz}, J_{3^{\prime}-3}=13.2 \mathrm{~Hz}, 1, \mathrm{H} 3^{\prime}\right), 4.79\left(\mathrm{t}, J_{2-1 / 3}=3.9 \mathrm{~Hz}, 1, \mathrm{H} 2\right), 5.71\left(\mathrm{ddd}, J_{4-5}=8.7 \mathrm{~Hz}, J_{4-3}=\right.$ $\left.10.6 \mathrm{~Hz}, J_{4-3^{\prime}}=4.5 \mathrm{~Hz}, 1, \mathrm{H} 4\right), 5.84-5.85(\mathrm{~m}, 1, \mathrm{H} 1), 5.86\left(\mathrm{dd}, J_{5-\mathrm{F}}=20.1 \mathrm{~Hz}, J_{5-4}=8.6 \mathrm{~Hz}\right.$, H5), 7.56-7.97 (m, 5, Ar); ${ }^{19} \mathrm{~F}$ NMR $\delta-114.04\left(\mathrm{~d}, J_{\mathrm{F}-\mathrm{H} 5}=20.0 \mathrm{~Hz}, 0.33\right)$; MS m/z $329(100$, $\left.\mathrm{MH}^{+}\right)$.

\section{(E/Z)-3,5,6-Trideoxy-6-fluoro-1,2-O-isopropylidene-6-tributylstannyl-a-D-erythro-hex-5- enofuranose (38)}

Treatment of $35(128 \mathrm{mg}, 0.39 \mathrm{mmol})$ with $\mathrm{Bu}_{3} \mathrm{SnH}(0.21 \mathrm{~mL}, 228 \mathrm{mg}, 0.78 \mathrm{mmol}$, ) and AIBN (481 mg, $0.29 \mathrm{mmol}$ ), as described for 23, gave 38 (83 mg, 44\%; E/Z, 1:1): ${ }^{19} \mathrm{~F} \mathrm{NMR} \delta-92.83$ $\left(\mathrm{d}, J_{\mathrm{F}-\mathrm{H} 5}=33.9 \mathrm{~Hz}, 84 \%\right.$ of $\left.0.50 \mathrm{~F}, Z\right),-92.83\left(\mathrm{ddd}, J_{\mathrm{F}-\mathrm{Sn}}=230.4 \mathrm{~Hz}, J_{\mathrm{F}-\mathrm{H} 5}=34.7 \mathrm{~Hz}, J_{\mathrm{F}-\mathrm{H} 4}\right.$ $=5.2 \mathrm{~Hz} 16 \%$ of $0.50 \mathrm{~F}, Z),-96.75\left(\mathrm{~d}, J_{\mathrm{F}-\mathrm{H} 5}=52.7 \mathrm{~Hz}, 84 \%\right.$ of $\left.0.50 \mathrm{~F}, E\right),-96.75\left(\mathrm{ddd}, J_{\mathrm{F}-\mathrm{Sn}}\right.$ $=221.1 \mathrm{~Hz}, J_{\mathrm{F}-\mathrm{H} 5}=52.7 \mathrm{~Hz}, J_{\mathrm{F}-\mathrm{H} 4}=4.9 \mathrm{~Hz}, 16 \%$ of $\left.0.50 \mathrm{~F}, E\right) ; \mathrm{MS} \mathrm{m} / z .479(100$,

$\left.\mathrm{MH}^{+},{ }^{120} \mathrm{Sn}\right), 477\left(73, \mathrm{MH}^{+},{ }^{118} \mathrm{Sn}\right), 475\left(48, \mathrm{MH}^{+},{ }^{116} \mathrm{Sn}\right)$. Compound $(E)-38$ had: ${ }^{1} \mathrm{H}$ NMR $\delta$ 0.98-1.70 (m, 34, $\left.3 \times \mathrm{Bu} / 2 \times \mathrm{CH}_{3} / \mathrm{H} 3\right), 2.26\left(\mathrm{dd}, J_{3^{\prime}-4}=4.3 \mathrm{~Hz}, J_{3^{\prime}-3}=13.4 \mathrm{~Hz}, 1, \mathrm{H} 3\right)$, 4.45-4.55 (m, 1, H4), $4.75\left(\mathrm{t}, J_{2-1 / 3}=4.2 \mathrm{~Hz}, 1, \mathrm{H} 2\right), 4.96\left(\mathrm{dd}, J_{5-\mathrm{F}}=52.9 \mathrm{~Hz}, J_{5-4}=7.5 \mathrm{~Hz}\right.$, 1, H5), $5.83\left(\mathrm{~d}, J_{1-2}=3.8 \mathrm{~Hz}, 1, \mathrm{H} 1\right) ;{ }^{13} \mathrm{C}$ NMR $\delta 10.31(\mathrm{Bu}), 11.00(\mathrm{Bu}), 13.97(\mathrm{Bu}), 27.04$ \& 27.08 $\left(\mathrm{CMe}_{2}\right), 27.50(\mathrm{Bu}), 40.19\left(\mathrm{~d},{ }^{2} J_{3-\mathrm{F}}=1.6 \mathrm{~Hz}, \mathrm{C} 3\right), 71.25\left(\mathrm{~d},{ }^{3} J_{4-\mathrm{F}}=17.3 \mathrm{~Hz}, \mathrm{C} 4\right)$, $81.06(\mathrm{C} 2), 105.47(\mathrm{C} 1), 111.41\left(\mathrm{CMe}_{2}\right), 123.42\left(\mathrm{~d},{ }^{2} J_{5-\mathrm{F}}=3.7 \mathrm{~Hz}, \mathrm{C} 5\right), 174.29\left(\mathrm{~d},{ }^{1} \mathrm{~J}_{5-\mathrm{F}}=\right.$ $323.5 \mathrm{~Hz}, \mathrm{C6})$. Compound (Z)-38 had: ${ }^{1} \mathrm{H}$ NMR $\delta$ 0.98-1.70 (m, 34, $\left.3 \times \mathrm{Bu} / 2 \times \mathrm{CH}_{3} / \mathrm{H} 3\right), 2.11$ $\left(\mathrm{dd}, J_{3^{\prime}-4}=4.3 \mathrm{~Hz}, J_{3^{\prime}-3}=13.4 \mathrm{~Hz}, 1, \mathrm{H} 3^{\prime}\right), 4.73\left(\mathrm{t}, J_{2-1 / 3}=4.2 \mathrm{~Hz}, 1, \mathrm{H} 2\right), 5.21\left(\mathrm{ddd}, J_{4-5}=\right.$ 
$\left.7.5 \mathrm{~Hz}, J_{4-3}=4.4 \mathrm{~Hz}, J_{4-3^{\prime}}=15.2 \mathrm{~Hz}, 1, \mathrm{H} 4\right), 5.81\left(\mathrm{~d}, J_{1-2}=3.7 \mathrm{~Hz}, 1, \mathrm{H} 1\right), 5.84\left(\mathrm{dd}, J_{5-\mathrm{F}}=\right.$ $\left.34.2 \mathrm{~Hz}, J_{5-4}=9.2 \mathrm{~Hz}, 1, \mathrm{H} 5\right) ;{ }^{13} \mathrm{C}$ NMR $\delta 10.31(\mathrm{Bu}), 11.00(\mathrm{Bu}), 13.97(\mathrm{Bu}), 27.04 \& 27.08$ $(\mathrm{CMe}), 27.50(\mathrm{Bu}), 41.00\left(\mathrm{~d},{ }^{2} J_{3-\mathrm{F}}=1.8 \mathrm{~Hz}, \mathrm{C} 3\right), 74.73\left(\mathrm{~d},{ }^{3} J_{4-\mathrm{F}}=21.7 \mathrm{~Hz}, \mathrm{C} 4\right), 80.83(\mathrm{C} 2)$, $105.69(\mathrm{C} 1), 111.17\left(\mathrm{CMe}_{2}\right), 123.26\left(\mathrm{~d},{ }^{2} J_{5-\mathrm{F}}=8.1 \mathrm{~Hz}, \mathrm{C} 5\right), 177.16\left(\mathrm{~d},{ }^{1} J_{6-\mathrm{F}}=316.5 \mathrm{~Hz}, \mathrm{C} 6\right)$.

\section{(E/Z)-5,6-Dideoxy-6-fluoro-1,2-O-isopropylidene- $\alpha$-D-xylo-hex-5-enofuranose (39)}

Step (a). Compound 23 (200 mg, $0.34 \mathrm{mmol} ; E / Z, 7: 3$ ) was dissolved in saturated $\mathrm{NH}_{3} / \mathrm{MeOH}$ $(20 \mathrm{~mL})$ and the resulting solution was stirred overnight at ambient temperature. The volatiles were evaporated to give $\mathbf{3 6}$ in quantitative yield of sufficient purity to use in the subsequent reaction. Step (b). Compound $\mathbf{3 6}$ (crude from step $a, 0.34 \mathrm{mmol}$ ) was dissolved in $\mathrm{NH}_{3} / \mathrm{MeOH}$ $\left(20 \mathrm{~mL}\right.$ ) and the resulting mixture was heated in a pressure Ace tube at $65^{\circ} \mathrm{C}$ for $18 \mathrm{~h}$. The volatiles were evaporated and the residue was column chromatographed (hexanes/EtOAc, 8:2 $\rightarrow 3: 7)$ to give $(E)-39$ (20 mg, 29\% from 23) and (Z)-39 (33 mg, 48\% from 23). Compound (E)-39 had: ${ }^{1} \mathrm{H}$ NMR $\delta 1.35 \& 1.58\left(2 \times \mathrm{s}, 2 \times 3,2 \times \mathrm{CH}_{3}\right), 1.78$ (br s, 1, OH3), $4.32\left(\mathrm{~d}, J_{3-4}\right.$ $=2.5 \mathrm{~Hz}, 1, \mathrm{H} 3$ ), 4.59 (d, $\left.J_{2-1}=3.7 \mathrm{~Hz}, 1, \mathrm{H} 2\right), 4.69$ ("dm", $\left.J_{4-5}=7.0 \mathrm{~Hz}, 1, \mathrm{H} 4\right), 5.53$ (ddd, $\left.J_{5-\mathrm{F}}=18.1 \mathrm{~Hz}, J_{5-6}=11.2 \mathrm{~Hz}, J_{5-4}=7.1 \mathrm{~Hz}, 1, \mathrm{H} 5\right), 5.94\left(\mathrm{~d}, J_{1-2}=3.7 \mathrm{~Hz}, 1, \mathrm{H} 1\right), 6.86$ (ddd, $\left.J_{6-\mathrm{F}}=82.9 \mathrm{~Hz}, J_{6-5}=11.2 \mathrm{~Hz}, J_{6-4}=1.0 \mathrm{~Hz}, 1, \mathrm{H6}\right) ;{ }^{13} \mathrm{C} \mathrm{NMR} \delta 26.47 \& 27.06\left(\mathrm{CMe}_{2}\right), 76.48$ $\left(\mathrm{d},{ }^{4} J_{3-\mathrm{F}}=2.0 \mathrm{~Hz}, \mathrm{C} 3\right), 76.80\left(\mathrm{~d},{ }^{3} J_{4-\mathrm{F}}=12.6 \mathrm{~Hz}, \mathrm{C} 4\right), 85.31(\mathrm{C} 2), 104.87(\mathrm{C} 1), 106.20$ $\left(\mathrm{d},{ }^{2} J_{5-\mathrm{F}}=13.7 \mathrm{~Hz}, \mathrm{C} 5\right), 112.25\left(\mathrm{CMe}_{2}\right), 153.79\left(\mathrm{~d},{ }^{1} J_{6-\mathrm{F}}=262.6 \mathrm{~Hz}, \mathrm{C} 6\right) ;{ }^{19} \mathrm{~F}$ NMR $\delta-122.18$ $\left(\mathrm{dd}, J_{\mathrm{F}-\mathrm{H} 5}=17.8 \mathrm{~Hz}, J_{\mathrm{F}-\mathrm{H} 6}=82.9 \mathrm{~Hz}\right)$. Compound $(Z)-39$ had: $1.35 \& 1.54(2 \times \mathrm{s}, 2 \times 3,2 \times$ $\mathrm{CH}_{3}$ ), 1.81 (br s, 1, OH3), 4.22 (br s, $\left.1, \mathrm{H} 3\right), 4.58\left(\mathrm{~d}, J_{2-1}=3.7 \mathrm{~Hz}, 1, \mathrm{H} 2\right), 5.07$ (ddd, $J_{5-\mathrm{F}}=$ $\left.40.1 \mathrm{~Hz}, J_{5-6}=4.9 \mathrm{~Hz}, J_{5-4}=7.5 \mathrm{~Hz}, 1, \mathrm{H} 5\right), 5.12-5.15(\mathrm{~m}, 1, \mathrm{H} 4), 5.96\left(\mathrm{~d}, J_{1-2}=3.7 \mathrm{~Hz}, 1\right.$, $\mathrm{H} 1), 6.63\left(\mathrm{dd}, J_{6-\mathrm{F}}=82.7 \mathrm{~Hz}, J_{6-5}=4.8 \mathrm{~Hz}, J_{6-4}=1.2 \mathrm{~Hz}, 1, \mathrm{H} 6\right) ;{ }^{13} \mathrm{C}$ NMR $\delta 26.57 \& 27.10$ $\left(\mathrm{CMe} e_{2}\right), 74.49\left(\mathrm{~d},{ }^{3} J_{4-\mathrm{F}}=5.1 \mathrm{~Hz}, \mathrm{C} 4\right), 76.74\left(\mathrm{~d},{ }^{4} J_{3-\mathrm{F}}=1.9 \mathrm{~Hz}, \mathrm{C} 3\right), 85.47(\mathrm{C} 2), 104.80(\mathrm{C} 1)$, 106.24 (C5), $112.24\left(\mathrm{CMe}_{2}\right), 150.20\left(\mathrm{~d},{ }^{1} J_{6-\mathrm{F}}=265.2 \mathrm{~Hz}, \mathrm{C} 6\right) ;{ }^{19} \mathrm{~F}$ NMR $\delta-121.02(\mathrm{dd}$, $\left.J_{\mathrm{F}-\mathrm{H} 5}=41.1 \mathrm{~Hz}, J_{\mathrm{F}-\mathrm{H} 6}=83.3 \mathrm{~Hz}\right)$. MS $\left(\mathrm{APCI}^{+}\right) \mathrm{m} / \mathrm{z} 205\left(100, \mathrm{MH}^{+}\right)$. Anal. Calcd for $\mathrm{C}_{9} \mathrm{H}_{13} \mathrm{FO}_{4}$ (204.19): C, 52.94; H, 6.42. Found: C, 53.19; H, 6.63.

\section{(E/Z)-5,6-Dideoxy-6-fluoro-1,2-O-isopropylidene- $\alpha$-D-ribo-hex-5-enofuranose (40)}

Step (a). Compound 24 (200 mg, $0.34 \mathrm{mmol}$; E/Z, 1:1) was dissolved in $\mathrm{NH}_{3} / \mathrm{MeOH}$ (20 mL) and stirred overnight at ambient temperature. The volatiles were evaporated to give $\mathbf{3 7}$ in quanitative yield of sufficient purity to use in the subsequent step. Step (b). Treatment of $\mathbf{3 7}$ (crude, $0.34 \mathrm{mmol}$ ) with $\mathrm{NH}_{3} / \mathrm{MeOH}(20 \mathrm{~mL})$ at $65^{\circ} \mathrm{C}$, as described for 39 , gave unchanged 37 (17 mg, $10 \%$ from 24; $E / Z, 2: 3)$ and $\mathbf{4 0}$ as separable isomers $(E ; 22 \mathrm{mg}, 32 \%$ from 24$)$ and $\left(Z ; 18 \mathrm{mg}, 26 \%\right.$ from 24). Compound $(E)-\mathbf{4 0}$ had: ${ }^{1} \mathrm{H}$ NMR $\delta 1.40 \& 1.60(2 \times \mathrm{s}, 2 \times 3,2 \times$ $\left.\mathrm{CH}_{3}\right), 2.37\left(\mathrm{~d}, J_{\mathrm{OH} 3-3}=10.0 \mathrm{~Hz}, 1, \mathrm{OH} 3\right), 3.70-3.73(\mathrm{~m}, 1, \mathrm{H} 3), 4.12\left(\mathrm{t}, J_{4-5 / 3}=8.3 \mathrm{~Hz}, 1, \mathrm{H} 4\right)$, $4.60\left(\mathrm{t}, J_{2-1 / 3}=4.6 \mathrm{~Hz}, 1, \mathrm{H} 2\right), 5.53\left(\mathrm{ddd}, J_{5-\mathrm{F}}=17.1 \mathrm{~Hz}, J_{5-6}=11.2 \mathrm{~Hz}, J_{5-4}=7.8 \mathrm{~Hz}, 1, \mathrm{H} 5\right)$, $5.84\left(\mathrm{~d}, J_{1-2}=3.9 \mathrm{~Hz}, 1, \mathrm{H} 1\right), 6.82\left(\mathrm{ddd}, J_{6-\mathrm{F}}=82.4 \mathrm{~Hz}, J_{6-5}=11.1 \mathrm{~Hz}, J_{6-4}=0.7 \mathrm{~Hz}, 1\right.$, H6); ${ }^{13} \mathrm{C}$ NMR $\delta 26.75 \& 26.84\left(\mathrm{CMe}_{2}\right), 76.55\left(\mathrm{~d},{ }^{3} J_{4-\mathrm{F}}=17.0 \mathrm{~Hz}, \mathrm{C} 4\right), 76.49$ (C3), 78.57 (C2), $104.08(\mathrm{C} 1), 109.44\left(\mathrm{~d},{ }^{2} J_{5-\mathrm{F}}=12.9 \mathrm{~Hz}, \mathrm{C} 5\right), 113.11\left(\mathrm{CMe}_{2}\right), 152.81\left(\mathrm{~d},{ }^{1} J_{6-\mathrm{F}}=262.1\right.$ $\mathrm{Hz}, \mathrm{C} 6) ;{ }^{19} \mathrm{~F}$ NMR $\delta-123.67\left(\mathrm{dd}, J_{\mathrm{F}-\mathrm{H} 5}=17.1 \mathrm{~Hz}, J_{\mathrm{F}-\mathrm{H} 6}=82.5 \mathrm{~Hz}\right.$ ). Compound $(Z)-40$ had: $1.40 \& 1.60\left(2 \times \mathrm{s}, 2 \times 3,2 \times \mathrm{CH}_{3}\right), 2.39\left(\mathrm{~d}, J_{\mathrm{OH} 3-3}=11.0 \mathrm{~Hz}, 1, \mathrm{OH} 3\right), 3.74\left(\mathrm{ddd}, J_{3-\mathrm{OH} 3}=\right.$ $\left.10.9 \mathrm{~Hz}, J_{3-4}=8.9 \mathrm{~Hz}, J_{3-2}=5.1 \mathrm{~Hz}, 1, \mathrm{H} 3\right), 4.60\left(\mathrm{t}, J_{2-1 / 3}=4.5 \mathrm{~Hz}, 1, \mathrm{H} 2\right), 4.70\left(\mathrm{t}, J_{4-3 / 5}=\right.$ $8.8 \mathrm{~Hz}, 1, \mathrm{H} 4), 4.89$ (ddd, $\left.J_{5-\mathrm{F}}=40.0 \mathrm{~Hz}, J_{5-6}=4.9 \mathrm{~Hz}, J_{5-4}=8.9 \mathrm{~Hz}, 1, \mathrm{H} 5\right), 5.84\left(\mathrm{~d}, J_{1-2}=\right.$ $3.9 \mathrm{~Hz}, 1, \mathrm{H} 1), 6.69\left(\mathrm{ddd}, J_{6-\mathrm{F}}=82.7 \mathrm{~Hz}, J_{6-5}=4.9 \mathrm{~Hz}, J_{6-4}=0.8 \mathrm{~Hz}, 1, \mathrm{H} 6\right) ;{ }^{13} \mathrm{C} \mathrm{NMR} \delta$ $26.79 \& 26.92\left(\mathrm{CMe}_{2}\right), 73.18\left(\mathrm{~d},{ }^{3} J_{4-\mathrm{F}}=5.1 \mathrm{~Hz}, \mathrm{C} 4\right), 76.74\left(\mathrm{~d},{ }^{4} J_{3-\mathrm{F}}=2.0 \mathrm{~Hz}, \mathrm{C} 3\right), 78.58(\mathrm{C} 2)$, $104.20(\mathrm{C} 1), 108.69\left({ }^{2} J_{5-\mathrm{F}}=1.9 \mathrm{~Hz}, \mathrm{C} 5\right), 113.17\left(\mathrm{CMe}_{2}\right), 153.71\left(\mathrm{~d},{ }^{1} J_{6-\mathrm{F}}=265.8 \mathrm{~Hz}\right.$, C6); ${ }^{19} \mathrm{~F} \mathrm{NMR} \delta-123.90\left(\mathrm{dd}, J_{\mathrm{F}-\mathrm{H} 5}=40.1 \mathrm{~Hz}, J_{\mathrm{F}-\mathrm{H} 6}=82.6 \mathrm{~Hz}\right): \mathrm{MS}\left(\mathrm{APCI}^{+}\right) \mathrm{m} / z 205(100$, $\mathrm{MH}^{+}$). Anal. Calcd for $\mathrm{C}_{9} \mathrm{H}_{13} \mathrm{FO}_{4}$ (204.19): C, 52.94; H, 6.42. Found: C, 53.07; H, 6.67. 
(E/Z)-3,5,6-Trideoxy-6-fluoro-1,2-O-isopropylidene-a-D-erythro-hex-5-enofuranose (41)

Treatment of 38 (100 mg, $0.21 \mathrm{mmol} ; E / Z, 1: 1)$ with $\mathrm{NH}_{3} / \mathrm{MeOH}(15 \mathrm{~mL})$ and $\mathrm{C}_{\mathrm{s}} \mathrm{F}(51 \mathrm{mg}$, $0.33 \mathrm{mmol}$ ) at $65^{\circ} \mathrm{C}$ for $4 \mathrm{~h}$, as described for 39 (Step b), gave 41 (16 mg, 40\%; E/Z, $\sim 45: 55):{ }^{19} \mathrm{~F}$ NMR $\delta-124.79\left(\mathrm{dd}, J_{\mathrm{F}-\mathrm{H} 5}=41.8 \mathrm{~Hz}, J_{\mathrm{F}-\mathrm{H} 6}=83.0 \mathrm{~Hz}, 0.55 \mathrm{~F}\right),-125.95(\mathrm{dd}$, $\left.J_{\mathrm{F}-\mathrm{H} 5}=16.7 \mathrm{~Hz}, J_{\mathrm{F}-\mathrm{H} 6}=82.9 \mathrm{~Hz}, 0.45 \mathrm{~F}\right) ; \mathrm{MS}\left(\mathrm{APCI}^{+}\right) \mathrm{m} / z 189\left(100, \mathrm{MH}^{+}\right)$. Compound (E)-41 had: ${ }^{1} \mathrm{H}$ NMR $\delta 1.35 \& 1.55\left(2 \times \mathrm{s}, 2 \times 3,2 \times \mathrm{CH}_{3}\right), 1.55-1.68(\mathrm{~m}, 1, \mathrm{H} 3), 2.20(\mathrm{dd}$, $\left.J_{3^{\prime}-3}=13.5 \mathrm{~Hz}, J_{3^{\prime}-4}=4.3 \mathrm{~Hz}, 1, \mathrm{H} 3^{\prime}\right), 4.62\left(\mathrm{ddd}, J_{4-3}=11.5 \mathrm{~Hz}, J_{4-5}=8.2 \mathrm{~Hz}, J_{4-3^{\prime}}=4.3 \mathrm{~Hz}\right.$, 1, H4), 4.75-4.79 (m, $1, \mathrm{H} 2), 5.42$ (ddd, $J_{5-\mathrm{F}}=16.8 \mathrm{~Hz}, J_{5-6}=11.2 \mathrm{~Hz}, J_{5-4}=8.3 \mathrm{~Hz}, 1, \mathrm{H} 5$ ), 5.82-5.84 (m, 1, H1), $6.80\left(\mathrm{dd}, J_{6-\mathrm{F}}=82.7 \mathrm{~Hz}, J_{6-5}=11.2 \mathrm{~Hz}, 1, \mathrm{H} 6\right)$. Compound $(Z)-\mathbf{4 1}$ had: $1.28 \& 1.57\left(2 \times \mathrm{s}, 2 \times 3,2 \times \mathrm{CH}_{3}\right), 1.55-1.68(\mathrm{~m}, 1, \mathrm{H} 3), 2.28\left(\mathrm{dd}, J_{3^{\prime}-3}=13.5 \mathrm{~Hz}, J_{3^{\prime}-4}=4.3\right.$ $\mathrm{Hz}, 1, \mathrm{H}^{\prime}$ ) , 4.75-4.79 (m, 1, H2), 4.92 (ddd, $J_{5-\mathrm{F}}=41.3 \mathrm{~Hz}, J_{5-4}=8.1 \mathrm{~Hz}, J_{5-6}=4.8 \mathrm{~Hz}, 1$, H5), $5.13\left(\mathrm{ddd}, J_{4-3}=11.5 \mathrm{~Hz}, J_{4-5}=8.0 \mathrm{~Hz}, J_{4-3^{\prime}}=4.1 \mathrm{~Hz}, 1, \mathrm{H} 4\right), 5.82-5.84(\mathrm{~m}, 1, \mathrm{H1}), 6.53$ $\left(\mathrm{dd}, J_{6-\mathrm{F}}=82.8 \mathrm{~Hz}, J_{6-5}=4.8 \mathrm{~Hz}, 1, \mathrm{H} 6\right)$.

\section{(E)-5,6-Dideoxy-6-fluoro- $\alpha / \beta-D-x y l o-h e x-5$-enofuranose (42)}

A solution of $(E)-\mathbf{3 9}(13 \mathrm{mg}, 0.064 \mathrm{mmol})$ in TFA/ $\mathrm{H}_{2} \mathrm{O}(9: 1 ; 3 \mathrm{~mL})$ was stirred for $50 \mathrm{~min}$ at $0{ }^{\circ} \mathrm{C}$ (ice bath). The volatiles were evaporated, coevaporated [toluene (3x) and $\mathrm{MeCN}(2 \times)$ ], and the residue was flash column chromatographed $(50 \rightarrow 95 \%$ EtOAc/hexanes) to give 42 (4 $\mathrm{mg}, 38 \%$; $\alpha / \beta, 1: 1):{ }^{1} \mathrm{H}$ NMR (MeOH- $\left.d_{4}\right) \delta 3.91-4.03$ (m, $2 \mathrm{H} 2 / 3$ ), 4.56-4.63 (m, 1, H4), 5.07 (s, $0.5, \mathrm{H} 1 \beta$ ), 5.37 (d, $\left.J_{1-2}=4.0 \mathrm{~Hz}, 0.5, \mathrm{H} 1 \alpha\right), 5.51$ (ddd, $J_{5-\mathrm{F}}=17.8 \mathrm{~Hz}, J_{5-6}=11.2 \mathrm{~Hz}$, $\left.J_{5-4}=8.9 \mathrm{~Hz}, 0.5, \mathrm{H} 5\right), 5.65\left(\mathrm{ddd}, J_{5-\mathrm{F}}=17.9 \mathrm{~Hz}, J_{5-6}=11.1 \mathrm{~Hz}, J_{5-4}=8.9 \mathrm{~Hz}, 0.5, \mathrm{H} 5\right), 6.87$ $\left(\mathrm{dd}, J_{6-\mathrm{F}}=84.0 \mathrm{~Hz}, J_{6-5}=11.0 \mathrm{~Hz}, 0.5, \mathrm{H6}\right), 6.90\left(\mathrm{dd}, J_{6-\mathrm{F}}=83.7 \mathrm{~Hz}, J_{6-5}=11.0 \mathrm{~Hz}, 0.5\right.$, H6); ${ }^{13} \mathrm{C} \mathrm{NMR}\left(\mathrm{MeOH}-d_{4}\right) \delta 75.29\left(\mathrm{~d},{ }^{3} J_{4-\mathrm{F}}=13.8 \mathrm{~Hz}, \mathrm{C} 4\right), 77.00 \& 77.20(\mathrm{C} 3), 77.73(\mathrm{C} 2)$, $78.17\left(\mathrm{~d},{ }^{3} J_{4-\mathrm{F}}=13.7 \mathrm{~Hz}, \mathrm{C} 4\right), 81.26(\mathrm{C} 2), 96.72(\mathrm{C} 1 \alpha), 103.17(\mathrm{C} 1 \beta), 108.71\left(\mathrm{~d},{ }^{2} J_{5-\mathrm{F}}=12.0\right.$ $\mathrm{Hz}, \mathrm{C} 5), 109.32\left(\mathrm{~d},{ }^{2} J_{5-\mathrm{F}}=11.7 \mathrm{~Hz}, \mathrm{C} 5\right), 152.14\left(\mathrm{~d},{ }^{1} J_{6-\mathrm{F}}=258.7 \mathrm{~Hz}, \mathrm{C} 6\right), 152.24\left(\mathrm{~d},{ }^{1} J_{6-\mathrm{F}}=\right.$ $259.2 \mathrm{~Hz}, \mathrm{C} 6) ;{ }^{19} \mathrm{~F}$ NMR $\left(\mathrm{MeOH}-d_{4}\right) \delta-126.55\left(\mathrm{dd}, J_{\mathrm{F}-\mathrm{H} 5}=17.8 \mathrm{~Hz}, J_{\mathrm{F}-6}=83.9 \mathrm{~Hz}, 0.5 \mathrm{~F}\right)$, $-126.85\left(\mathrm{dd}, J_{\mathrm{F}-\mathrm{H} 5}=18.1 \mathrm{~Hz}, J_{\mathrm{F}-\mathrm{H} 6}=84.0 \mathrm{~Hz}, 0.5 \mathrm{~F}\right) ; \mathrm{MS}\left(\mathrm{APCI}^{-}\right) \mathrm{m} / \mathrm{z} 163\left(100, \mathrm{MH}^{-}\right)$.

Analogous treatment of $\mathbf{3 9}(E / Z, 1: 1 ; 20 \mathrm{mg}, 0.040 \mathrm{mmol})$ gave $\mathbf{4 2}(5 \mathrm{mg}, 76 \%)$ as a mixture $(E / Z, \sim 1: 1 ; \alpha / \beta, \sim 1: 1)$. Compound $(E / Z)-37$ had: ${ }^{19} \mathrm{~F} \mathrm{NMR}\left(\mathrm{MeOH}-d_{4}\right) \delta-126.55\left(\mathrm{dd}, J_{\mathrm{F}-\mathrm{H} 5}=\right.$ $\left.17.3 \mathrm{~Hz}, J_{\mathrm{F}-\mathrm{H} 6}=84.0 \mathrm{~Hz} ; E, 0.25, \beta\right),-126.85\left(\mathrm{dd},{ }^{3} J_{\mathrm{F}-\mathrm{H} 5}=17.5 \mathrm{~Hz},{ }^{2} J_{\mathrm{F}-\mathrm{H} 6}=84.0 \mathrm{~Hz} ; E, 0.25\right.$, $\beta),-127.66\left(\mathrm{dd}, J_{\mathrm{F}-\mathrm{H} 5}=41.5 \mathrm{~Hz}, J_{\mathrm{F}-\mathrm{H} 6}=84.9 \mathrm{~Hz} ; Z, 0.25, \beta\right),-128.34\left(\mathrm{dd}, J_{\mathrm{F}-\mathrm{H} 5}=42.2 \mathrm{~Hz}\right.$, $\left.J_{\mathrm{F}-\mathrm{H} 6}=84.8 \mathrm{~Hz} ; Z, 0.25, \alpha\right)$; $\mathrm{MS}\left(\mathrm{APCI}^{-}\right) \mathrm{m} / z .163\left(100, \mathrm{MH}^{-}\right)$.

Treatment of the crude 36 [from step (a) for the preparation of 39] with TFA $/ \mathrm{H}_{2} \mathrm{O}\left(1 \mathrm{~h}, 0{ }^{\circ} \mathrm{C}\right)$ followed by evaporation, coevaporation [toluene $(2 \times)$ and $\mathrm{MeCN}(1 \times)$ ], partition $\left(\mathrm{H}_{2} \mathrm{O} /\right.$ ethyl ether), and evaporation of the aqueous layer also gave $\mathbf{4 2}$ (55\% from $23, \alpha / \beta, 1: 1)$.

\section{(E)-5,6-Dideoxy-6-fluoro- $\alpha / \beta-D-r i b o-h e x-5-e n o f u r a n o s e ~(43)$}

Treatment of $(E)-\mathbf{4 0}(13 \mathrm{mg}, 0.064 \mathrm{mmol})$ with TFA/ $\mathrm{H}_{2} \mathrm{O}(9: 1,3 \mathrm{~mL})$, as described for $\mathbf{4 2}$, gave $43(7 \mathrm{mg}, 67 \%$; $\alpha / \beta, 1: 4):{ }^{1} \mathrm{H}$ NMR $\left(\mathrm{MeOH}-d_{4}\right) \delta 3.77\left(\mathrm{t}, J_{3-2 / 4}=6.1 \mathrm{~Hz}, 0.2, \mathrm{H} 3\right), 3.87$ (d, $\left.J_{2-1}=4.5 \mathrm{~Hz}, 0.8, \mathrm{H} 2\right), 4.01-4.05(\mathrm{~m}, 1, \mathrm{H} 2 \alpha \& \mathrm{H} 3 \beta), 4.20$ (t, $\left.J_{4-3 / 5}=8.0 \mathrm{~Hz}, 0.8, \mathrm{H} 4\right), 4.30$ (dd, $\left.J_{4-5}=8.2 \mathrm{~Hz}, J_{4-3}=6.4 \mathrm{~Hz}, 0.2, \mathrm{H} 4\right), 5.12(\mathrm{br} \mathrm{s}, 0.8, \mathrm{H1}), 5.28\left(\mathrm{~d}, J_{1-2}=4.1 \mathrm{~Hz}, 0.2, \mathrm{H} 1\right.$ ), 5.42 (ddd, $\left.J_{5-\mathrm{F}}=17.5 \mathrm{~Hz}, J_{5-6}=11.1 \mathrm{~Hz}, J_{5-4}=8.3 \mathrm{~Hz}, 0.2, \mathrm{H} 5\right), 5.49\left(\mathrm{ddd}, J_{5-\mathrm{F}}=17.6 \mathrm{~Hz}\right.$, $\left.J_{5-6}=11.1 \mathrm{~Hz}, J_{5-4}=8.5 \mathrm{~Hz}, 0.8, \mathrm{H} 5\right), 6.86\left(\mathrm{dd}, J_{6-\mathrm{F}}=83.9 \mathrm{~Hz}, J_{6-5}=11.1 \mathrm{~Hz}, 0.8, \mathrm{H6}\right), 6.87$ $\left(\mathrm{dd}, J_{6-\mathrm{F}}=83.7 \mathrm{~Hz}, J_{6-5}=11.0 \mathrm{~Hz}, 0.2, \mathrm{H} 6\right) ;{ }^{13} \mathrm{C} \mathrm{NMR}\left(\mathrm{MeOH}-d_{4}\right) \delta 70.90(\mathrm{C} 2 \alpha), 75.32$ $\left(\mathrm{d},{ }^{4} J_{3-\mathrm{F}}=2.6 \mathrm{~Hz}, \mathrm{C} 3 \alpha\right), 75.5\left(\mathrm{~d},{ }^{4} J_{3-\mathrm{F}}=2.5 \mathrm{~Hz}, \mathrm{C} 3 \beta\right), 76.13(\mathrm{C} 2 \beta), 77.55\left(\mathrm{~d},{ }^{3} J_{4-\mathrm{F}}=13.6 \mathrm{~Hz}\right.$, $\mathrm{C} 4 \alpha), 77.88\left(\mathrm{~d},{ }^{3} J_{4-\mathrm{F}}=13.7 \mathrm{~Hz}, \mathrm{C} 4 \beta\right), 96.63(\mathrm{C} 1 \alpha), 102.09(\mathrm{C} 1 \beta), 111.19\left(\mathrm{~d},{ }^{2} J_{5-\mathrm{F}}=11.4 \mathrm{~Hz}\right.$, $\mathrm{C} 5 \alpha), 112.65\left(\mathrm{~d},{ }^{2} J_{5-\mathrm{F}}=10.6 \mathrm{~Hz}, \mathrm{C} 5 \beta\right), 151.98\left(\mathrm{~d},{ }^{1} J_{6-\mathrm{F}}=258.6 \mathrm{~Hz}, \mathrm{C} 6 \beta\right), 152.17\left(\mathrm{~d},{ }^{1} J_{6-\mathrm{F}}=\right.$ $258.7 \mathrm{~Hz}, \mathrm{C} 6 \alpha) ;{ }^{19} \mathrm{~F} \mathrm{NMR}\left(\mathrm{MeOH}-d_{4}\right) \delta-128.55\left(\mathrm{dd}, J_{\mathrm{F}-\mathrm{H} 5}=17.4 \mathrm{~Hz}, J_{\mathrm{F}-\mathrm{H} 6}=83.5 \mathrm{~Hz}, 0.2 \mathrm{~F}\right.$,

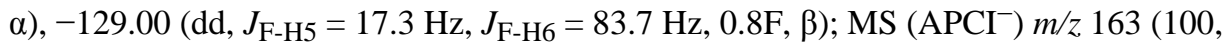
$\left.\mathrm{MH}^{-}\right)$. 
Analogous treatment of $\mathbf{4 0}(E / Z, 1: 1 ; 16 \mathrm{mg}, 0.032 \mathrm{mmol})$ gave $\mathbf{4 3}(3 \mathrm{mg}, 57 \%)$ as a mixture ( $E / Z, \sim 3: 1 ; \alpha / \beta, \sim 1: 4$ for $E$ isomer and $\alpha / \beta, \sim 1: 15$ for $Z$ isomer): ${ }^{19} \mathrm{~F} \mathrm{NMR}\left(\mathrm{MeOH}-d_{4}\right) \delta-128.01$ $\left(\mathrm{dd}, J_{\mathrm{F}-\mathrm{H} 5}=41.3 \mathrm{~Hz}, J_{\mathrm{F}-\mathrm{H} 6}=83.4 \mathrm{~Hz} ; Z, 0.02 \mathrm{~F}, \alpha\right)-128.55\left(\mathrm{dd}, J_{\mathrm{F}-\mathrm{H} 5}=17.6 \mathrm{~Hz}, J_{\mathrm{F}-\mathrm{H} 6}=84.2\right.$ $\mathrm{Hz} ; E, 0.14 \mathrm{~F}, \alpha),-129.00\left(\mathrm{dd}, J_{\mathrm{F}-\mathrm{H} 5}=17.5 \mathrm{~Hz}, J_{\mathrm{F}-\mathrm{H} 6}=83.8 \mathrm{~Hz} ; E, 0.60 \mathrm{~F}, \beta\right),-129.69(\mathrm{dd}$, $\left.J_{\mathrm{F}-\mathrm{H} 5}=40.8 \mathrm{~Hz}, J_{\mathrm{F}-\mathrm{H} 6}=84.4 \mathrm{~Hz} ; Z, 0.24 \mathrm{~F}, \beta\right) ; \mathrm{MS}\left(\mathrm{APCI}^{-}\right) \mathrm{m} / z .163\left(100, \mathrm{MH}^{-}\right)$.

Treatment of the crude 37 [from step (a) for the preparation of 40] with TFA/ $\mathrm{H}^{2} \mathrm{O}\left(1 \mathrm{~h}, 0{ }^{\circ} \mathrm{C}\right)$ followed by evaporation, coevaporation [toluene $(2 \times)$ and $\mathrm{MeCN}(1 \times)$ ], partition $\left(\mathrm{H}_{2} \mathrm{O} /\right.$ ethyl ether), and evaporation of the aqueous layer also gave $\mathbf{4 3}$ (45\% from $\mathbf{2 4}, \alpha / \beta, 1: 3)$.

\section{(E/Z)-3,5,6-Trideoxy-6-fluoro- $\alpha$-D-erythro-hex-5-enofuranose (44)}

Treatment of $\mathbf{3 8}(62 \mathrm{mg}, 0.13 \mathrm{mmol} ; E / Z, 3: 2)$ with TFA/ $\mathrm{H}_{2} \mathrm{O}\left(9: 1,1 \mathrm{~mL} ; 1 \mathrm{~h}, 0{ }^{\circ} \mathrm{C}\right)$ followed by evaporation, coevaporation [toluene $(2 \times)$ and $\mathrm{MeCN}(1 \times)$ ], partition $\left(\mathrm{H}_{2} \mathrm{O} /\right.$ ethyl ether), and evaporation of the aqueous layer gave $44(10 \mathrm{mg}, 52 \% ; E / Z \sim 1: 3, \alpha / \beta, \sim 1: 4):{ }^{1} \mathrm{H}$ NMR $\left(\mathrm{D}_{2} \mathrm{O}\right)$ $\delta$ 1.85-2.10 (m, 2, H3,3'), 4.05-4.25 (m, 1, H2), 4.58-4.75 (m, 1, H4), 4.86 (ddd, $J_{5-\mathrm{F}}=41.7$ $\left.\mathrm{Hz}, J_{5-4}=8.9 \mathrm{~Hz}, J_{5-6}=4.7, \mathrm{~Hz}, 0.15, \mathrm{H} 5\right), 4.92\left(\mathrm{ddd}, J_{5-\mathrm{F}}=41.6 \mathrm{~Hz}, J_{5-4}=8.9 \mathrm{~Hz}, J_{5-6}=4.7\right.$

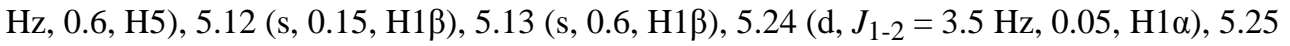
$\left(\mathrm{d}, J_{1-2}=3.8 \mathrm{~Hz}, 0.2, \mathrm{H} 1 \alpha\right), 5.39$ (ddd, $\left.J_{5-\mathrm{F}}=17.4 \mathrm{~Hz}, J_{5-6}=11.2 \mathrm{~Hz}, J_{5-4}=9.3 \mathrm{~Hz}, 0.2, \mathrm{H} 5\right)$, $5.45\left(\mathrm{ddd}, J_{5-\mathrm{F}}=17.6 \mathrm{~Hz}, J_{5-6}=11.1 \mathrm{~Hz}, J_{5-4}=9.1 \mathrm{~Hz}, 0.05, \mathrm{H} 5\right), 6.52\left(\mathrm{ddd}, J_{6-\mathrm{F}}=83.7 \mathrm{~Hz}\right.$, $\left.J_{6-5}=4.7 \mathrm{~Hz}, J_{6-4}=1.0 \mathrm{~Hz}, 0.15, \mathrm{H6}\right), 6.55\left(\mathrm{dd}, J_{6-\mathrm{F}}=83.7 \mathrm{~Hz}, J_{6-5}=4.7 \mathrm{~Hz}, J_{6-4}=1.0,0.60\right.$, H6), $6.77\left(\mathrm{dd}, J_{6-\mathrm{F}}=83.9 \mathrm{~Hz}, J_{6-5}=10.7 \mathrm{~Hz}, 0.05, \mathrm{H6}\right), 6.78\left(\mathrm{dd}, J_{6-\mathrm{F}}=83.9 \mathrm{~Hz}, J_{6-5}=11.0\right.$ $\mathrm{Hz}, 0.20, \mathrm{H} 6) ;{ }^{19} \mathrm{~F}$ NMR $\left(\mathrm{D}_{2} \mathrm{O}\right) \delta-126.35\left(\mathrm{dd}, J_{\mathrm{F}-\mathrm{H} 5}=17.3 \mathrm{~Hz}, J_{\mathrm{F}-\mathrm{H} 6}=83.6 \mathrm{~Hz} ; E, 0.20 \mathrm{~F}\right.$, $\beta),-126.45\left(\mathrm{dd}, J_{\mathrm{F}-\mathrm{H} 5}=17.2 \mathrm{~Hz}, J_{\mathrm{F}-\mathrm{H} 6}=82.8 \mathrm{~Hz} ; E, 0.05 \mathrm{~F}, \alpha\right),-126.81\left(\mathrm{dd}, J_{\mathrm{F}-\mathrm{H} 5}=42.0 \mathrm{~Hz}\right.$, $\left.J_{\mathrm{F}-\mathrm{H} 6}=83.7 \mathrm{~Hz} ; Z, 0.15 \mathrm{~F}, \alpha\right),-127.55\left(\mathrm{dd}, J_{\mathrm{F}-\mathrm{H} 5}=42.0 \mathrm{~Hz}, J_{\mathrm{F}-\mathrm{H} 6}=83.8 \mathrm{~Hz} ; Z, 0.60 \mathrm{~F}, \beta\right)$; HRMS (LCT-ESI) $\mathrm{m} / z$ : calcd for $\mathrm{C}_{6} \mathrm{H}_{9} \mathrm{FO}_{3}[\mathrm{M}+\mathrm{Na}]^{+}$171.0433; found 171.0434.

Analogous treatment of $\mathbf{4 1}(10 \mathrm{mg}, 0.053 \mathrm{mmol}$; $E / Z, \sim 45: 55)$ with TFA/ $\mathrm{H}_{2} \mathrm{O}$ gave $\mathbf{4 4}(5 \mathrm{mg}$, $64 \% ; E / Z \sim 1: 2, \alpha / \beta \sim 1: 3)$.

\section{Enzymatic assay}

Inhibition assays were performed in a buffer containing $50 \mathrm{mM}$ HEPES ( $\mathrm{pH} 7.0), 150 \mathrm{mM}$ $\mathrm{NaCl}, 150 \mu \mathrm{M}$ 5,5'-dithio-bis-(2-nitrobenzoic acid), ${ }^{23}$ and various concentrations of SRH (0$55 \mu \mathrm{M})$ and inhibitors $(0-1 \mathrm{mM})$. The reactions were initiated by the addition of $\mathrm{Co}^{2+}$ substituted LuxS from Bacillus subtilis (final concentration 0.4-0.5 $\mu \mathrm{M}$ ) and monitored continuously at $412 \mathrm{~nm}\left(\varepsilon=14150 \mathrm{M}^{-1} \mathrm{~cm}^{-1}\right)$ in a Perkin-Elmer $\lambda 25 \mathrm{UV}-\mathrm{VIS}$ spectrophotometer at room temperature. The initial rates recorded from the early regions of the progress curves were fitted into the Lineweaver-Burk equation $1 / V=K_{\mathrm{M}^{\prime}} /\left(k \mathrm{kcat}[\mathrm{E}]_{0}\right) \times 1 /$ $[\mathrm{S}]+1 /(k \mathrm{cat}[\mathrm{E}] 0)$ and the Michaelis-Menten equation $V=k \mathrm{cat}[\mathrm{E}] 0[\mathrm{~S}] /\left(K_{\mathrm{M}^{\prime}}+[\mathrm{S}]\right)$ using KaleidaGraph 3.5 to determine the inhibition pattern. $K_{\mathrm{I}}$ values were calculated from the equation $K_{\mathrm{M}}{ }^{\prime}=K_{\mathrm{M}} \times\left(1+[\mathrm{I}] / K_{\mathrm{I}}\right)$, where $K_{\mathrm{M}}=2.2 \mu \mathrm{M}$.

\section{Acknowledgements}

This work was partially supported by grants from the National Institutes of Health (S06GM08205 and R01AI062901). C.A.G and J.R were sponsored by MBRS RISE program (NIH/NIGMS; R25GM61347). C.A.G is also thankful to R. E. McNair Program for summer support. The support of US Army Research Office (W911NF-04-1-0022) in the purchase of $600 \mathrm{MHz}$ NMR spectrometer is gratefully acknowledged.

\section{References and Notes}

1. Yuan, C-S.; Liu, S.; Wnuk, SF.; Robins, MJ.; Borchardt, RT. Advances in Antiviral Drug Design. De Clercq, E., editor. Vol. 2. Greenwich: JAI Press; 1996. p. 41-88. (b) Turner MA, Yang X, Yin D, 
Kuczera K, Borchardt RT, Howell PL. Cell Biochem. Biophys 2000;33:101. [PubMed: 11325033] (c) Wnuk SF. Mini-Rev. Med. Chem 2001;1:307. [PubMed: 12369977]

2. (a) Schneyder G, Roffi M, Pin R, Flammer Y, Lange H, Eberli FR, Meier B, Turi ZG, Hess OM. N. Engl. J. Med 2001;345:1593. [PubMed: 11757505] (b) Langheinrich AC, Braun-Dullaeus RC, Walker G, Jeide I, Schiling R, Tammoscheit K, Dreyer T, Fink L, Bohle RM, Haberbosch W. Atherosclerosis 2003;171:181. [PubMed: 14644386]

3. (a) Lee JE, Cornel KA, Riscoe, Howell PL. Structure 2001;9:941. [PubMed: 11591349] (b) Lee JE, Cornel KA, Riscoe MK, Howell PL. J. Biol. Chem 2003;278:8761. [PubMed: 12496243]

4. (a) Chen X, Schauder S, Potier N, Van Dorsselaer A, Pelczer I, Bassler BL, Hughson FM. Nature 2002;415:545. [PubMed: 11823863] (b) Zhu J, Hu X, Dizin E, Pei D. J. Am. Chem. Soc 2003;125:13379. [PubMed: 14583032] (c) Zhu J, Dizin E, Hu X, Wavreille AS, Park J, Pei D. Biochemistry 2003;42:4717. [PubMed: 12705835] (d) Zhu J, Patel R, Pei D. Biochemistry 2004;43:10166. [PubMed: 15287744] (e) Alfaro JF, Zhang T, Wynn DP, Karschner EL, Zhou ZS. Org. Lett 2004;6:3043. [PubMed: 15330583] (f) Pei D, Zhu J. Curr. Opin. Chem. Biol 2004;8:492. [PubMed: 15450491] (g) Rajan R, Zhu J, Hu X, Pei D, Bell CE. Biochemistry 2005;44:3745. [PubMed: 15751951] (h) Shen G, Rajan R, Zhu J, Bell CE, Pei D. J. Med. Chem 2006;49:3003. [PubMed: 16686542]

5. (a) Meijler MM, Hom LG, Kaufmann GF, McKenzie KM, Sun C, Moss JA, Matsushita M, Janda KD. Angew. Chem. Int. Ed 2004;43:2106. (b) Semmelhack MF, Campagna SR, Federle MJ, Bassler BL. Org. Lett 2005;7:569. [PubMed: 15704896] (c) De Keersmaecker SCJ, Varszegi C, van Boxel N, Habel LW, Metzger K, Daniels R, Marchal K, De Vos D, Vanderleyden J. J. Biol. Chem 2005;280:19563. [PubMed: 15790567] (d) Frezza M, Soulere L, Balestrino D, Gohar M, Deshayes C, Queneau Y, Forestier C, Doutheau A. Bioorg. Med. Chem. Lett 2007;17:1428. [PubMed: 17169556]

6. (a) Waters CM, Bassler BL. Annu. Rev. Cell Dev. Biol 2005;21:319. [PubMed: 16212498] (b) Bassler BL, Losick R. Cell 2006;125:237. [PubMed: 16630813]

7. (a) Geske GD, Wezeman RJ, Siegel AP, Blackwell HE. J. Am. Chem. Soc 2005;127:12762. [PubMed: 16159245] (b) Pomianek ME, Semmelhack MF. ACS Chem. Biol 2007;2:293. [PubMed: 17518429] (c) Higgins DA, Pomianek ME, Kraml CM, Taylor RK, Semmelhack MF, Bassler BL. Nature 2007;450:883. [PubMed: 18004304]

8. (a) Wnuk SF, Yuan C-S, Borchardt RT, Balzarini J, De Clercq E, Robins MJ. J. Med. Chem 1994;37:3579. [PubMed: 7932585] (b) Yuan C-S, Wnuk SF, Robins MJ, Borchardt RT. J. Biol. Chem 1998;273:18191. [PubMed: 9660780] (c) Wnukx SF, Mao Y, Yuan CS, Borchardt RT, Andrei J, Balzarini J, DeClercq E, Robins MJ. J. Med. Chem 1998;41:3078. [PubMed: 9685247]

9. (a) Xie M, Berges DA, Robins MJJ. Org. Chem 1996;61:5178. (b) Maryanoff BE, Reitz AB. Chem. Rev 1989;89:863.

10. Analogous bromination-dehydrobromination strategy applied to the adenosine derivatives bearing a C5'-C6' double bond produced a single (5'-bromo)vinyl SAH analogue: Andrei D, Wnuk SF. Org. Lett 2006;8:5093. [PubMed: 17048851]

11. (a) Although Pd-catalyzed cross-coupling reactions are powerful methods for the formation of new carbon-carbon bonds, ${ }^{11 \mathrm{~b}}$ monocross-coupling reactions of 1,1-dihalovinyl electrophiles with $\mathrm{C}_{\mathrm{sp}} 2$ and $\mathrm{C}_{\mathrm{sp}}$ nucleophiles are less common ${ }^{12}$ and monocouplings between 1,1-dihalovinyl electrophiles and $\mathrm{C}_{\mathrm{sp}} 3$ nucleophiles are scarce. ${ }^{13}$ de MeijereADiederichFMetal-Catalyzed Cross-Coupling Reactions2004WeinheimWiley-VCH

12. Negishi E-I, Hu Q, Huang Z, Qian M, Wang G. Aldrichim. Acta 2005;38:71.; references cited therein.

13. For successful Pd-catalyzed monoalkylation of vinyl dihalides via trans-selective monobutylation of 1,1-dichloro-2-phenylethene with $n$ - $\mathrm{C}_{4} \mathrm{H}_{9} \mathrm{ZnCl}$ in $81 \%$ yield see: Minato A, Suzuki K, Tamao K. J. Am. Chem. Soc 1987;109:1257. For studies on differentiation of two chlorine atoms in stepwise double alkylation reactions of 1,1-dichloroalkenes see: (b) Tan Z, Negishi E-i. Angew. Chem. Int. Ed 2006;45:762.For Suzuki-Miyaura protocol to the selective monocoupling of 1,1-dichloroalkenes with 9-alkyl-9-BBN see: (c) Liron F, Fosse C, Pernolet A, Roulland E. J. Org. Chem 2007;72:2220. [PubMed: 17311458]

14. (a) Corey EJ, Fuchs PL. Tetrahedron Lett 1972;36:3769. (b) Tronchet JMJ, Bonenfant AP, Perret F, Gonzalez A, Zumwald JB, Martinez EM, Baehler B. Helv. Chim. Acta 1980;63:1181.

15. Robins MJ, Wnuk SF, Yang X, Yuan C-S, Borchardt RT, Balzarini J, De Clercq E. J. Med. Chem 1998;41:3857. [PubMed: 9748360] 
16. Pd-catalyzed Negishi monoalkylation of 1-fluoro-1-(iodo, or bromo, or chloro)alkenes with alkylzincs give stereoselective access to the internal fluoroalkenes: Andrei D, Wnuk SF. J. Org. Chem 2006;71:405. [PubMed: 16388671]

17. For Pd-catalyzed couplings of 1-fluoro-1-haloalkenes with $\mathrm{C}_{\mathrm{sp}} 2$ and $\mathrm{C}_{\mathrm{sp}}$ nucleophiles see: (a) Chen C, Wilcoxen K, Huang CQ, Strack N, McCarthy JR. J. Fluorine Chem 2000;101:285. (b) Xu J, Burton DJ. Tetrahedron Lett 2002;43:2877-2879. (c) Xin Z, Burton DJ. J. Fluorine Chem 2001;112:317.

18. (a) McCarthy JR, Huber EW, Le T-B, Laskovics M, Matthews DP. Tetrahedron 1996;52:45. (b) McCarthy JR, Matthews DP, Stemerick DM, Bey P, Lippert BJ, Snyder RD, Sunkara PS. J. Am. Chem. Soc 1991;113:7439.

19. For other examples of synthetic sequences involving introduction of alkenes substituted with $\mathrm{F} /$ $\mathrm{SO}_{2} \mathrm{Ph}, \mathrm{F} / \mathrm{SnBu}_{3}$, or F/H into amino acids or nucleoside frames see: (a) Berkowitz DB, De la SaludBea R, Jahng W-J. Org. Lett 2004;6:1821. [PubMed: 15151423] (b) Karukurichi KR, De la SaludBea R, Jahng W-J, Berkowitz DB. J. Am. Chem. Soc 2007;129:258. [PubMed: 17212389] (c) Pan Y, Calvert K, Silverman RB. Bioorg. Med. Chem 2004;12:5719. [PubMed: 15465348] (d) Shen Y. J. Organomet. Chem 2006;691:1452. (e) Rapp M, Haubrich TA, Perrault J, Mackey ZB, McKerrow JH, Chiang PK, Wnuk SF. J. Med. Chem 2006;49:2096. [PubMed: 16539398]

20. (a) Appel RB. Synth. Commun 1995;25:3593. (b) Wnuk SF, Bergolla LA, Garcia PI Jr. J. Org. Chem 2002;67:3065. [PubMed: 11975568] (c) Wnuk SF, Garcia PI Jr, Wang Z. Org. Lett 2004;6:2047. [PubMed: 15176815]

21. Wnuk SF, Lalama J, Robert J, Garmendia CA. Nucleosides Nucleotides Nucleic Acids 2007;26:1051. [PubMed: 18058535]

22. Robins MJ, Wilson JS, Hansske F. J. Am. Chem. Soc 1983;105:4059.

23. Ellman GL. Arch. Biochem. Biophys 1959;82:70. [PubMed: 13650640] 


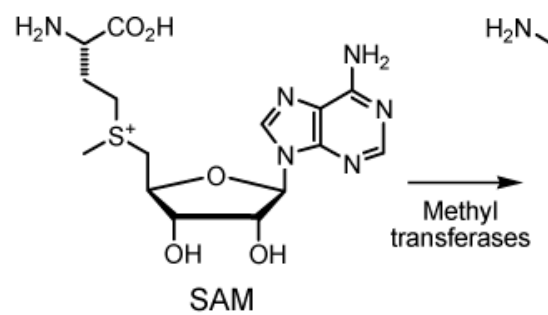<smiles>Nc1ncnc2c1ncn2[C@@H]1O[C@H](CO)[C@@H](O)[C@H](CO)O[C@H]1CO</smiles><smiles>N[C](CCS)C(=O)O</smiles>

\section{SAM}

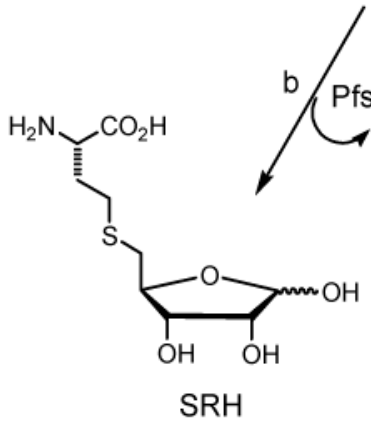

$\mathrm{SAH}$

Figure 1.

Reaction pathways for SAH detoxification in eukaryotes (a) and the majority of bacteria (b). The latter is also utilized by the bacteria to produce the type 2 autoinducer. 
<smiles>N[C@@H](CSCCC1O[C@@H](O)C(O)C1O)C(=O)O</smiles><smiles>N[C@@H](CCSC[C@H](O)[C@@H](O)C(=O)NO)C(=O)O</smiles>

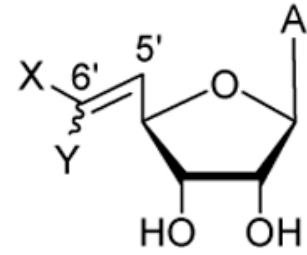

$3 X=\mathrm{I}, \mathrm{Br}, \mathrm{Cl}$, or $\mathrm{F} ; \mathrm{Y}=\mathrm{H}$
$4 \mathrm{X}=\mathrm{Br} ; \mathrm{Y}=\mathrm{Br}$ or $\mathrm{F}$<smiles>[X]C(CC[C@H](N)C(=O)O)=C(S)[C@H]1O[C@H](O)[C@H](O)[C@H]1O</smiles>

$5 \mathrm{X}=\mathrm{H}$ or halogen

Figure 2.

Inhibitors of LuxS enzyme (1, 2). ${ }^{4}$ e,h $5^{\prime}$-Deoxy-5'-(halomethylene)adenosine analogues $(\mathbf{3}$, 4) which serve as suicide substrates for SAH hydrolase ${ }^{8}$ and targeted SRH analogues (5) in which the sulfur and C5 atoms are replaced by a vinyl unit. 


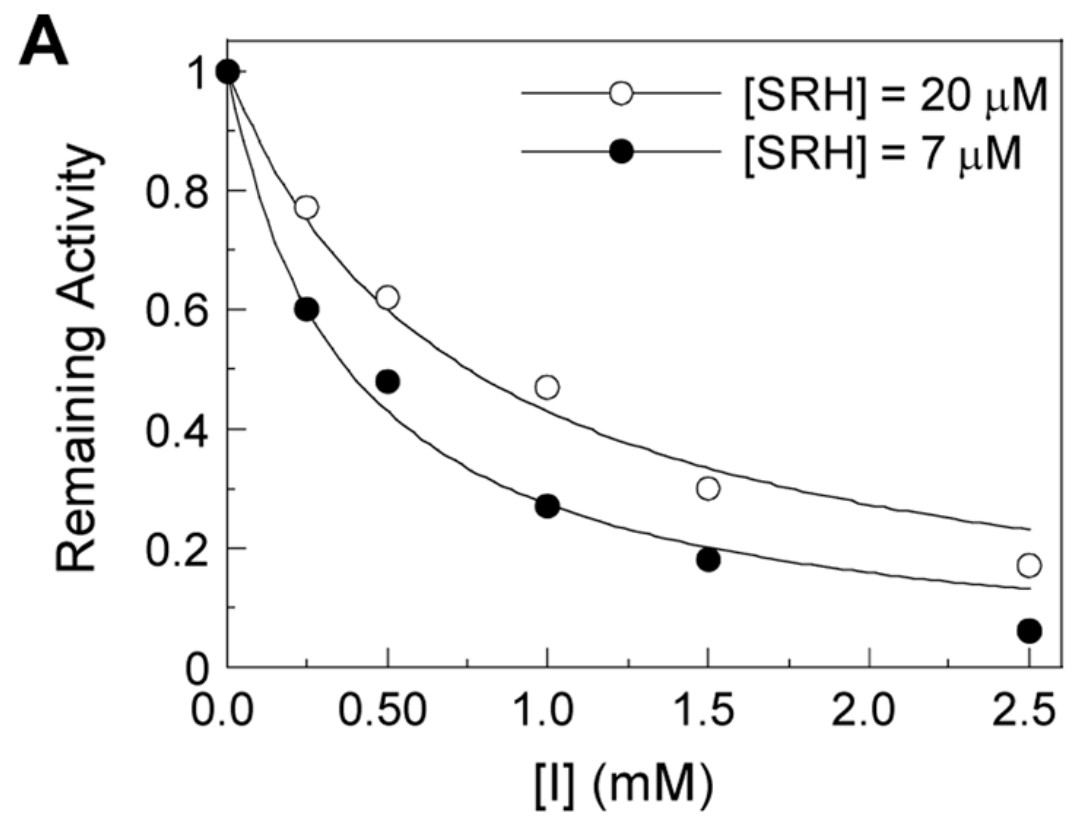

B

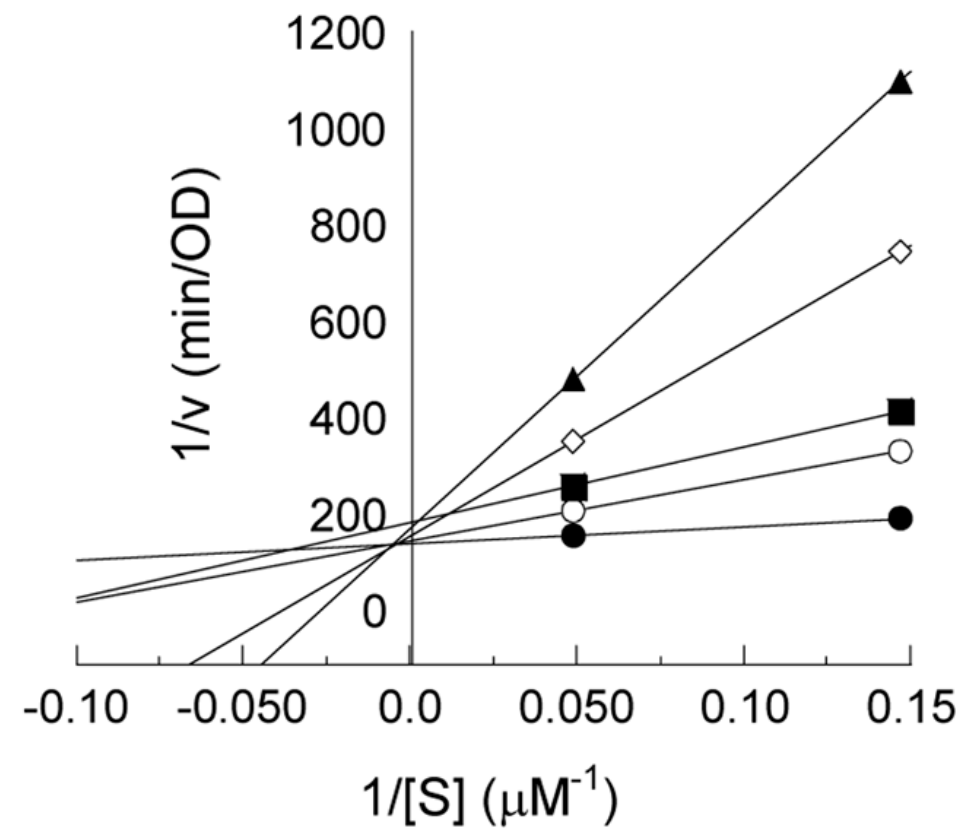

Figure 3.

Inhibition of $\mathrm{Co}^{2+}$-substituted B. subtilis LuxS by compound 44. (A) Plot of remaining LuxS activity (relative to that in the absence of inhibitor) as a function of [I]. (B) Lineweaver-Burke plot of data from part A to show the competitive inhibition mode. 


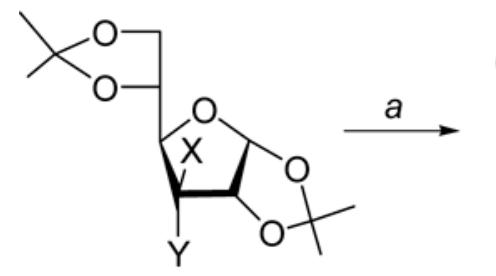

$X X=O B z, Y=H$
$7 X=H, Y=O B z$

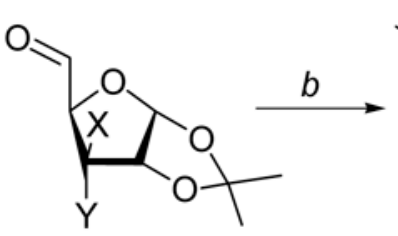

$8 X=O B z, Y=H$

$9 \mathrm{X}=\mathrm{H}, \mathrm{Y}=\mathrm{OBZ}$

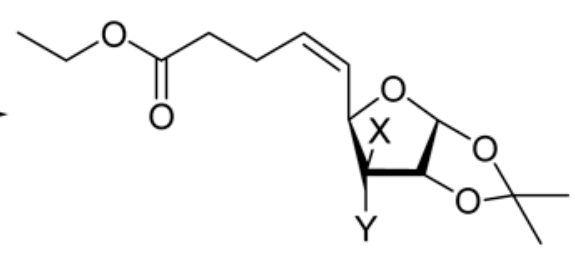

$10 X=O B z, Y=H$

$11 \mathrm{X}=\mathrm{H}, \mathrm{Y}=\mathrm{OBZ}$

Scheme 1.

(a) $\mathrm{H}_{5} \mathrm{IO}_{6}$ /EtOAc; (b) $\mathrm{Ph}_{3} \mathrm{PCH}_{2} \mathrm{CH}_{2} \mathrm{CH}_{2} \mathrm{CO}_{2} \mathrm{Et} / \mathrm{HMDS} / \mathrm{THF}$. 


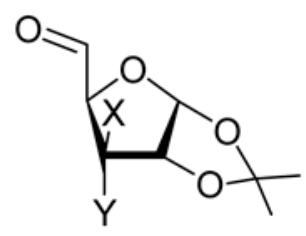

$8 X=O B z, Y=H$

$9 \mathrm{X}=\mathrm{H}, \mathrm{Y}=\mathrm{OBZ}$

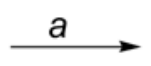

$\mathrm{Br}$

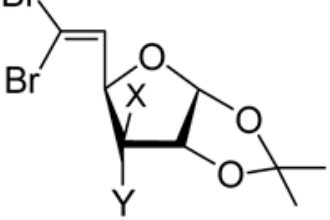

$12 X=O B z, Y=H$

$13 X=H, Y=O B z$

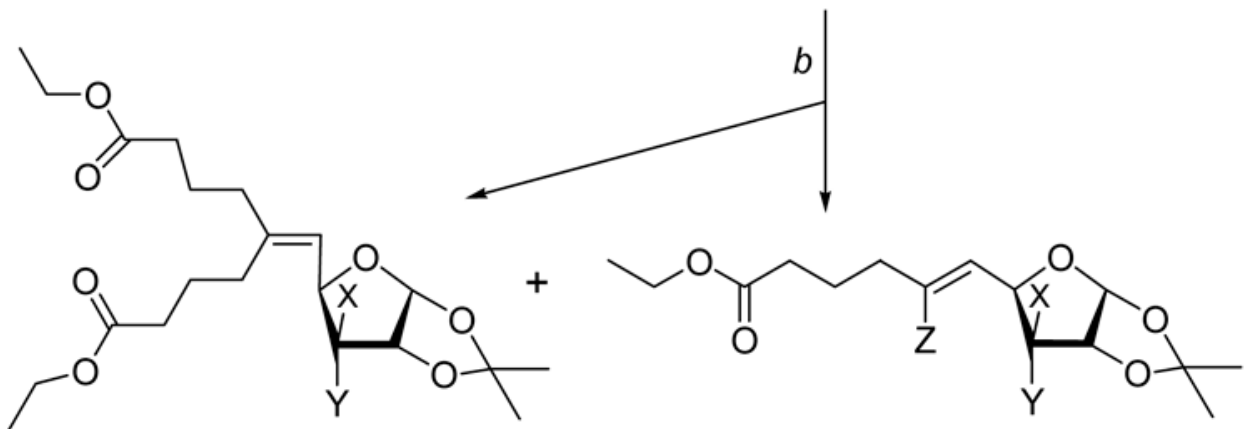

$18 X=O B z, Y=H$

$14 X=O B z, Y=H, Z=H$

$19 \mathrm{X}=\mathrm{H}, \mathrm{Y}=\mathrm{OBz}$

$15 X=O B z, Y=H, Z=B r$

$16 X=H, Y=O B z, Z=H$

$17 X=H, Y=O B z, Z=B r$

Scheme 2.

(a) $\mathrm{PPh}_{3} / \mathrm{CBr}_{4} ;$ (b) $\mathrm{BrZn}\left(\mathrm{CH}_{2}\right)_{3} \mathrm{CO}_{2} \mathrm{Et} / \mathrm{Pd}\left(\mathrm{PPh}_{3}\right)_{4} /$ benzene/ $\Delta$ 

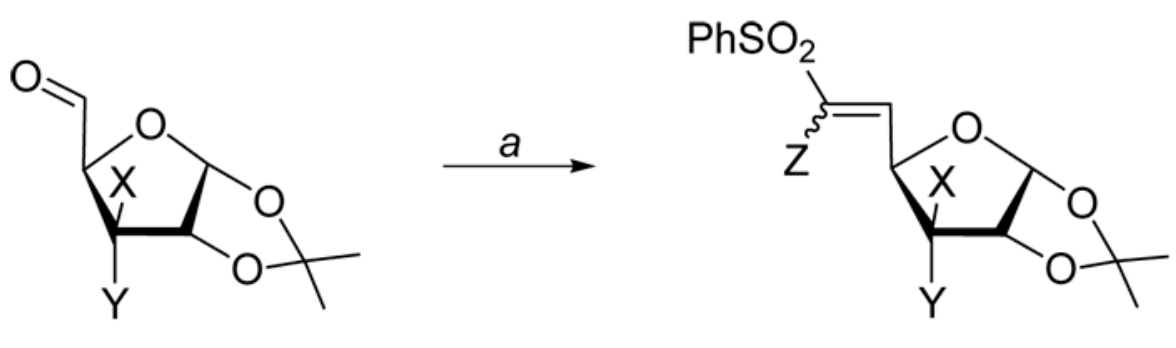

$$
\begin{aligned}
& 8 X=O B Z, Y=H \\
& 9 X=H, Y=O B z
\end{aligned}
$$

$20 \mathrm{X}=\mathrm{OBZ}, \mathrm{Y}=\mathrm{H}, \mathrm{Z}=\mathrm{F}$

$21 \mathrm{X}=\mathrm{H}, \mathrm{Y}=\mathrm{OBz}, \mathrm{Z}=\mathrm{F}$

$22 X=H, Y=O B Z, Z=H$
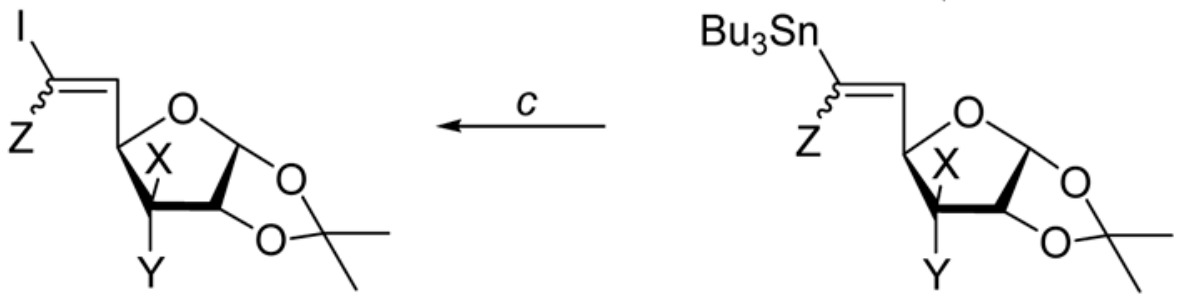

$$
\begin{aligned}
& 26 X=O B Z, Y=H, Z=F \\
& 27 X=H, Y=O B Z, Z=F \\
& 28 X=H, Y=O B Z, Z=H
\end{aligned}
$$

$$
\begin{aligned}
& 23 X=O B z, Y=H, Z=F \\
& 24 X=H, Y=O B Z, Z=F \\
& 25 X=H, Y=O B z, Z=H
\end{aligned}
$$

Scheme 3.

(a) $\mathrm{PhSO}_{2} \mathrm{CHFPO}(\mathrm{OEt})_{2}$ or $\mathrm{PhSO}_{2} \mathrm{CH}_{2} \mathrm{PO}(\mathrm{OEt})_{2} / \mathrm{LHMDS} / \mathrm{THF} /-78{ }^{\circ} \mathrm{C}$; $(b) \mathrm{Bu}_{3} \mathrm{SnH} / \mathrm{AIBN} /$ toluene $/ 85{ }^{\circ} \mathrm{C}$; (c) $\mathrm{NIS} / \mathrm{CH}_{2} \mathrm{Cl}_{2}$ 


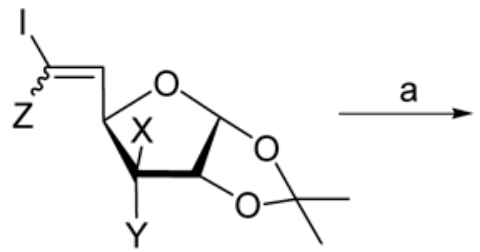

$26 \mathrm{X}=\mathrm{OBZ}, \mathrm{Y}=\mathrm{H}, \mathrm{Z}=\mathrm{F}$

$27 X=H, Y=O B z, Z=F$

$28 \mathrm{X}=\mathrm{H}, \mathrm{Y}=\mathrm{OBZ}, \mathrm{Z}=\mathrm{H}$

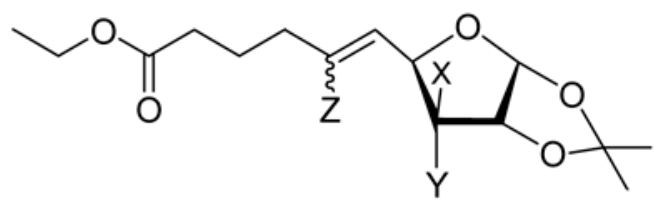

$29 X=O B z, Y=H, Z=F$ $30 X=H, Y=O B Z, Z=F$ $16 \mathrm{X}=\mathrm{H}, Y=\mathrm{OBZ}, \mathrm{Z}=\mathrm{H}$

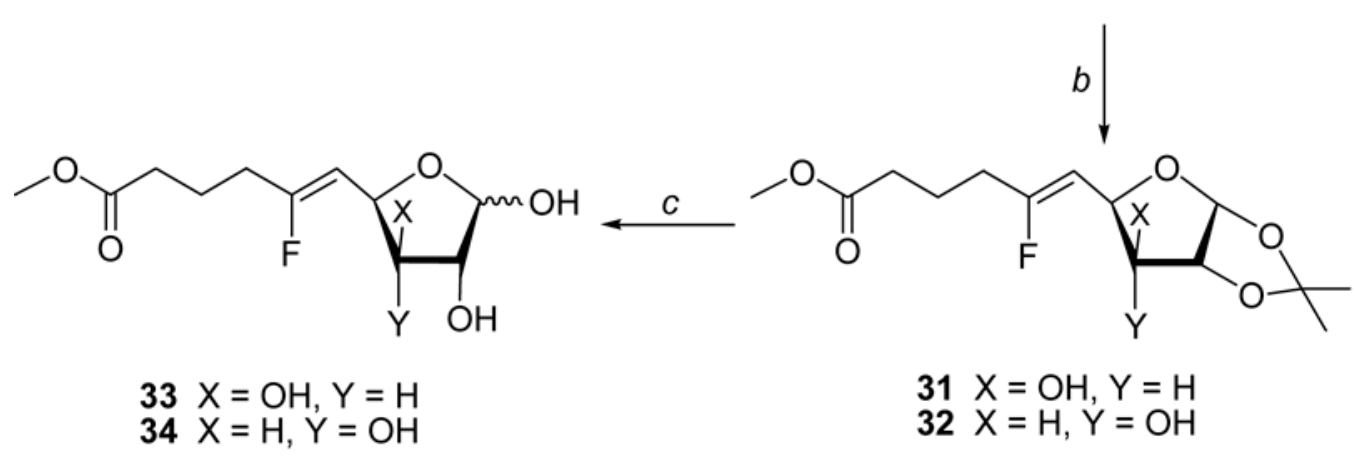

Scheme 4.

(a) $\mathrm{BrZn}\left(\mathrm{CH}_{2}\right)_{3} \mathrm{CO}_{2} \mathrm{Et} / \mathrm{Pd}\left(\mathrm{PPh}_{3}\right)_{4} /$ benzene/ $\Delta$; (b) $\mathrm{NH}_{3} / \mathrm{MeOH}$; (c) TFA/H $\mathrm{H}_{2} \mathrm{O}$ 


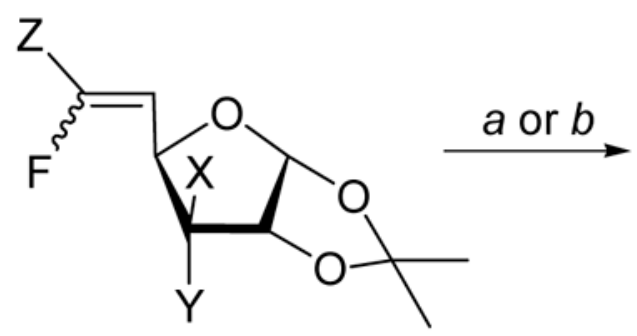
$23 \mathrm{X}=\mathrm{OBz}, \mathrm{Y}=\mathrm{H}, \mathrm{Z}=\mathrm{Bu}_{3} \mathrm{Sn}$
$24 \mathrm{X}=\mathrm{H}, \mathrm{Y}=\mathrm{OBz}, \mathrm{Z}=\mathrm{Bu}_{3} \mathrm{Sn}$
$35 \mathrm{X}=\mathrm{Y}=\mathrm{H}, \mathrm{Z}=\mathrm{PhSO}_{2}$
$36 \mathrm{X}=\mathrm{OH}, \mathrm{Y}=\mathrm{H}$
$37 \mathrm{X}=\mathrm{H}, \mathrm{Y}=\mathrm{OH}$
$38 \mathrm{X}=\mathrm{Y}=\mathrm{H}$
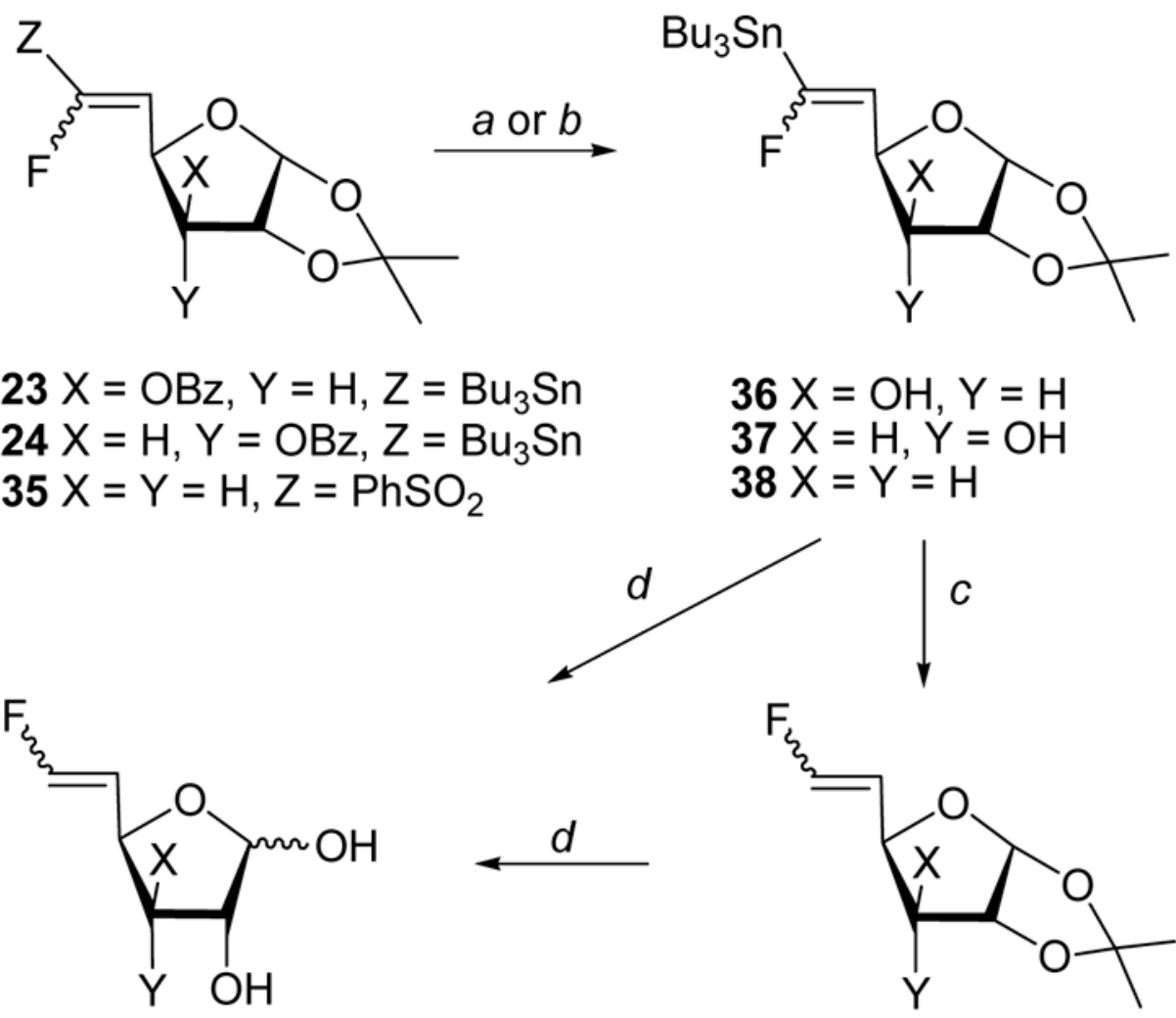

$$
\begin{aligned}
& 42 X=O H, Y=H \\
& 43 X=H, Y=O H \\
& 44 X=Y=H
\end{aligned}
$$

Scheme 5 .

(a) $\mathrm{NH}_{3} / \mathrm{MeOH} / 25{ }^{\circ} \mathrm{C}$; (b) $\mathrm{Bu}_{3} \mathrm{SnH} / \mathrm{AIBN} /$ toluene/85 ${ }^{\circ} \mathrm{C}$; (c) $\mathrm{NH}_{3} / \mathrm{MeOH} / 65{ }^{\circ} \mathrm{C}$ or $\mathrm{NH}_{3} /$ $\mathrm{MeOH} / \mathrm{CsF} / 65^{\circ} \mathrm{C}$; (d) $\mathrm{TFA} / \mathrm{H}_{2} \mathrm{O}$ 